\title{
A Social Portrait of Travellers in Ireland
}

Dorothy Watson, Oona Kenny and Frances McGinnity

RESEARCH SERIES

NUMBER 56

January 2017

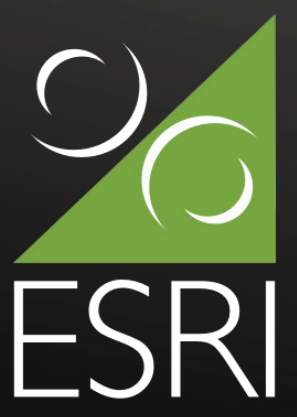




\section{A Social Portrait of Travellers in Ireland}

Dorothy Watson, Oona Kenny and Frances McGinnity

\section{RESEARCH SERIES \\ NUMBER 56}

January 2017

Available to download from www.esri.ie

(C) The Economic and Social Research Institute

Whitaker Square, Sir John Rogerson's Quay, Dublin 2

ISBN 978-0-7070-0415-0 


\section{The ESRI}

The Economic Research Institute was founded in Dublin in 1960, with the assistance of a grant from the Ford Foundation of New York. In 1966 the remit of the Institute was expanded to include social research, resulting in the Institute being renamed the Economic and Social Research Institute (ESRI). In 2010 the Institute entered into a strategic research alliance with Trinity College Dublin, while retaining its status as an independent research institute.

The ESRI is governed by an independent Council which acts as the board of the Institute with responsibility for guaranteeing its independence and integrity. The Institute's research strategy is determined by the Council in association with the Director and staff. The research agenda seeks to contribute to three overarching and interconnected goals, namely, economic growth, social progress and environmental sustainability. The Institute's research is disseminated through international and national peer reviewed journals and books, in reports and books published directly by the Institute itself and in the Institute's working paper series. Researchers are responsible for the accuracy of their research. All ESRI books and reports are peer reviewed and these publications and the ESRI's working papers can be downloaded from the ESRI website at www.esri.ie

The Institute's research is funded from a variety of sources including: an annual grant-in-aid from the Irish government; competitive research grants (both Irish and international); support for agreed programmes from government departments/agencies and commissioned research projects from public sector bodies. Sponsorship of the Institute's activities by Irish business and membership subscriptions provide a minor source of additional income. 


\section{The Authors}

Dorothy Watson is an Associate Research Professor at the ESRI and Adjunct Professor at the Department of Sociology, Trinity College Dublin and joint coordinator of the research areas Social Inclusion and Equality. Oona Kenny is a Research Assistant in the Social Research Division of the ESRI. Frances McGinnity is an Associate Research Professor at the ESRI and Adjunct Professor of Sociology at Trinity College Dublin. She is joint coordinator of the research areas Social Inclusion and Equality and Migration, Integration and Demography at the ESRI.

\section{Acknowledgements}

This research was completed as part of a programme of research on Equality funded by the Department of Justice and Equality (DJE). We would like to express our thanks to the members of the steering group for the study, particularly Deaglán O'Broin of the DJE and Ronnie Fay of Pavee Point Traveller and Roma Centre. We also thank our ESRI colleagues Emer Smyth and Alan Barrett, who provided valuable comments. We are grateful to the Central Statistics Office for making available the micro-census data files for 2006 and 2011 and to the research team of the All Ireland Traveller Health Study, whose data we also use here. We also thank the three anonymous peer reviewers. Neither the DJE, the ESRI nor the CSO is responsible for the content of the report, which is the independent work of the authors.

This report has been accepted for publication by the Institute, which does not itself take institutional policy positions. All ESRI Research Series reports are peer reviewed prior to publication. The authors are solely responsible for the content and the views expressed. 


\section{Table of Contents}

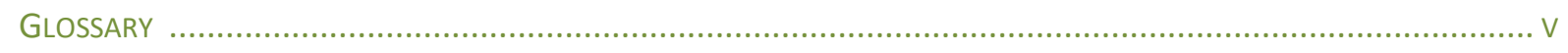

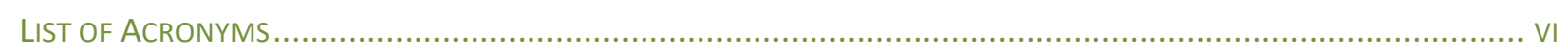

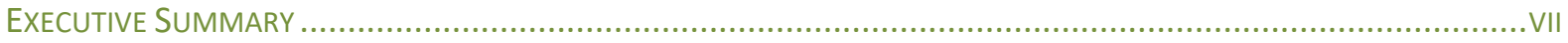

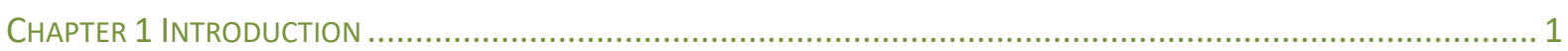

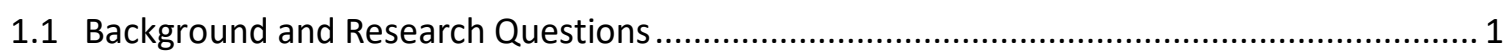

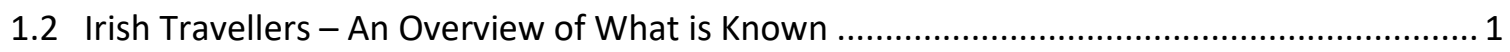

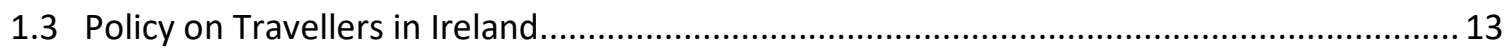

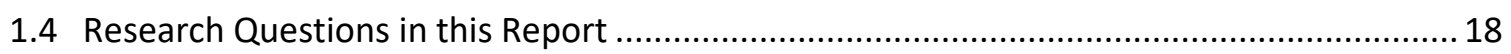

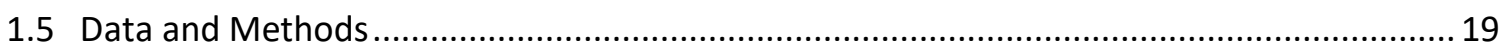

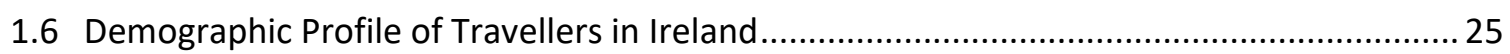

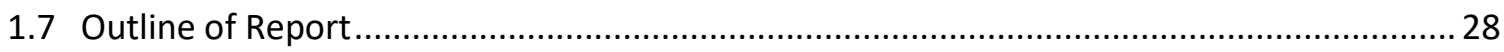

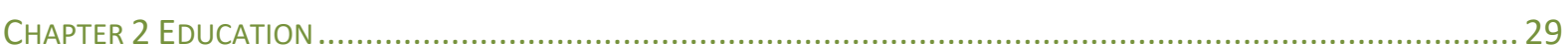

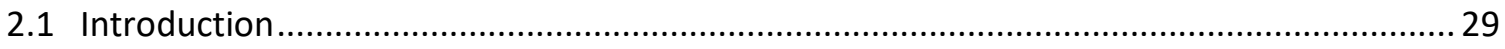

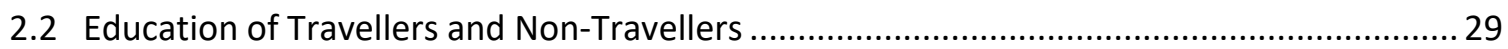

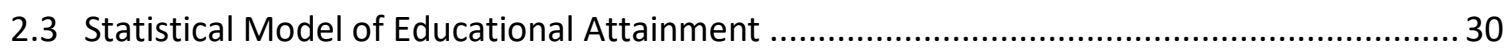

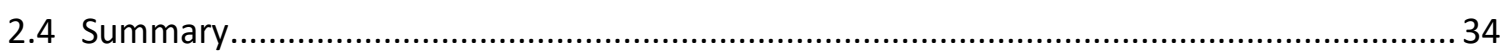

CHAPTER 3 WORK

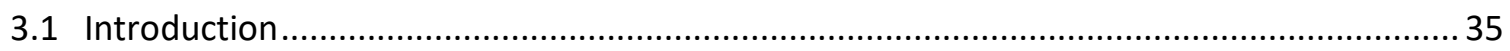

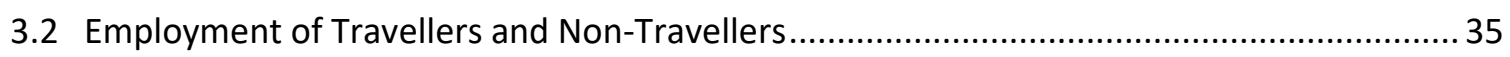

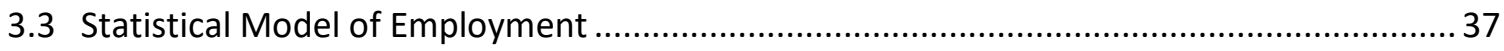

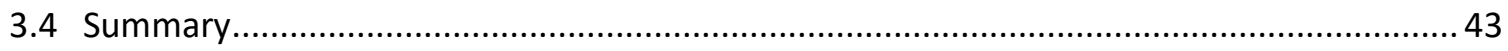

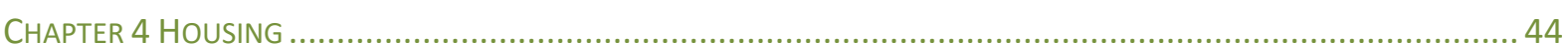

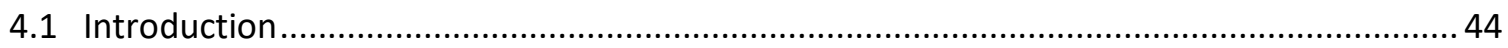

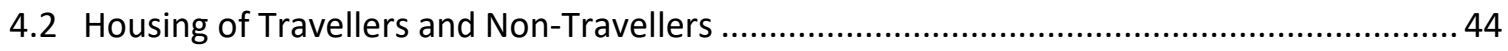

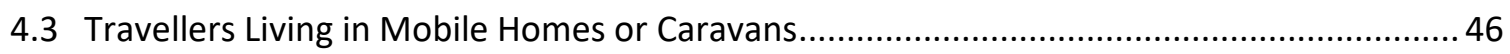

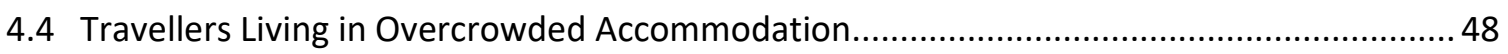

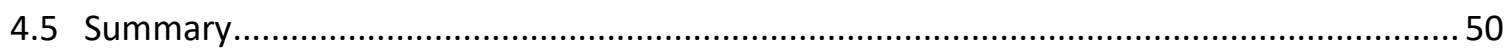

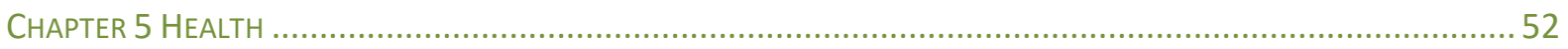

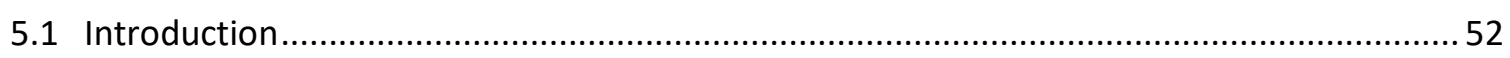

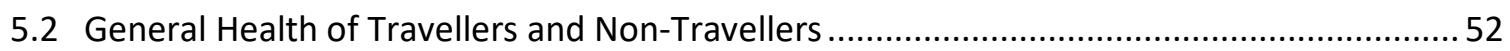

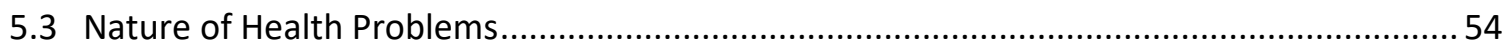

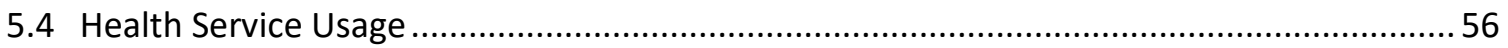

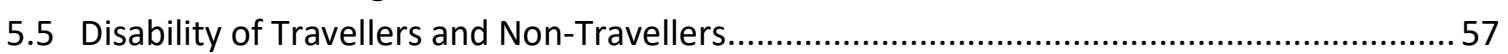

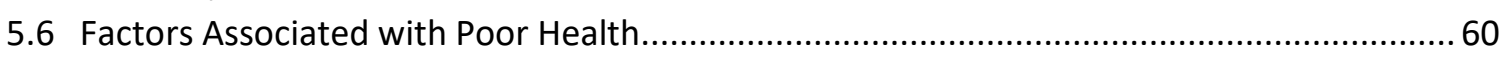

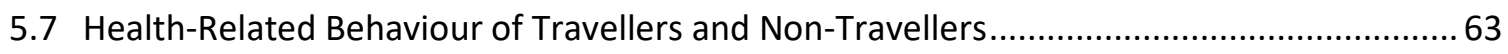

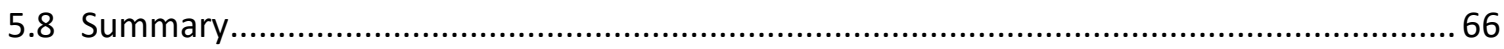


ii | A Social Portrait of Travellers

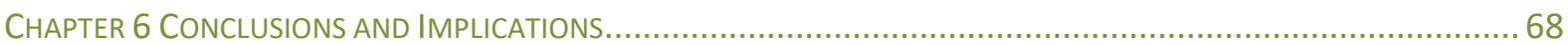

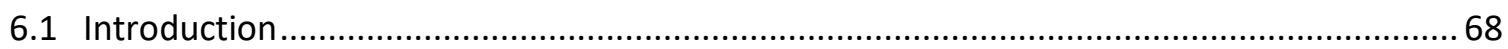

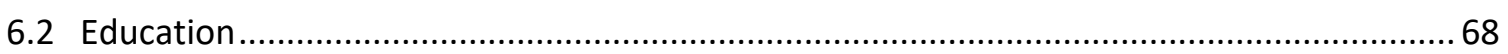

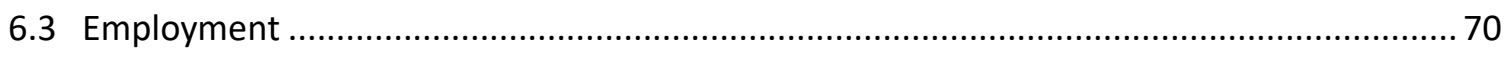

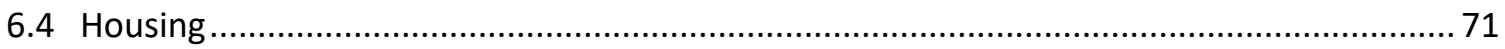

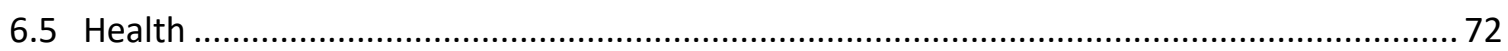

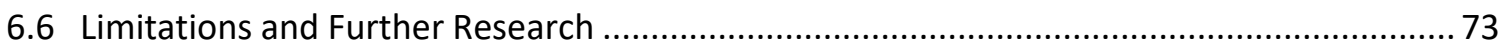

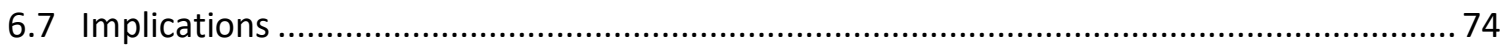

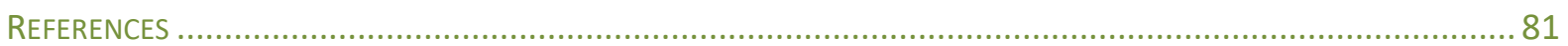

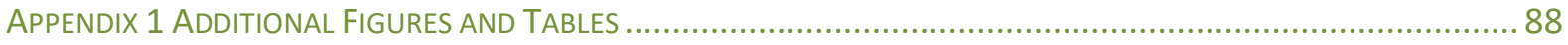




\section{List of Figures}

Figure 1.1 Regional Patterns in Local Authority Housing Provision for Travellers, 2012-2014.... 9

Figure 1.2

Figure 1.3

Figure 1.4

Figure 1.5

Figure 2.1

Figure 2.2

Figure 2.3

Figure 2.4

Figure 3.1

Figure 3.2

Figure 3.3

Figure 3.4

Figure 4.1

Figure 4.2

Figure 4.3

Figure 4.4

Figure 4.5

Figure 5.1

Figure 5.2

Figure 5.3

Figure 5.4

Figure 5.5

Figure 5.6

Figure 5.7

Figure 5.8

Figure 5.9

Figure 5.10

Figure A1.1

Figure A1.2

Figure A1.3

Figure A1.4

Figure A1.5
Age Profile of Traveller and Other Population by Age, 2011 ..................................... 25

Marital Status by Age Group for Travellers and Non-Travellers, 2011 ...................... 26

Number of Children Ever Born to Traveller and Non-Traveller Women, 45-64 Years,

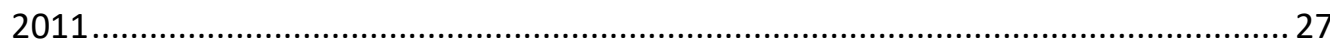

Percentage of Travellers and Non-Travellers in Households of Different Size, 2011 . 28

Age Education Ceased Among Those Aged 25 and Over, 2011 ............................... 29

Highest Level of Education Achieved, 25-64 Years, 2011........................................ 30

Adjusted Percentage Leaving Education Before Completing Second Level, 25-64

Years

Adjusted Percentage with Leaving Certificate by Year in Which the Person was Age

18. .33

Present Economic Status, 25-64 Years, 2011

Participation Rate, Employment Rate and Unemployment Rate, 25-64 Years, 201137

Adjusted Percentage at Work, 15-64 years (Excluding Those in Education), 2011 ... 41

Adjusted Percentage at Work by Level of Education, 2011.

Housing Characteristics of Travellers and Non-Travellers (Private Households),

2011

Housing Amenities of Travellers and Non-Travellers (Private Households), 2011 ..... 46

Housing Amenities of Travellers by Type of Dwelling (Private Households), 2011 .... 47

Adjusted Percentage of Travellers Living in a Caravan or Mobile Home, 2011 .......... 48

Adjusted Percentage Living in Overcrowded Accommodation, 2011......................... 50

General Health of Travellers and Non-Travellers, All Ages, 2011 .............................. 53

General Health of Travellers and Other Adults, 35-54 Years, 2011 ..........................53

Percentage Visiting a GP in the Past 12 Months by Whether Traveller and Age

Group. .56

Disability or Difficulty with Everyday Activities by Whether Traveller, 35-54 Years.. 58 Daily Activities Limited by Illness, Health Problem or Disability, by Whether

Traveller. 60

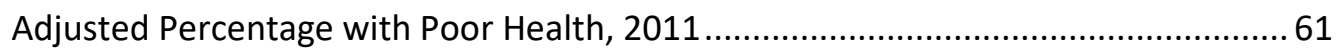

Adjusted Percentage with Poor Health by Age Group, 2011 ....................................62

Smoking, Consumption of Fried Food and Use of Alcohol by Whether Traveller ......6 64

Frequency of Alcohol Consumption by Gender among Travellers and Non-

Travellers. .65

Typically Consuming more than Nine Units of Alcohol by Whether Traveller............66

Age Distribution of Irish Travellers in Census 2011 and AITHS 2008 Data.................. 88

Education Level of Irish Travellers in Census 2011 and AITHS 2008 Data ................. 88

Main Economic Status of Irish Travellers in Census 2011 and AITHS 2008 Data........ 89

Labour Market Statistics for Irish Travellers in Census 2011 and AITHS 2008 Data ... 89

Housing Type and Tenure of Irish Travellers in Census 2011 and AITHS 2008 Data... 89 


\section{List of Tables}

Table 1.1

Table 1.2

Table 1.3

Table 2.1

Table 3.1

Table 3.2

Table 5.1

Table 5.2

Table A2.1

Table A3.1

Table A4.1

Table A4.1

Table A4.2
Changes in Accommodation Type, Travellers, 2007-2014 8 Wording of Question to Identify Travellers in Census Years 2002, 2006 and 2011.... 20 Main Indicators Used in the Analysis 23 Odds Ratios for Finishing Education Without Completing Second Level, 25-64 Years,

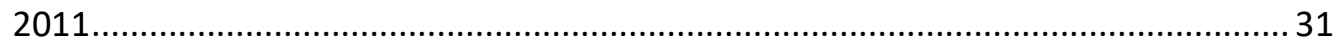

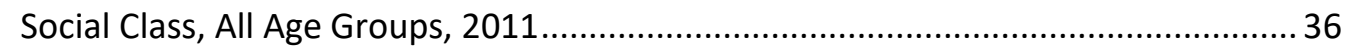
Odds of Not Being at Work for Adults 15-64 Years, Excluding Students .................... 39 Percentage of Adults Reporting Different Types of Chronic Illness........................... 55

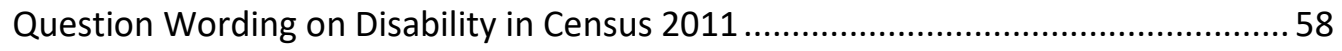
Odds Ratios for Finishing Education Without Completing Second Level (2011 Census),

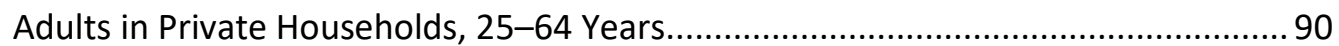
Odds of Not Being at Work for Adults, 15-64 Years, Excluding Students, 2011 ......... 89 Odds of Living in a Caravan or Mobile Home, Travellers ......................................... 92 Odds of Living in Overcrowded Accommodation, 2011............................................. 93

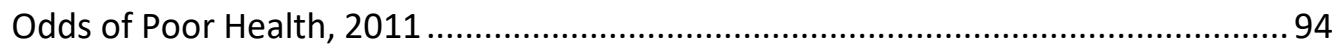




\section{Glossary}

Employment Equality Acts 1998-2015

Equal Status Acts, 2000-2015

Labour market participation

Multivariate analysis

Odds ratio

Overall and adjusted risk
These Acts prohibit discrimination on any of the nine 'equality grounds' in the employment-related areas of: recruitment; promotion; pay; working conditions; training or experience; dismissal and harassment, including sexual harassment. The 'equality grounds' are gender, age, civil (formerly 'marital') status, family status, sexual orientation, religion, race, disability and membership of the Traveller community.

These Acts prohibit discrimination in the provision of goods and services (including accommodation and education), wither in the public or private sector, on any of the nine 'equality' grounds (see Employment Equality Acts, above). A further ground - being in receipt of housing assistance payment - also applies to the provision of accommodation.

This involves being in employment (or self-employment) or being available for and actively seeking employment.

A statistical analysis methodology used when we want to look at the impact of one factor (such as age) on another (such as health problems), after taking account of other differences (such as level of education, gender and so on).

This is an indicator of how much more or less likely an outcome is for one group than another. An odds ratio greater than one indicates a greater likelihood, while an odds ratio less than one indicates a lower likelihood. For instance, if the odds ratio for poor health is 1.5 for Travellers compared to Non-Travellers, then Travellers have 50\% higher odds of being in poor health.

Overall risk is the actual rate of an outcome in the population (e.g. 12 per cent of Travellers have poor health compared to 9 per cent of non-Travellers). The adjusted risk is the risk we would observe if the groups were similar in respect of other characteristics taken into account in the statistical model (e.g. gender, age group, marital status, education, region, housing). For instance, the adjusted risk of poor health for married Traveller men would be 22 per cent compared to 12 per cent for non-Traveller married men.

Traveller-specific This refers to group housing schemes or halting sites. accommodation 


\section{List of Acronyms}

AITHS The All Ireland Traveller Health Study was a census of all Traveller families, in both Northern Ireland and the Republic of Ireland, conducted in 2008. In this report we focus on results from the Republic of Ireland sample.

CSO Central Statistics Office

DEIS Delivering Equality of Opportunity in Schools programme

DES Department of Education and Science

DHPCLG Department of Housing, Planning, Community and Local Government

DoJE Department of the Justice and Equality

$\mathrm{NI} \quad$ Northern Ireland

ROI Republic of Ireland

SILC Survey on Income and Living Conditions

SLÁN Survey of Lifestyle Attitudes and Nutrition

SMR Standardised morality ratio

STTC Senior Traveller training centres 


\section{Executive Summary}

\section{BACKGROUND}

Although a relatively small group in Ireland, accounting for less than 1 per cent of the population, Travellers stand out as a group that experiences extreme disadvantage in terms of employment, housing and health (Nolan and Maître, 2008; All Ireland Traveller Health Study, 2010; Watson et al., 2011), and that faces exceptionally strong levels of prejudice (MacGréil, 2011). ${ }^{1,2}$ In this report we draw on a special analysis of Census 2011 to examine in detail the patterns of disadvantage experienced by Travellers in the areas of education, employment, housing and health. The full population from Census 2011 gives a large enough number of Travellers to investigate. ${ }^{3}$ Rather than treating Travellers as a homogenous group, the study explores whether specific groups of Travellers (in terms of gender, age and region) experience particularly high levels of disadvantage.

\section{RESEARCH QUESTIONS}

The main research questions we address are as follows:

1. Are there differences in educational disadvantage by gender, age group and region among Travellers? Are these patterns the same as for non-Travellers?

2. What are the factors associated with non-employment for Travellers gender and family situation, age, level of education and region? Do these differ when compared to the non-Traveller population?

3. Which Travellers are more likely to live in caravans or mobile homes or to live in overcrowded accommodation? Does this vary by age group, presence of children, level of education and employment?

4. Are there also differences between Travellers and non-Travellers in the influence of factors such as age and education on poor health?

\section{EDUCATION}

Travellers are much less likely to have completed education to Leaving Certificate level: only 8 per cent have done so, compared to 73 per cent of non-Travellers.

\footnotetext{
${ }^{1}$ The term Travellers refers to 'the community of people who are commonly called Travellers and who are identified (both by themselves and others) as people with a shared history, culture and traditions including, historically, a nomadic way of life on the island of Ireland.' (Ireland, Equal Status Act, 2000, Sec 2 (1)).

2 Throughout this report, unless otherwise specified, 'Ireland' refers to the Republic of Ireland.

${ }^{3}$ Other general social surveys often have too few Travellers for meaningful analysis.
} 
Only 1 per cent of Travellers aged 25-64 years have a college degree compared to 30 per cent of non-Travellers. Travellers are more likely to have left school at an early age, with 28 per cent of Travellers over 25 years having left before the age of 13 , compared to only 1 per cent of non-Travellers. When we adjust for the fact that Travellers tend to be younger than non-Travellers (and younger adults tend to have higher levels of education), the 'education gap' becomes even larger.

Among Travellers and among the general population, women and younger adults were more likely to complete second level education. However, the pattern by age differs between Travellers and non-Travellers so that the gap in terms of completing second level is larger in the younger age groups. Among those aged 5564 years, 97 per cent of Traveller and 49 per cent of non-Travellers left school without completing second level. Among those in the 25-34 age group, the figures are 91 per cent of Travellers and 14 per cent of non-Travellers. This suggests that Travellers have not benefitted as much as non-Travellers from the general improvement in levels of education since the 1960s.

As noted above, women are more likely to have completed Leaving Certificate level. While Traveller women are more likely than Traveller men to have completed the Leaving Certificate, the gender gap is smaller than among non-Travellers. Traveller women still remain very disadvantaged in educational terms, with an estimated 92 per cent leaving school without having completed second level. The figure is 95 per cent for Traveller men.

\section{EMPLOYMENT}

The main difference between Travellers and non-Travellers in employment terms is their very high levels of unemployment. Among those aged 25-64 years, the unemployment rate was 82 per cent for Travellers in Census 2011, compared to 17 per cent for non-Travellers. Travellers also had a lower rate of labour market participation, that is, being either in employment or unemployed. The labour market participation gap was not as large, however: 61 per cent of Travellers were in the labour market compared to 79 per cent of non-Travellers. Therefore, the lower employment rate of Travellers (11 per cent versus 66 per cent) was mainly driven by differences in unemployment.

We constructed a statistical model to check how much of the non-employment of Travellers and non-Travellers was associated with low levels of education and with other characteristics such as gender, marital and family status, age group and region. The results suggested that education was very important indeed. After accounting for the impact of education, the employment gap between Travellers and non-Travellers was very dramatically reduced. For instance, the employment rate of non-Travellers is about six times higher than that of Travellers, as noted above. If the two groups were similar in terms of education, age group, gender, 
marital status, presence of children and region, the rate would be just 1.9 times higher. This is a very substantial reduction in the gap, though the gap remains very large.

This suggests that there are additional barriers that operate within the labour market to make getting a job more difficult for Travellers. With the analysis here, it is not possible to say how important direct discrimination and generalised prejudice are in this regard, but these undoubtedly play a role.

The second finding worth highlighting is the sharp increase in the chance of being in a job as level of education increases for Travellers. This is partly a function of the employment rate being so low among Travellers who have just primary level education or less (9 per cent adjusted rate), but the increase is observed as we move to lower second level (15 per cent adjusted rate), upper second level (Leaving Certificate, adjusted rate of 27 per cent) and further or higher education ( 57 per cent). It is true that the employment rate of Travellers with further or higher education still lags behind the rate for their non-Traveller counterparts, but the improvement in employment chances compared to Travellers with lower levels of education is very substantial.

\section{HOUSING}

Census 2011 indicated that 12 per cent of Travellers lived in a caravan or mobile home. Although associated with their traditionally nomadic way of life, this type of accommodation is likely to be overcrowded ( 84 per cent) and to lack internet access (91 per cent). It is also more likely than standard accommodation to lack central heating, piped water and sewerage facilities. Travellers living in mobile homes or caravans are somewhat more likely than those in standard accommodation to be married young adults, to have lower levels of education and to live in the Dublin or Mid-West regions.

Overcrowding in this report refers to living in accommodation where there is more than one person per room, counting living rooms as well as bedrooms. As noted above, overcrowding is associated with living in a caravan or mobile home, but only 12 per cent of Travellers live in a caravan or mobile home, while 56 per cent live in overcrowded accommodation. The statistical model showed that overcrowding was more common among children under age 15 and adults age 35-44, the stage where the family is likely to be complete but the older children have not yet left home. Overcrowding is also associated with low levels of education, not being in employment and it is higher in the West and Mid-West than in Midlands, Mid-East and South-East. 


\section{HEALTH}

Since the poorer health outcomes of Travellers, compared to non-Travellers, have been documented elsewhere (AITHS, 2010; Kelleher et al., 2012), we focused our analysis on whether poor health was associated with different socio-demographic factors for Travellers compared to non-Travellers. The most striking finding in this regard was that there is a steeper increase in poor health with age for Travellers, particularly in the 34-64 age range. As a result, the gap in poor health between Travellers and non-Travellers is smaller in childhood and early adulthood, but increases very rapidly after the age of 35 . For instance, among those under the age of 15 , there is a two percentage point difference between the adjusted rate of poor health among Travellers and that among non-Travellers (about 3 per cent versus about 1 per cent). In the 55-64 age group, the gap is 28 percentage points (50 per cent of Travellers versus 22 per cent of non-Travellers). This pattern of an increasing gap with age has also been found for other minority ethnic groups and suggests that poor health among Travellers has the character of a disadvantage that cumulates or worsens across the life course.

\section{LIMITATIONS AND FURTHER RESEARCH}

It was not possible to compare the census results from 2006 and 2011 because there was evidence of greater under-coverage of the Traveller population in 2006. As a result, we cannot be sure to what extent differences between the two census years are due to a real change in circumstances or to improved coverage of Travellers living in conventional accommodation in 2011. Given the relatively small size of the Traveller population, there are few national data sources that contain a sufficient number of cases to permit a comparison of the circumstances of Travellers and non-Travellers. As a result, the importance of maintaining a high rate of coverage and identification of the Traveller population in future census rounds cannot be overemphasised.

\section{POLICY IMPLICATIONS}

In general, our results on the sheer magnitude of the gap between Travellers and non-Travellers in terms of education, employment, housing and health highlight the tension between policies which seek to 'mainstream' services to Travellers and those which target the group. It raises the question of the best way to combine the implied quality assurance that comes with mainstreaming with the proper attention to the urgency of the situation of Travellers that is implied by targeting. While the results reported here do not directly address the issue of recognition of Travellers as an ethnic group, as recommended by the Joint Oireachtas Committee on Justice, Equality and Defence (2014), recognition could be of considerable benefit in ensuring respect for the cultural identity of Travellers in the context of targeted services. This recognition would also facilitate the routine use of an ethnic 
identifier on administrative databases, which would allow the monitoring of progress towards equality for Travellers.

The policy implications that follow from this analysis in specific areas are as follows.

Both the findings of large differences in educational attainment and the benefits in terms of employment to Travellers with higher levels of education point to the importance of enhancing the levels of education among Travellers. The depth of educational disadvantage experienced by Travellers means that specific targeted additional supports will be required for them to participate in mainstream education on equal terms, encompassing the need to address the educational needs of parents as well as children, ensuring that school admission policies are inclusive, providing access to after-school study and homework clubs and, more broadly, educating both teachers and the general body of pupils on Traveller culture and history.

There is still a need to address barriers in the labour market, since the employment gap persists even after taking account of education, region, age, gender and family circumstances. Although not directly measured here, prejudice and discrimination are likely to play a significant role in accounting for the remaining gap. In this context, the reliance on mainstream employment supports may be premature. Mainstream services that support self-employment may be particularly beneficial to Travellers, who have a strong history of enterprise and self-employment.

Among Travellers living in caravans or mobile homes, there is a need to improve services in areas such as the provisions of piped water and sewerage facilities. These dwellings are also likely to be overcrowded, pointing to the need for more space for families.

In order to address overcrowding, the nature of the accommodation provided needs careful consideration. With larger family sizes, average-sized accommodation simply does not provide enough space. The increasing reliance on privately rented accommodation is regrettable as this accommodation is not likely to be large enough for Traveller families.

While the government has delegated responsibility for providing Traveller-specific accommodation to local authorities, this obligation is not being met. The national government needs to do more to ensure that local authorities are acting in a coordinated fashion to meet the need for Traveller-specific accommodation.

The widening of the health gap between Traveller and non-Travellers with age is a clear example of cumulative disadvantage, where the situation later in life results from an accumulation of the effects of earlier disadvantage in education, employment, housing and other areas such as prejudice and discrimination. This highlights the need for policy to intervene at all stages of the life course. Since 
health status can be seen as the outcome of general social processes - in education, work, housing, income and social life more generally - ensuring improved health for Travellers requires action in all of these areas and not just in clinical services. 


\section{Chapter 1}

\section{Introduction}

\subsection{BACKGROUND AND RESEARCH QUESTIONS}

According to the Equal Status Act, 2000, the term Travellers refers to 'the community of people who are commonly called Travellers and who are identified (both by themselves and others) as people with a shared history, culture and traditions including, historically, a nomadic way of life on the island of Ireland' (Ireland, Equal Status Act, 2000, Sec 2 (1)). Although a relatively small group in Ireland, accounting for less than 1 per cent of the population, they have been identified as experiencing extreme disadvantage in terms of education, employment, housing, health and in facing exceptionally strong levels of prejudice (Nolan and Maître, 2008; AITHS, 2010; Watson et al., 2011; MacGréil, 2011). ${ }^{4}$

In this chapter, we provide a brief overview of what is already known about the circumstances of Travellers in Ireland, as well as policy in Ireland with respect to Travellers, the research questions that are the focus of this report, and the data and methods of analysis used. Before proceeding to the next chapter, we provide some important background descriptive information on the Traveller population from Census 2011.

\subsection{IRISH TRAVELLERS - AN OVERVIEW OF WHAT IS KNOWN}

Unlike the UK and Northern Ireland, where Travellers are recognised as an ethnic group, Travellers have yet to be given a specific status as a minority ethnic group in Ireland. They are however recognised as having distinct grounds for protection under Irish anti-discrimination laws (Employment Equality Act, 1998; and Equal Status Act, 2000). Numerous health surveys, specific studies, government commissioned reports and national strategy and public policy documents highlight the disproportionately poorer outcomes faced by Irish Travellers compared to the general population in areas such as mortality, morbidity and health, education and employment, poverty, housing, living conditions and other social inequalities (see for example, AITHS, 2010).

\footnotetext{
${ }^{4}$ Throughout this report, unless otherwise specified, 'Ireland' refers to the Republic of Ireland.
} 
A background and history of extreme prejudice and discrimination against Travellers has necessitated their identification as a group to be protected against discrimination under Irish equality legislation. This negative attitude towards Travellers is documented in MacGréil's work (2010,2011). Drawing on a national survey of attitudes towards different groups, MacGréil reports that 60 per cent of the population in Ireland would not welcome a Traveller as a member of the family; 64 per cent reject Travellers on the basis of their 'way of life' and 18 per cent would deny Irish citizenship to Travellers. Findings by Tormey and Gleeson (2012) indicate that attitudes towards Travellers among young people are less favourable than attitudes towards migrant groups.

\subsubsection{Demographic profile}

Previous work has estimated the size and demographic profile of the Traveller population in Ireland. According to Census 2011, the Traveller population consists of 29,573 individuals, or only 0.6 per cent of the Irish population. The 2011 figure represents an additional 7,000 persons or a 32 per cent increase on Census 2006 figures, a difference that is most likely attributable to an increase in people identifying themselves as Travellers (see section 1.5.1 below). This can be compared to Asian and African populations of 1.9 per cent and 1.3 per cent respectively.

The All Ireland Traveller Health Study (AITHS), carried out in 2008, was a census of Travellers and collected socio-demographic information for all Traveller families on the island of Ireland. The AITHS study enumerated 9,056 Traveller families in Ireland. Based on an average of four persons per Traveller household, the total Traveller population would reach an estimated 36,224 - close to 0.8 per cent of the total Irish population. ${ }^{5}$ The annual count of Traveller families provided by the Department of Housing, Planning, Community and Local Government (DHPCLG), based on local authority records, put the figure at 9,535 families in 2011 and 10,226 families in 2014 (DHPCLG, 2015). This gives an estimate of 38,140 individual Travellers in 2011 and 40,904 in 2014, if we assume an average of four persons per family.

The undercount in the census relative to other sources is likely to reflect a certain reluctance on the part of Travellers - particularly those in standard housing - to identify themselves as part of a group that has historically been the subject of prejudice and discrimination. Nevertheless, Traveller representative bodies have emphasised the

\footnotetext{
${ }^{5}$ The AITHS also covered Northern Ireland and estimated the number of Traveller families there at 1,562, with an average of 2.5 individuals per family = 3,905 Travellers in Northern Ireland. In this report, however, we focus on the Republic of Ireland.
} 
importance of including an ethnic identifier in official statistics in order to monitor the impact of policies on minority groups such as Travellers (e.g. Pavee Point, 2016a).

The Traveller population is relatively young. Census 2011 showed that the average age among Travellers is 22.4 years, compared with 36.1 years in the general population, and over that half ( 52 per cent) of Irish Travellers are aged under 20 years of age. Only 2.3 per cent are over 65 (CSO, 2012a, p. 27).

Irish Travellers tend to marry younger and have larger families (CSO, 2012a). One-third of 15-29 year old Travellers are married compared to 8 per cent of the general population of the same age and Irish Traveller women have an average of five children compared to a national average of three children. The makeup of Traveller households also differs from the general population with a higher number of lone parents (20 per cent compared to 12 per cent), fewer cohabiting couples with no children ( 2 per cent compared to 5 per cent), more families living together in the same household (2.5 per cent compared to 1.1 per cent) and fewer single person households (10 per cent compared to 24 per cent).

Census 2011 data also show that the Traveller population is not evenly spread across the country with the highest number of Irish Travellers living in Galway county (8.4 per cent), followed by South County Dublin (7.5 per cent; CSO, 2012a). The DHPCLG's annual counts of Traveller families, which use local authority records, confirm this distribution. Moreover, the proportion of Travellers living in urban areas is 82 per cent compared to 62 per cent of the general population (CSO, 2012a).

\subsubsection{Socio-economic Circumstances of Travellers}

The best source of data on household income, poverty and living standards for most purposes is the annual EU Survey on Income and Living Conditions (SILC). However, for small populations such as Irish Travellers, the number of cases in these surveys is too small to provide useful information. The census of population does not have information on household income. However, 'these data show levels of unemployment, poor health, disability, low educational attainment, inadequate housing, and premature mortality among the Traveller population, which suggest that they are also exposed to distinctively high levels of poverty and deprivation' (Nolan and Maître, 2008, p.62).

The AITHS (2010) found overall that in terms of health and mortality rates, and in areas of education, employment and housing, 'relative to the general population [Travellers] are falling constantly further behind' 
(AITHS 2010, p. 162; see also Committee to Monitor and Co-Ordinate the Implementation of the Recommendations of the [1995] Task Force on the Travelling Community, 2005).

\subsubsection{Education}

There is a very large disparity between Travellers and non-Travellers in the level of education completed. The labour market disadvantage of Travellers is largely linked to this educational disadvantage.

The age by which 90 per cent of Irish Travellers have ceased full-time education is 17 years compared to 24 years in the general population. Only 1 per cent had completed third level education, compared to 31 per cent of the general population (CSO, 2012a). The majority - seven out of ten Travellers - have only primary or lower levels of education. Given the very low numbers of Travellers aged over 65 years (CSO, 2012a), this cannot be explained by generational differences or historical cultural differences alone.

The AITHS authors (2010) question the often-cited mobility patterns and tradition of nomadic lifestyle as an explanation for the low levels of educational attainment among Travellers. This study found that most Travellers are in one place during term time; only 14 per cent of Irish Travellers said they 'go on the road' at least once a year and were more likely to travel during school holidays. In addition, in terms of important cultural traditions, a 'nomadic lifestyle' is ranked lowest out of five other areas of importance by Travellers (AITHS, 2010).

Indeed, a survey of nearly 800 Traveller pupils found that the majority (76 per cent) of primary school Traveller pupils lived in a house and that most (68 per cent) had only ever enrolled in one school. The study did find, however, that school attendance tended to be poor and varied by type of accommodation, being highest among those living in a house, somewhat lower among those living on an official halting site and lowest for those living in an unofficial halting site. Interviews with Traveller children and their parents indicated that they perceived their attendance as satisfactory (Department of Education and Science, 2005).

Reasons for leaving school early are likely to include the negative experiences of Traveller children in school. Traveller children, along with immigrant children and those with a disability, are significantly more likely to report being bullied at school (Department of Children and Youth Affairs, 2016, citing Kelly et al., 2012). Discussion of poor school attendance in the AITHS study points to a reluctance to continue mainstream education as it is not associated with any positive outcomes 
because of the high level of discrimination Travellers face when seeking employment.

Transgenerational issues are also highlighted; poor education among parents means it is more difficult to read or interpret their children's educational material, making it harder for them to help children with their homework (AITHS, 2010). Over two-thirds of Traveller children (67.3 per cent) live in families where the mother had either no formal education or primary education only (Department of Health and Children, 2012).

The AITHS also draws attention to school policies and practices in the past that led to the segregation of Traveller children, along with a lack of inclusionary education strategies, interagency support, adequate resources and ways to meaningfully engage parents in their children's education (AITHS, 2010).

Traveller children are more likely than non-Traveller children to attend a designated disadvantaged school (DES, 2005; Smyth et al., 2015b). The Department of Education and Science survey (2005) found that nearly one half of the primary level Traveller population (48 per cent) was enrolled in a disadvantaged school, while in Dublin this figure was as high as 95 per cent. Attendance at DEIS schools brings the advantage of a greater level of resources including teaching resources, the school meals programme and additional funding for the purchase of textbooks. Other issues identified in the DES study included the tendency for Traveller children to start school a year later than other children and a greater likelihood of being assessed as having a special educational need (DES, 2005). Starting school later may lead to Traveller children beginning their school careers at a disadvantage relative to their non-Traveller peers.

Standardised test data at primary school level showed much lower attainment among Traveller children compared to the general population. ${ }^{6}$ More than two-thirds of Traveller children scored in the bottom 20 per cent for reading and slightly less than two-thirds were in the bottom 20 per cent for mathematics (DES, 2005). In the first evaluation of DEIS ${ }^{7}$ schools, Weir et al. (2011) found that a subset of Traveller children in these schools scored significantly below nonTraveller children at every grade level in 2007 and 2010 for both reading

\footnotetext{
${ }^{6}$ Standardised tests were administered by schools themselves as part of their annual assessment process for all pupils. Data were available for 56 per cent of the Traveller pupils in reading and for about 50 per cent in mathematics.

7 The Delivering Equality of Opportunity in Schools (DEIS) programme, introduced in 2006, brought together a number of earlier stand-alone schemes addressing specific aspects of educational disadvantage (Smyth et al., 2015b).
} 
and mathematics. These findings of lower educational attainment among Irish Traveller children reflect those from similar studies in the UK of Gypsy, Roma and Traveller children (Wilkin et al., 2010). In Weir et al. (2011) there was some suggestion of an improvement among Traveller children over time, but the improvement was not statistically significant. The low enrolment of Traveller children in preschools, noted by the Houses of the Oireachtas Joint Committee on Health and Children (2016), is of concern in this regard, as it means that Traveller children 'are entering primary school already at a great disadvantage' (p. 22), particularly when attendance at preschool has become almost universal in other groups since the introduction of the free preschool years.

In a review of the School Completion Programme in Ireland, Smyth et al. (2015a) indicate that the withdrawal of the visiting teacher service and resource teachers for Travellers is seen by stakeholders as having had a negative impact on the school retention of these pupils.

\subsubsection{Employment}

There is a strong link between educational attainment and employment in the Irish labour market, and young people leaving school early face a far higher risk of unemployment (Byrne, McCoy and Watson, 2008; Gorby, McCoy and Watson, 2005). In 2012, only 35 per cent of Irish people with no qualifications were active participants in the labour market, compared to 50 per cent of those with a Junior Certificate, 70 per cent of those with Leaving Certificate and 79 per cent of those with a postLeaving Certificate qualification (CSO, 2012). Furthermore, lower qualifications generally lead to low skilled jobs and low earnings throughout the life course (Byrne and Smyth, 2010; McCoy et al., 2014).

Figures from Census 2011 show that 57 per cent of Irish Travellers aged 15 and over participated in the labour market, compared with 62 per cent among the general population. Just over 9 per cent of all Travellers over 15 years were unable to work due to permanent sickness or disability more than double that of the general population (4 per cent). The unemployment rate among Travellers was 84 per cent compared to only 19 per cent nationally (CSO, 2012). ${ }^{8}$ The AITHS cites low education, lack of role models and discrimination as acting as barriers to employment for Travellers. Watson et al. (2011), using figures from Census 2006, found that the unemployment rate was much higher among Travellers than the general population even after factors such as similar education level and

\footnotetext{
${ }^{8}$ The unemployment rate is measured as the number of adults who are unemployed divided by the number in the labour market (unemployed or at work) among those aged 15 and over. The census classifies as 'unemployed' those who are 'unemployed, looking for first regular job' and 'unemployed, having lost or given up previous job'.
} 
other characteristics (gender, marital / family status, age, religion, nationality, presence of disability, region) were taken into account. This shows that while some of the gap between unemployment rates in the two populations was due to the lower educational level of Travellers, even after taking this into account Travellers are much more likely to remain unemployed.

While female employment among the general population grew by 55 per cent between the years 1998 to 2007 (Russell et al., 2009), the number of Irish Traveller women who recorded their principal economic status as looking after the home and family in Census 2011 was nearly twice the rate of the general population, at 33 per cent compared to 17.5 per cent.

The AITHS study (2010) reported differences in employment status between Travellers from the Republic of Ireland (ROI) and those from Northern Ireland ( $\mathrm{NI}$ ). Only 2 per cent of ROI Travellers classed themselves as self-employed compared to 22 per cent of NI Travellers. This may be due to a decline in traditional modes of income generation such as recycling, waste disposal and horse trading, as a result of regulation and enforcement (AITHS, 2010). This study also found that almost twice the number of Travellers (48 per cent) from Ireland reported themselves as being unemployed compared to 25 per cent from NI. This is despite the finding that twice the number of $\mathrm{NI}$ Travellers (28 per cent) reported 'going on the road' at least once a year compared to Travellers in the ROI (14 per cent) and that NI Travellers were less likely to live in a house or apartment; 64 per cent compared to 78 per cent. Part of the difference may be due to legislation in Ireland following the enactment of the Housing [Miscellaneous Provisions] Act 2002, which criminalised camping on private and public property (Crowley and Kitchen, 2007).

Further support for the argument that a nomadic lifestyle may not fully explain the low employment rates among Travellers comes from the KW Research and Associates report for the Housing Agency (2014). Data from an online survey of local authorities, carried out in 2013 as part of that research, suggests that the vast majority of Traveller households live permanently in their local authority area. Only eight county councils reported Traveller families living in their area on a seasonal basis; this ranged from 3 per cent of all Traveller families in Kildare County to 9 per cent and 10 per cent in Limerick and Cork County respectively. ${ }^{9}$

${ }^{9}$ However, that report notes that Traveller organisations - national and local - believe these seasonal figures to be significantly underestimated. 


\subsubsection{Housing}

The finding by AITHS (2010) that more Irish Travellers live in a house (73 per cent) than in a caravan or mobile home (18 per cent) is echoed by Census 2011, which reports an even higher number of Travellers living in standard accommodation (85 per cent) and only 12 per cent living in a caravan or mobile home. However, Travellers are much less likely than the general population to own their home (20 per cent, which may include ownership of a caravan in some cases, compared to 70 per cent for non-Travellers) and four times as many Traveller families were living in only one room (CSO, 2012a).

The DHPCLG's annual Traveller count gives totals for the number of Traveller families living in local authority housing or local authority assisted housing, such as housing provided by voluntary bodies, group housing or accommodation on halting sites, as well as those living on unauthorised sites or in shared accommodation, accommodation provided through own resources (estimated) and private rented accommodation (estimated). Table 1.1 summarises changes in accommodation type between the years 2007 and 2014. It shows a general decrease in Traveller families living in housing provided by or assisted through local authorities, along with an increase in the number of families living in private rented accommodation.

Table 1.1 Changes in Accommodation Type, Travellers, 2007-2014

\begin{tabular}{|lrrrrrrrr|}
\hline & \multicolumn{7}{c|}{ Year of Count } \\
\hline Accommodation Type & 2007 & 2008 & 2009 & 2010 & 2011 & 2012 & 2013 & 2014 \\
\hline $\begin{array}{l}\text { Accommodated by or with } \\
\text { the assistance of LA }\end{array}$ & $67 \%$ & $65 \%$ & $63 \%$ & $59 \%$ & $59 \%$ & $56 \%$ & $56 \%$ & $57 \%$ \\
\hline On unauthorised sites & $7 \%$ & $6 \%$ & $5 \%$ & $5 \%$ & $3 \%$ & $3 \%$ & $4 \%$ & $4 \%$ \\
\hline Own resources (estimate) & $6 \%$ & $6 \%$ & $6 \%$ & $6 \%$ & $6 \%$ & $6 \%$ & $6 \%$ & $6 \%$ \\
\hline Private rented (estimate) & $14 \%$ & $18 \%$ & $22 \%$ & $26 \%$ & $27 \%$ & $28 \%$ & $27 \%$ & $26 \%$ \\
\hline Sharing housing & $5 \%$ & $4 \%$ & $4 \%$ & $5 \%$ & $5 \%$ & $6 \%$ & $7 \%$ & $7 \%$ \\
\hline Total number of families & $\mathbf{8 , 0 9 9}$ & $\mathbf{8 , 3 9 8}$ & $\mathbf{8 , 9 4 3}$ & $\mathbf{9 , 4 7 0}$ & $\mathbf{9 , 5 3 5}$ & $\mathbf{9 , 8 9 1}$ & $\mathbf{9 , 8 9 9}$ & $\mathbf{1 0 , 2 2 6}$ \\
\hline
\end{tabular}

Note: Columns may not sum to $100 \%$ due to rounding.

Source: DHPCLG's annual counts of Traveller families, 2007-2014.

There are differences between local authority areas regarding the extent to which Traveller housing is provided directly by the local authority, as well as the extent to which Traveller-specific accommodation (such as group housing or halting sites) is provided. Although an analysis at the level of local authorities is beyond our scope here, it is useful to examine the regional patterns as the analysis later in the report will include differences between the regional authority areas. Drawing on the 
DHPCLG annual counts, Figure 1.1 shows how this differs by the eight regional authority areas. The regions are sorted according to the proportion of Travellers who are provided with housing by the local authorities, with the highest figure in the Dublin local authorities at 65 per cent and the lowest figure in the South-East local authorities (counties Carlow, Kilkenny, South Tipperary, Wexford, Waterford and Waterford City) at 45 per cent. The bars in the figure show the proportion of local authority-provided housing that is in standard accommodation, group housing schemes and local authority halting sites. The local authorities in Dublin also stand out in this regard, providing a higher proportion of accommodation in Traveller-specific schemes such as group housing or halting sites (30-31 per cent).

Figure 1.1 Regional Patterns in Local Authority Housing Provision for Travellers, 2012-2014

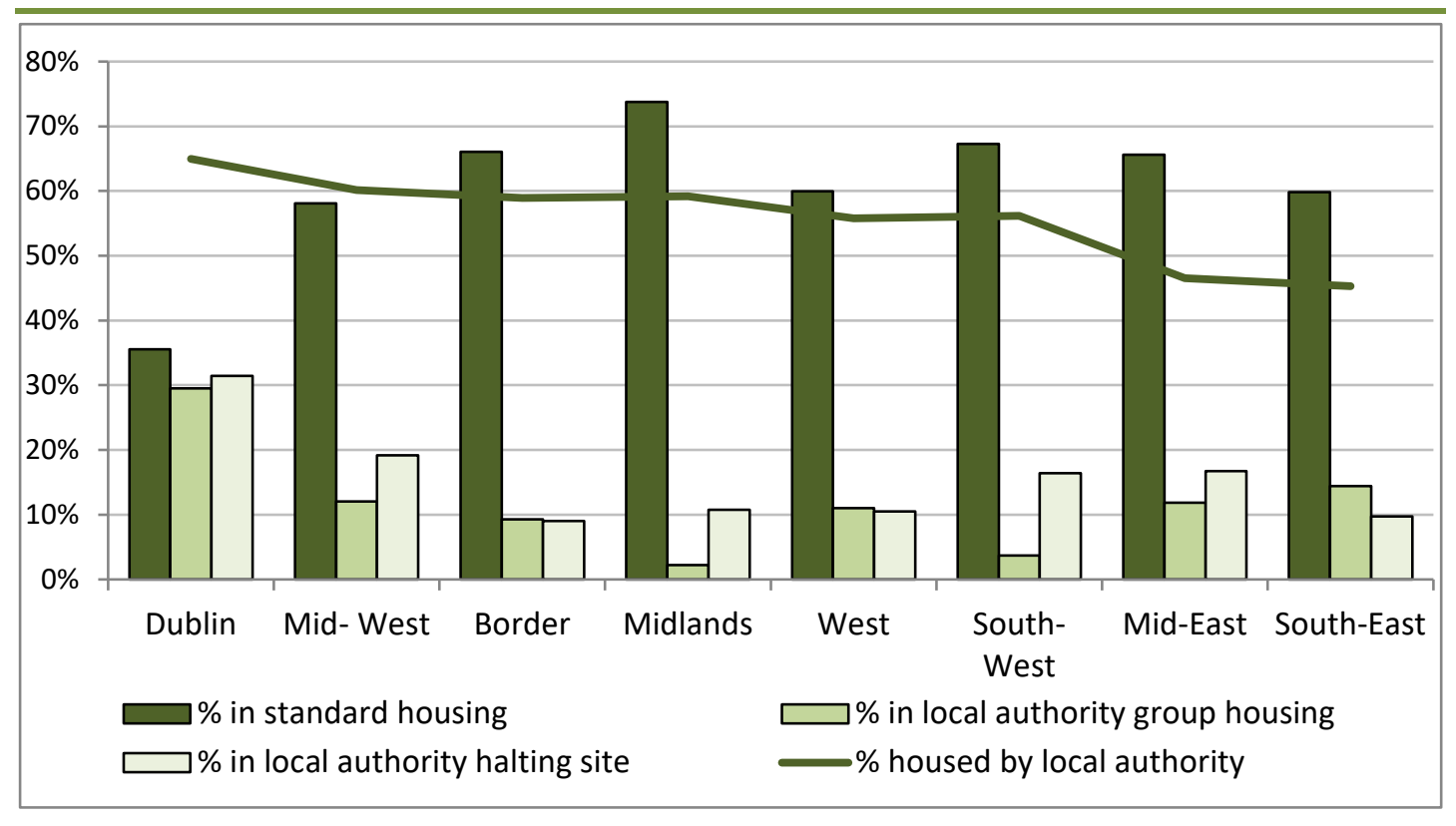

Source: DHPCLG annual counts, 2012-2014.

Of the 9,281 Traveller families identified by local authorities in a survey carried out for the Housing Agency (KW Research and Associates, 2014), only 18 per cent were living in Traveller-specific accommodation; mainly group housing schemes and permanent halting sites (15 per cent). This survey reported a national total of 1,860 units of Traveller-specific accommodation, including group housing schemes, halting sites, basic service bays, transient and 'other' sites. ${ }^{10}$ Almost one-third (32 per cent) of this stock was found to be more than 25 years old and while 133 units had been refurbished (to varying extents), a further 136 were in need of refurbishment with 27 units requiring complete redevelopment. The

10 Other sites cited in this survey included unofficial halting sites, sites without services, houses for Travellers purchased out of the Traveller Accommodation budget and temporary bays. 
average void rate (unoccupied) in this Traveller-specific accommodation was 19 per cent.

KW Research and Associates (2014) also reported the local authority perspective on the reasons for a high number of vacant Traveller-specific accommodation units, which included internal tensions between Traveller families. Some local authority representatives thought that there was an overprovision of halting sites and bays, given what they viewed as a preference for standard local authority and private rented accommodation (KW Research and Associates, 2014).

Traveller representative organisations point to inadequacies in local authority statistics, however, noting that homelessness among Travellers is labelled as 'sharing' of housing or halting site bays, which results in chronically overcrowded conditions, or as living on 'unauthorised sites' (Pavee Point, 2016b). As such, it is not regarded as a housing crisis.

KW Research and Associates (2014) used qualitative case studies and a focus group consisting of local representative Traveller groups, individuals and organisations involved with Travellers and Travellers themselves in order to seek the perspective of Travellers on why they are leaving Traveller-specific accommodation. These groups felt that Traveller-specific accommodation was not overprovided but is not being used by Travellers for the following reasons: tension, conflict and intimidation within and between Traveller families; the location and design of sites and schemes; and issues relating to health, overcrowding and poor maintenance/management in certain locations. While some agreed that some Travellers, especially younger people, might have a preference for social and private rented housing, others expressed the view that Traveller-specific housing is preferred but for the reasons outlined above may be refused. In addition, there are difficulties in accessing and remaining in private rented accommodation for Travellers, including high costs, discrimination by landlords and the general public, overcrowding due to large family sizes and separation from family and community (KW Research and Associates, 2014).

Other studies (AITHS 2010; Kelleher et al., 2012) also point to environmental conditions - such as safety, proximity to family and extended family, and good facilities - as being more important to Travellers than whether the accommodation is a house or caravan on a halting site. Given the cultural importance of connection to the extended family among Travellers, this is likely to be significant for their mental well-being. 


\subsubsection{Health}

The question of whether health is determined by an individual's lifestyle or whether it is influenced by broader social factors is probably best answered by acknowledging both aspects. For example, Bambra et al. (2010), in a systematic review of wider social determinants of health inequalities, found that policies and interventions in the area of housing may have the most positive impact on disadvantaged groups. Nevertheless, it is not just the objective living circumstances that have an impact on health outcomes, but also the relative position within the society. Marmot (2015) argues that the relative position of people within their society can be even more important, with dramatic links to health inequalities: people at relative social disadvantage suffer health disadvantage in all countries. The classic life course perspective points to early childhood disadvantage exacerbated by difficult adult experiences and compounded through economic hardship (AITHS, 2010).

Insight from the qualitative component of the AITHS illustrates some of the difficult issues currently faced by Travellers. These include declining family structures and religious certainty, lack of employment and pressure to engage in damaging group activities such as heavy drinking. Such factors, coupled with a sense of exclusion and experiences of extreme prejudice, can result in generalised poor self-esteem and selfefficacy, which is associated with depression and other mental health problems. These conditions are, in turn, related to higher incidences of suicide. The suicide rate is almost seven times higher among Traveller men than in the general population (AITHS, 2010).

The AITHS study measures self-rated health, which is a widely accepted proxy for objective health (see Benyamini and Idler, 1999; DeSalvo et al., 2005). Self-rated health was reported as excellent, good or very good by 82.6 per cent of Traveller respondents and was rated more poorly as age increased (AITHS, 2010).

Kelleher et al. (2012) explored the relationship between self-reported health and quality of accommodation using data from the 2,065 AITHS study participants who completed the 'health status survey' in 2008. The authors found that in Ireland, controlling for age and gender, living in a house was not significantly related to good health but having sanitation services (running water, access to a flush toilet and to rubbish removal services), high social support and considering the living environment to be healthy were all associated with good health. With these factors taken into account, 'going on the road' was not associated with good health. This suggests that access to sanitary facilities and a healthy and 
supportive environment is more important than whether one lives in a caravan or house. Equally, in terms of nomadism, it may be that it is the ability and means to travel that influences good health rather than the actual practice of travelling itself (Kelleher et al., 2012).

The poorer health of Travellers compared to non-Travellers can be seen in their higher mortality rates and lower life expectancy. Allowing for differences in age between adult Travellers and the general adult population, AITHS (2010) reports Traveller mortality as being 3.5 times higher than non-Travellers overall, 3.7 times higher for men and 3.1 times higher for women. Controlling for age, the mortality rate of Traveller women fell at almost the same rate as the general population over the 20 years between 1987 and 2008, while the rate for Traveller men has remained almost the same although it fell in the general male population. Infant mortality is 3.6 times higher than that of the general population.

Life expectancy has not increased for male Travellers over the same 20year period and remains similar to the life expectancy of the general population in 1945. Female Travellers can expect to live an average of 4.8 years longer than they did in 1987 . Over the same period, the life expectancy for the general female population increased by 4.4 years (AITHS, 2010).

Health services have a role to play in dealing with the higher level of health problems among Travellers. Findings from the AITHS (2010) show that Travellers' access to health services was at least as good as that of the general population, although the service provider survey that was part of the AITHS found that Travellers are less likely to attend outpatient appointments or engage with preventive services. Furthermore, evidence from the qualitative survey suggests that the quality of consultations experienced by Travellers (who reported feeling less understood and not always fairly treated) may be more concerning than access issues.

\subsubsection{Travellers in Prison}

The Irish Penal Reform Trust Report notes that it is important to have an ethnic identifier, thus far absent in the Irish prison system, so that the situation of vulnerable ethnic groups can be monitored (Costello, 2014). A qualitative study by Bracken (2014) found that probation officers recognised the importance of ethnic identification when presenting judges with a complete picture of the offender, but were concerned with the potential for discrimination that this may bring. Certain risk assessment instruments may also have an in-built bias against Travellers, such as having frequent changes of address, along with early school leaving and lack of a work history. 
In 2008, the Irish Prison Service (IPS) carried out a census of Travellers within the IPS as part of the AITHS. It estimated a Traveller population of $320 .{ }^{11}$ This was made up of 299 male prisoners and 21 female prisoners. In total this represents 8.7 per cent of the Irish prison population, despite, as noted above, Travellers representing less than 1 per cent of the total population. According to AITHS findings (2010), based on estimates from the IPS, the risk of male Travellers being imprisoned is 11 times that of the general male population. Traveller women are 22 times more likely than non-Traveller women to be imprisoned.

\subsection{POLICY ON TRAVELLERS IN IRELAND}

The analysis reported above has shown that Travellers are a group that has experienced uniquely high levels of disadvantage in Irish society. Policy has sought to address this in a number of ways. The Irish state's first formal assessment of the position of Travellers was in the 1963 Report of the Commission on Itinerancy. This initial policy document sought to find a 'permanent solution' to the 'problem of itinerancy' through principles of absorption and assimilation. Subsequent reviews of the government policy shifted the emphasis first to integration (in 1983) and then to an intercultural approach with Traveller representation (in 1995). The Task Force on the Traveller Community reported in 1995 with an overview of the difficulties facing Travellers and a set of recommendations for policy. A monitoring committee was established in 1998, which produced two reports (in 2000 and 2005) on the implementation of the recommendations of the Task Force on the Travelling Community. The committee noted the difficulty in monitoring progress in the absence of good quality data on the number of Travellers availing of services in areas such as education, health and employment.

The current National Traveller/Roma Integration Strategy (Department of Justice and Equality, 2011) was developed under the EU Framework for the Implementation of National Roma Integration Strategies up to 2020. This document sets out the most recent policies on issues of education, employment, housing, health, anti-discrimination and social inclusion in relation to Irish Travellers. It reiterates the commitment made by the programme for government (2011-2016) to:

promote greater co-ordination and integration of delivery of services to the Traveller community across Government, using

\footnotetext{
${ }^{11}$ All Irish prisons responded, but three large all-male prisons could not identify the Traveller population so final estimates were scaled up to account for this. The Traveller population in prisons was based on Travellers' self identifying by means such as asking to be accommodated near other members of the Traveller community.
} 
available resources more effectively to deliver on principles of social inclusion, particularly in the area of Traveller education. (Department of Taoiseach, 2011, p. 52)

However, the implementation of the strategy was criticised in 2013 by the European Commission, as only four out of 22 effective implementation criteria established by the Commission were met in Ireland (European Commission, 2013). Pavee Point National Traveller and Roma Centre was also critical of the non-participative process through which this national strategy was developed (Pavee Point, 2014a).

Another report by European Commission (2014) pointed to the need to assess the impact of mainstream measures on Roma and Traveller communities and for policy actions in each area to be better coordinated and integrated with policy in other areas. For instance, mainstream legislation and policy, such as the Casual Trading Act, 1995, and the Control of Horses Act, 1996, have had a disproportionate effect on Travellers, reducing opportunities for them to engage in traditional occupations (AITHS, 2010).

A new strategy is currently being developed. This is being coordinated by the Department of Justice and Equality in consultation with a national steering group with input from various Traveller and Roma organisations.

\subsubsection{Traveller Education Policy}

The National Traveller and Roma Integration Strategy (DoJE, 2011) notes the historic practice of educating Traveller children and children with special needs in segregated settings. It reiterates the commitment in The Report and Recommendations for a Traveller Education Strategy (2006) for future actions and allocation of resources to be underpinned by a principle of 'individual educational need' rather than 'Traveller identity' (DoJE, 2011, p.7). Schools with a high concentration of Traveller pupils will however, be provided with 'limited alleviation or adjustment measures', including the allocation of additional staffing under the DEIS programme (ibid, p.8).

This shift in terminology reflects a recognition that, in previous policy and practice, 'Traveller identity' was effectively equated with educational need. However, removal of the term in current policy has the effect of lessening the recognition of Traveller ethnicity in mainstream provision.

The majority of educational supports that had been in place for Travellers were withdrawn following the austerity budget of 2011. The DES argued that this reflected a move to mainstreaming on foot of the 2006 report, 
Report and Recommendations for a Traveller Education Strategy. Harvey (2013) calculated a total cut of $86.6 \%$ to Traveller-specific education supports over successive budgets, which resulted in the withdrawal of Visiting Teachers Service for Travellers and resource teachers for Travellers. In a review of the School Completion Programme in Ireland, Smyth et al. (2015a) conclude that the removal of these services is seen by stakeholders as having a negative impact on the school retention of these pupils.

Senior Traveller Training Centres (STTCS) had provided access to training and support in making a transition to work for Travellers aged 15 years and over. However, in July 2012 all STTCs were closed. This is seen as a negative development, in terms of the loss of a valuable resource for Traveller education and training (KW Research and Associates, 2014), but also as a positive one, in terms of removing a segregated system (Harmon, 2015; DES, 2005). However, Harmon (2015) argues that the supports necessary to ensure that mainstreaming would not disadvantage Travellers were not put in place. As noted above, Travellers are overrepresented in DEIS schools and would receive the additional supports provided in these schools. However, only about one half of Traveller students are in DEIS schools (Harmon, 2015), so not all Travellers benefit from the additional supports available in them. ${ }^{12}$

\subsubsection{Traveller Employment Policy}

Policy has also sought to address the low employment rate among Travellers. The Travellers Initiative, a special initiative for the employment of Travellers, was implemented by FÁS in 2005, providing more than 50 full-time jobs and over 150 training positions (DoJE, 2011). However, this initiative, which also provided Traveller support workers to assist in funding employment and in enterprise development, was mainstreamed in 2011 (Harvey, 2013). Recent government employment strategies - Action Plan for Jobs, Pathways to Work and Strategy for Growth - outline no measures that specifically and directly target Travellers as a group; however, there is currently a focus on addressing long-term unemployment and supporting the active inclusion of the most disadvantaged people in the job market.

The European Commission, in response to the National Traveller/Roma Integration Strategy (Department of Justice and Equality, 2011), noted

12 Harmon (2015, p. 17), citing figures from the Social Inclusion Unit in the Department of Education and Skills, October 2012. 
the lack of concrete goals and insufficient budget relating to reducing gaps in education and employment (European Commission, 2012).

\subsubsection{Traveller Housing Policy}

The Housing (Traveller Accommodation) Act 1998 requires that each local authority prepare, adopt and implement a five-year rolling accommodation programme to meet the existing and projected accommodation needs of Travellers in their areas. However, between 2008 and 2013, Harvey (2013) reports that the Traveller accommodation budget was cut by 90 per cent, from $€ 40$ million to $€ 4$ million. Furthermore, using government figures, he shows there was a 36 per cent underspend of the allocated Traveller accommodation budgets by local authorities over the same period. This is reflected in the figures in Table 1.1, above, showing a decline between 2007 and 2014 in the provision of Traveller accommodation by, or with the assistance of, local authorities.

Another aspect of the delegation of responsibility to local authorities is the uneven implementation of national policy. Pavee Point argues that there remains a 'gap between agreed policy at national level and the implementation of this policy by the local authorities.' (Pavee Point, 2016b, p. 1). The European Committee of Social Rights (ECSR) notes that even if local authorities are responsible for implementing particular functions under domestic law, the state remains responsible for ensuring these obligations are met (ECSR, 2015, para. 78).

The cuts in provision, together with the national homelessness crisis, Pavee Point argues, has forced Traveller families to relocate to accommodation that may be unsafe and overcrowded. This is seen in an increase in the use of private rented accommodation by Travellers, shown in Table 1.1 above. An example of unsafe conditions is the tragic fire in which ten Travellers died in October 2015 in Carrickmines, a halting site that was intended to be temporary but was occupied for eight years (Pavee Point, 2016b). Pavee Point note that a subsequent national fire safety audit carried out on Traveller accommodation in all local authority areas led to evictions of Travellers from accommodation deemed unsafe, without adequate alternative accommodation being provided.

A decision by the ECSR found that the Irish government was deemed to have violated the right to social, legal and economic protection of Travellers under Article 16 of the Revised European Social Charter. Specifically, this case referred to a shortfall in sufficient accommodations for Travellers, inadequate conditions in existing Traveller accommodation, and the legislative framework and practice of evictions. In its report, the committee states that Article 16 required an adequate 
supply of housing of suitable size, given the composition of the family in question and including the provision of essential services such as heating and electricity (ECSR, 2016, para. 56, 88).

\subsubsection{Traveller Health Policy}

Since the National Traveller Health Strategy 2002-2005 and the National Intercultural Health Strategy 2007-2012, there has been no specific strategy to address Traveller health inequalities. The health pillar of the National Traveller and Roma Integration Strategy (2011) described the current infrastructure but brought no new proposals. The latter has been criticised for not involving Travellers in its development, being fragmented in its approach and lacking co-ordination with other state polices, with no funding linked to actions and no provision for monitoring of targets (Pavee Point, 2014b; European Commission, 2012 and 2014). The Department of Health's National Traveller Health Advisory Committee has not met since 2012. The HSE National Traveller Health Advisory Forum, established in 2007, continues to work with Traveller health units and Traveller organisations to promote Traveller health.

As noted above, the findings from the AITHS (2010) show that Travellers' access to health services in 2008 was at least as good as that of the general population. Ireland's positive action on promoting Travellerspecific health services was recognised by the European Commission in response to the National Traveller/Roma Integration Strategy (Department of Justice and Equality, 2011; European Commission, 2012). This suggests that some national and local health promotion actions have been successful. Nevertheless, the AITHS notes that concerns remain about the quality of the consultation experience, attendance at outpatient appointments and involvement with preventive services. In addition, the cuts in provision of healthcare services during the recession are likely to have had a particularly negative impact on disadvantaged and marginalised groups such as Travellers (IHREC, 2015).

While Ireland's positive action on promoting Traveller-specific health services was recognised by the European Commission, in response to the National Traveller/Roma Integration Strategy (Department of Justice and Equality, 2011), the Commission also highlighted a lack of concrete goals and insufficient budget relating to reducing gaps in education and employment (European Commission, 2012).

\subsubsection{Recognition}

As we saw in the last section, Travellers have experienced very high levels of discrimination. The Joint Oireachtas Committee on Justice, Equality 
and Defence (2014) has recommended full recognition of Irish Travellers as an ethnic group. At present, Travellers are specifically named and protected from discrimination under the Employment Equality Act (1998), which prohibits discrimination in the workplace and in vocational training, and the Equal Status Act (2000), which covers discrimination in the provision of goods and services, accommodation and educational establishments. They are not, however, automatically included in intercultural and anti-racism initiatives and policies.

\subsection{RESEARCH QUESTIONS IN THIS REPORT}

It is clear that Travellers are a group disadvantaged in several respects: in terms of educational attainment, employment, housing and health. They have an unusual age distribution, with a relatively large number of children and a smaller number of older adults. They have experienced exceptionally high levels of discrimination compared to other groups in Ireland. The goal of this report is to consider outcomes in the areas of education, employment, housing and health in order to draw out the interrelationships between them and ask whether these relationships differ for Travellers compared to the general population. Rather than treating Travellers as a homogenous group, the study explores whether specific groups of Travellers (in terms of gender, age and region) experience particularly high levels of disadvantage. As well as providing descriptive information on each topic, drawing mainly on the census data from 2006 and 2011, we construct statistical models in order to address the following research questions in this report.

1. Education - How does the educational attainment of Travellers differ by gender, age group and region? Are these patterns the same as for the general population?

2. Employment - What are the factors associated with non-employment for Travellers? How does gender and family situation, age, level of education and region affect this? Do these factors differ when compared to the nonTraveller population? Do low levels of education account for all or most of the employment differences between Travellers and non-Travellers?

3. Housing - The amenities and facilities available to Travellers differ by whether they live in temporary or permanent dwelling units. Which Travellers are more likely to live in caravans or mobile homes? Does this vary by age group, presence of children, level of education or employment?

4. Health - All the evidence points to poorer health among Travellers than among non-Travellers. Are there also differences between Travellers and 
non-Travellers in the influence of factors such as age and education on self-rated health? Are there any regional differences between Travellers in their self-rated health?

The analysis allows us to understand the experience of Travellers in terms of cumulative disadvantage. Cumulative disadvantage can be understood in terms of processes that operate over time, with earlier disadvantage persisting or even interacting with later events to exacerbate disadvantage (for example, see Elder, 1985 and 1994; Nolan and Whelan, 1999; Layte and Whelan, 2002; and Vandecasteele, 2011). Although we cannot look at the situation of the same people over time, by examining several outcomes, we are able to address this question to some extent. We are able to ask whether risks cumulate across education, employment, housing and health. In other words, are less favourable labour market outcomes accounted for by earlier differences in education? Do Travellers face further barriers to participation in the labour market, in access to housing and in the broader societal determinants of poor health as well? We are also able to examine patterns by age group to ask whether the health gap between Travellers and non-Travellers increases with age or remains about the same at different stages of life.

\subsection{DATA AND METHODS}

\subsubsection{The Census}

The census is a statutory survey and under Section 26 of the Statistics Act, 1993, participation is compulsory (CSO, 2009). Census 2011 was taken on the night of Sunday, 10 April 2011.

The census figures relate to the de facto population, that is, the population present in each area on census night as well as those present on the following morning who had not been enumerated elsewhere. The total figures include visitors as well as usual residents, while usual residents who are temporarily absent are excluded. The date of the census is chosen because it is a period where travel is at a minimum, so that the de facto population is as close as possible to the normally resident population.

The census covers the population in private households and in nonprivate households (also called communal establishments) such as hospitals, nursing homes and hotels. ${ }^{13}$ We focus here on private

${ }^{13}$ See CSO Definitions for more information, at http://www.cso.ie/en/media/csoie/census/documents/vol13 appendix.pdf. 
households. This includes Traveller families living in caravans on halting sites or on the roadside who have been enumerated in the census.

This report draws on special analysis of micro-data from Census 2011 to examine the situation and living circumstances of Travellers compared to non-Travellers in the Irish population. It should be noted that the format of the question used to identify Travellers was different in 2006 and 2011 to the question used in 2002 (see Table 1.2).

The CSO points out that the change in this question format may have affected comparability of results between 2002 and 2006, resulting in an undercount of the Traveller population of about 10 per cent in 2006, based on known fertility and mortality rates among Travellers (CSO, 2007a). The count increased again (by about 32 per cent) between 2006 and 2011, due to the activities of Traveller organisations in encouraging people to self-identify as Travellers. Because of the likely under-coverage in 2006, this report focuses on Census 2011.

Table 1.2 Wording of Question to Identify Travellers in Census Years 2002, 2006 and 2011

\begin{tabular}{|c|c|c|}
\hline & \multicolumn{2}{|r|}{ Census Year } \\
\hline & 2002 & 2006 and 2011 \\
\hline $\begin{array}{l}\text { Question } \\
\text { Format }\end{array}$ & $\begin{array}{l}\text { Are you a member of the Irish } \\
\text { Traveller Community? } \\
\text { Response categories: Yes or } \\
\text { no }\end{array}$ & $\begin{array}{l}\text { What is your ethnic or cultural background? } \\
\text { Response Categories: } \\
\text { A White } \\
1 \text { Irish } \\
2 \text { Irish Traveller } \\
3 \text { Any other white background } \\
\text { B Black or Black Irish } \\
4 \text { African } \\
5 \text { Any other black background } \\
\text { C Asian or Asian Irish } \\
6 \text { Chinese } \\
7 \text { Any other Asian background } \\
\text { D Other }\end{array}$ \\
\hline
\end{tabular}

Source: Census, 2002, 2006 and 2011.

\subsubsection{The All Ireland Traveller Health Study (AITHS) (2008)}

The AITHS was a study of Traveller health status and health needs that involved all Travellers living on the island of Ireland - both Northern Ireland (NI) and the Republic of Ireland (ROI). It was commissioned by the Department of Health and Children (ROI) and the Department of Health, Social Services and Public Safety (NI). Given the high participation rate and wide ranging scope of the AITHS study, we also draw on the results from the AITHS in this report, particularly in the area of health. 
The AITHS aimed to count the number of Travellers living on the island of Ireland and to gather socio-demographic information on them, including living conditions and health. In this report, we focus on respondents in Ireland. Alongside this, five sub-study interviews were completed, three of which were child interviews for children aged 5 years, 9 years or 14 years old. If there were no children in a household of these exact ages, then another adult was chosen at random to complete either a 'health status survey' $(n=1,648)$ or a 'health utilisation experience survey' ( $n=$ 1,968). The data were collected in 2008 following a two-year scoping exercise involving Pavee Point National Traveller and Roma Centre and other Traveller organisations and groups. Travellers themselves were involved as peer researchers and a specially designed oral-visual electronic survey instrument was used to administer the questionnaire. These factors ensured a high participation rate of 78 per cent of Traveller families.

Some background analysis showed that the age profile of Travellers described in the AITHS study was very similar to that found in the 2011 CSO census data (see Appendix Figures A1.1-A1.5). There were some differences in the recorded level of education, work status and housing between the two sources. This may partly reflect changes over the 20082011 period, differences in question wording and differences in coverage. The AITHS records a higher proportion of adults as having further or higher education, a higher percentage unemployed as opposed to looking after the home and family or engaged in home duties, and higher percentages living in a caravan or mobile home and renting rather than owning or purchasing. Because of the differences in design, it is not possible to draw any firm conclusions as to the reasons for the differences but the figures are provided in the appendix for information.

\subsubsection{Outcome Measures}

The choice of outcome measures was limited, to some extent, by the data available from the census. We wanted to select a small number of key outcomes that would allow us to examine whether disadvantage cumulates across different domains (for example, from education to the labour market) and that would work well in highlighting important differences between Travellers and non-Travellers in Ireland. Table 1.3 describes the measurement of the main indicators used in the analysis. The outcomes we examine are as follows.

1. Low education. This refers to completion of less than full second level education (the Leaving Certificate or equivalent). The analysis is based on the population aged $25-64$ years. 
2. Non-employment (working-age population). This outcome was chosen because it includes those who describe themselves as 'unemployed' and those who are outside of work for other reasons, such as being discouraged from searching for work, being ill or disabled or having caring responsibilities. Although some people may choose to be outside the labour market, particularly those who retire early or parents (usually mothers) who remain at home to care for their children, these choices will always be made in the context of constraints. Labour market participation is a key element in social inclusion (Berkel and Møller, 2002). Women's labour market participation is lower than that of men, as they remain most likely to take time off paid work to care for their children (Treas and Drobnič, 2010) and other family members (Bolin, Lindgren and Lundborg, 2008). However, women who do combine work and family tend to have higher levels of life satisfaction (Kotowska et al., 2010) and improved mental health (Barnett, 2004). In the models for labour employment, students are excluded from the analysis and, again, we focus on adults aged 25 to 64 years.

3. Housing. The main outcome in this section is living in housing that is temporary (such as a caravan or mobile home) or overcrowded (more than one person per room).

4. Poor health. In the chapter on health we draw on Census 2011 and examine those identified by the person completing the census form as having health that is fair, bad or very bad. This analysis is based on the population of all ages. We also use data from the AITHS carried out in 2008 and compare this with published results on the general population from the 2007 Survey of Lifestyle Attitudes and Nutrition (SLÁN) for a more detailed picture of the nature of poor health and an overview of usage of health services. 
Table 1.3 Main Indicators Used in the Analysis

\begin{tabular}{|c|c|}
\hline Measure & Note \\
\hline Traveller & Whether or not the person is an Irish Traveller. \\
\hline Level of education & $\begin{array}{l}\text { Highest level completed: primary or less; lower second level (e.g. Junior } \\
\text { Certificate); upper second Level (e.g. Leaving Certificate); non-degree } \\
\text { (certificate); degree or higher (ordinary Bachelor's degree or higher). }\end{array}$ \\
\hline Low education & $\begin{array}{l}\text { Aged } 25-64 \text { years and completed less than full second level education (Leaving } \\
\text { Certificate or equivalent). }\end{array}$ \\
\hline Economic status & $\begin{array}{l}\text { Main status: in employment; unemployed; other inactive in labour market } \\
\text { (including student, home duties, unable to work due to illness/disability, } \\
\text { retired). }\end{array}$ \\
\hline $\begin{array}{l}\text { Employment /non- } \\
\text { employment }\end{array}$ & $\begin{array}{l}\text { Aged } 25-64 \text { and in employment versus all other statuses. Non-employment } \\
\text { refers to those not in employment - including the unemployed but also those } \\
\text { outside the labour market. }\end{array}$ \\
\hline Unemployment & Aged $25-64$, in labour market (either unemployed or at work) and unemployed. \\
\hline $\begin{array}{l}\text { Caravan/mobile } \\
\text { home }\end{array}$ & Dwelling type = caravan or mobile home. \\
\hline $\begin{array}{l}\text { Overcrowded } \\
\text { housing }\end{array}$ & More than one person per room (counting living rooms and bedrooms). \\
\hline Health & $\begin{array}{l}\text { Health status as reported by person completing the census form: Very good, } \\
\text { good, fair, bad or very bad. }\end{array}$ \\
\hline Poor health & Health status reported as fair, bad or very bad. \\
\hline Disability & $\begin{array}{l}\text { Person reported to have a long-standing condition or disability: blindness; } \\
\text { deafness; mobility limitation; intellectual disability; learning disability; } \\
\text { psychological/emotional disability; other disability or difficulty with activities } \\
\text { such as dressing, bathing, going outside, attending school/work or another } \\
\text { difficulty. }\end{array}$ \\
\hline Gender & Whether the person is male or female. \\
\hline Age & Five-year age groups. \\
\hline Region & $\begin{array}{l}\text { Eight regional authority areas (Border, Midlands, West, Dublin, Mid-East, Mid- } \\
\text { West, South-East, South-West). }\end{array}$ \\
\hline
\end{tabular}

Source: Census 2011.

Table 1.3 also shows the main control variables used in the analysis. In the analysis of educational attainment, we consider the impact of being a Traveller, age group, gender and region. In the analysis of work, housing and health we include education as an explanatory variable. Whether the person is at work is included in the analysis of housing and health patterns.

\subsubsection{Analysis Methodology and Statistical Tests}

Typically, in research reports, readers may be accustomed to seeing tests of significance and confidence intervals presented with the results. These statistical tests are appropriate when the analysis is based on a probability sample and inferences are being made about the total population. The tests show how confident we can be of the sample results, given that a different random sample may yield a slightly different statistic (such as a mean, proportion or regression coefficient). In the 
present report, however, we mainly analyse census data based on the full population, so these types of significance test are not appropriate as we are not generalising from a random sample to the population. Of course, there may be other problems with the census data, such as incomplete coverage or non-response, but these are not the kind of issues that can be addressed by statistical tests and confidence intervals.

We do use data from probability sample surveys in chapter five, when reporting on health: the SLÁN 2007 survey for the general population $(n=10,364)$ and the randomly selected adults from the AITHS $(n=1,648$ for the health status survey and $n=1,968$ for the health services utilisation survey). ${ }^{14}$ Where we draw on these surveys for tables or figures, we provide an indication in the table note of the statistical significance and/or the margins of error for the reported figures.

\subsubsection{Overall and Adjusted Risks}

In this report we present the overall and adjusted risks of the five unfavourable outcomes for different groups. The overall figures are the overall differences between Travellers and the non-Traveller population. The 'adjusted' figures show the differences that remain when we have controlled for other characteristics (age, gender and so on). This calculation is based on the results of statistical models that are shown in the appendix. In a sense, the adjusted differences are an attempt to get at the 'pure' effects of being a Traveller. For instance, we know that Travellers tend to be younger than the general population and that younger people are less likely to have a disability than older people. The adjusted figures allow us to ask how much difference in the disability rate we would find between Travellers and non-Travellers if they had a similar age distribution and were similar in terms of the other characteristics (such as gender and region). The other factors that we take into account are described in each case before we present the adjusted figures. The adjusted risks are calculated using the 'margins' command in Stata (see Williams, 2012, for technical details).

The reader may be familiar with analyses where the researcher chooses between competing models, based on what is called the fit of the model. This would be appropriate in cases where the outcome (such as poor health) was the primary focus of the analysis. For instance, we might be concerned with accounting for poor health in order to develop health promotion or treatment policies. If that were so, the analysis would be guided by choosing the statistical model that best accounted for the patterns in the data (referred to as model fit). In the present case,

\footnotetext{
${ }^{14}$ The sample size for specific questions may be lower than this due to filtering or non-response.
} 
however, our main focus is on the gap in a range of outcomes between Travellers and non-Travellers. As such, we are not mainly interested in explaining all inequalities in education, employment, housing or health. Our focus, therefore, is not on overall model fit but on the coefficients that give an indication of the magnitude of this gap - the main effect for 'Traveller' and, in certain models, the interaction effect between 'Traveller' and other variables.

\subsection{DEMOGRAPHIC PROFILE OF TRAVELLERS IN IRELAND}

We know that because of differences in health, mortality and fertility rates, the age profile of Travellers differs from that of the population generally. This is shown in Figure 1.2, where we compare the age distribution of Travellers and non-Travellers in 2011.

The difference is dramatic, with Travellers concentrated in the younger age groups. Only 2 per cent of Travellers are over the age of 65 compared to 12 per cent of non-Travellers. By contrast, 41 per cent of Travellers are under age 15 compared to 22 per cent of non-Travellers. Compared to the non-Traveller population, there is a greater concentration of Travellers in each five-year age group up to age 30.

Figure 1.2 Age Profile of Traveller and Other Population by Age, 2011

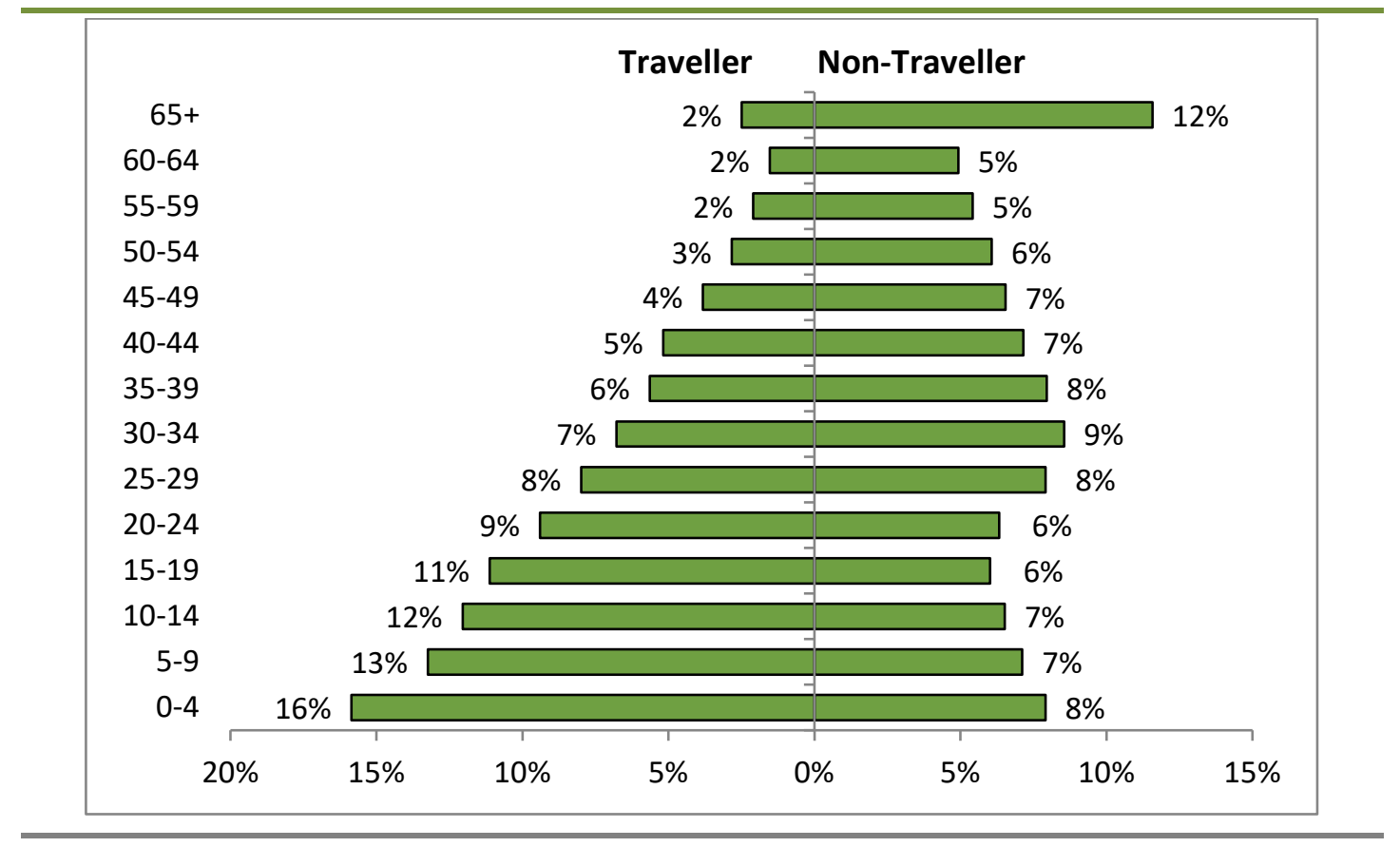

Census of population micro-data files for 2011, analysis by authors. Percentages are rounded.

Figure 1.3 shows the marital status by age group for Traveller and nonTraveller adults aged 15 years and over in 2011. This chart shows both the higher rate of marriage among Travellers and the younger marriage age. In the 15 to 24 age group, 24 per cent of Travellers have married 
compared to less than 2 per cent of non-Travellers. The figures for those aged 25-34 years are 59 per cent (with an additional 9 per cent formerly married) among Travellers and 32 per cent ( 2 per cent formerly married) among the other population.

Figure 1.3 Marital Status by Age Group for Travellers and Non-Travellers, 2011

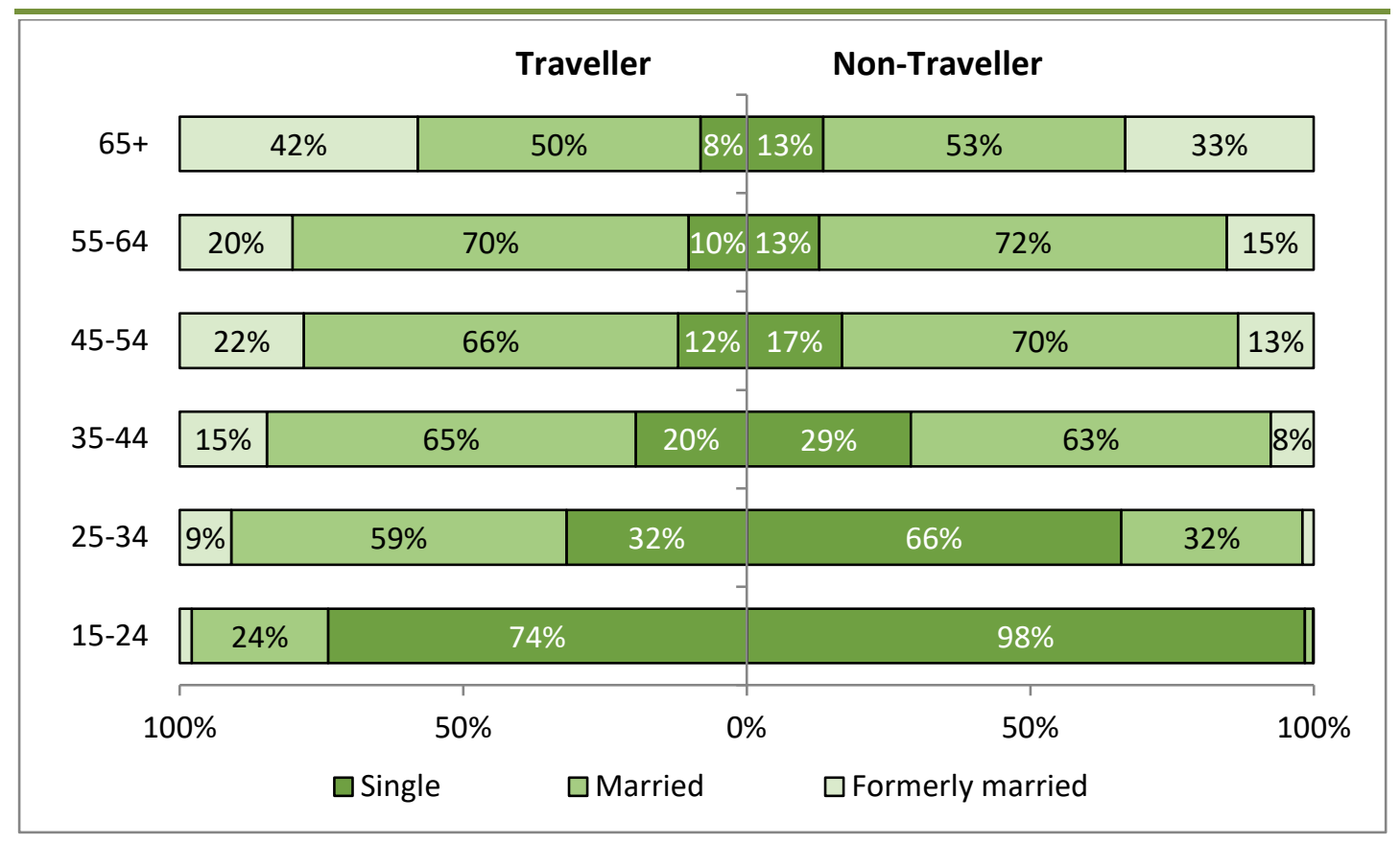

Source: Census of population micro-data files for 2011; population aged 15 and over, analysis by authors.

At each age, more of the non-Traveller population are single (never married), with figures of 17 per cent for those aged 45 to 54,13 per cent aged 55 to 64 and 14 per cent aged 65 and over, compared to figures of 12 per cent, 10 per cent and 8 per cent, respectively, among Travellers.

Another big difference between Travellers and the general population is the larger family size. Figure 1.4 shows the number of children ever born to women aged 45-64 years in 2011. Note that this is not the average family size at a point in time, but the fertility rate of women. Just over half of Traveller women in this age group had over six children, compared to only 3 per cent of non-Traveller women. The percentage of Traveller women who had five and four children is also higher than the corresponding figures for other women. The largest category for other women is two children ( 29 per cent), but only 5 per cent of Traveller women had two children. The percentages of women with no children are also different: 17 per cent of other women aged $45-64$ years had no children, compared to just 9 per cent of Traveller women. 
Figure 1.4 Number of Children Ever Born to Traveller and Non-Traveller Women, 45-64 Years, 2011

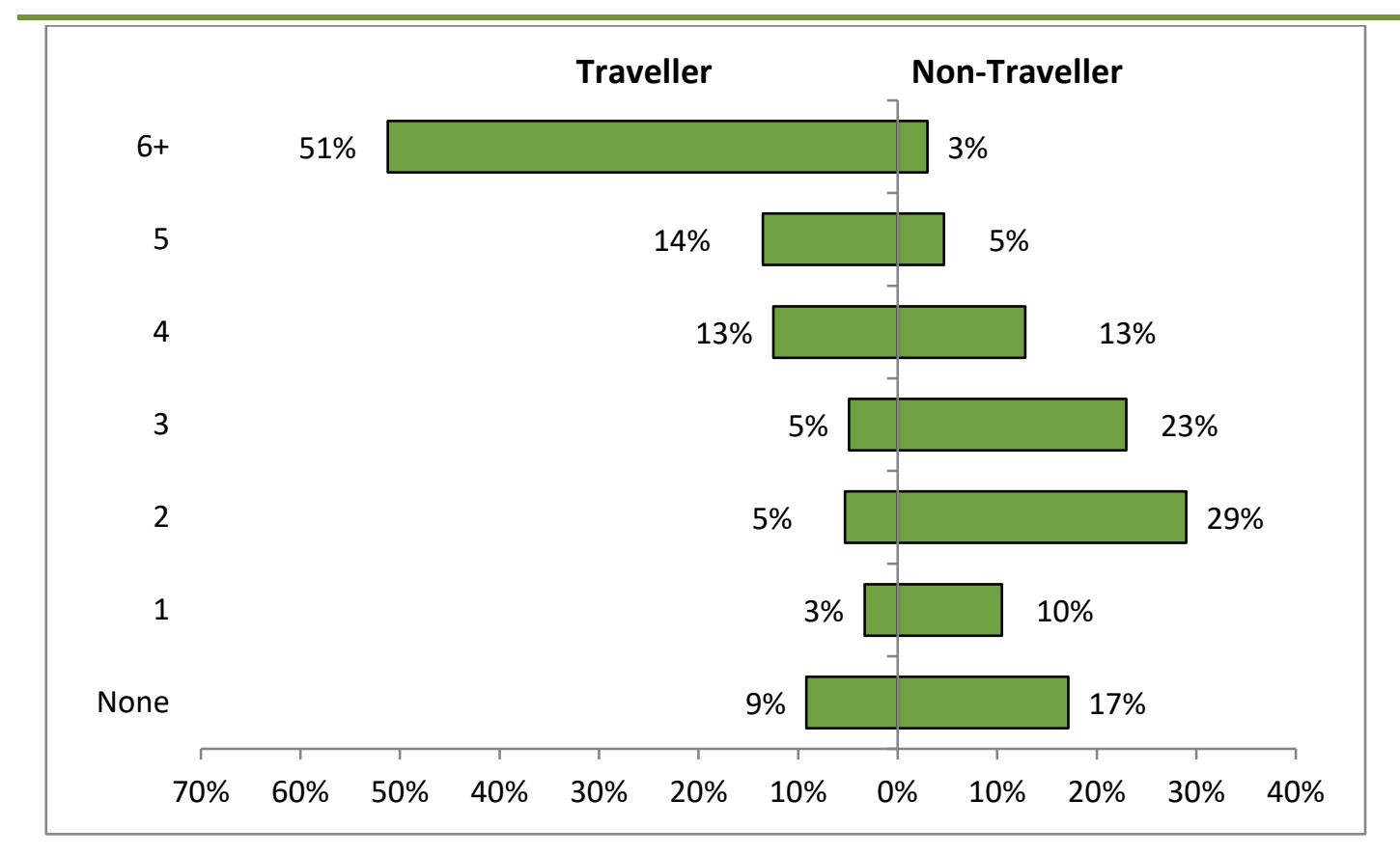

Source: Census of population micro-data files for 2011; female population aged 45-64 years, analysis by authors.

As we might expect from the figures on marriage and fertility, Traveller households tend to be larger. This can be seen in Figure 1.5, which shows the distribution of household size for Travellers and non-Travellers in 2011. Note that these figures show the percentage of individual Travellers and non-Travellers in households of different sizes and not the percentage of households of different sizes. The distribution would be different at the household level because each household would be counted only once. When we report the results at the individual level, a household containing five persons, for instance, is 'counted' five times, once for each of the persons. The figures pertain to private households only, so we are excluding communal establishments such as hospitals, nursing homes and hotels.

Nineteen per cent of Travellers live in a household with eight or more people, compared to only 1 per cent of non-Travellers. For all sizes from five to eight or more persons, the percentage of Travellers is higher while for sizes from one to four persons, the percentage of non-Travellers is higher. Almost two-thirds (63 per cent) of Travellers live in a household with five or more persons. The corresponding figure for non-Travellers is 25 per cent. At the other end of the scale, very few Travellers live alone (3 per cent, compared to 9 per cent of the non-Traveller population). 
Figure 1.5 Percentage of Travellers and Non-Travellers in Households of Different Size, 2011

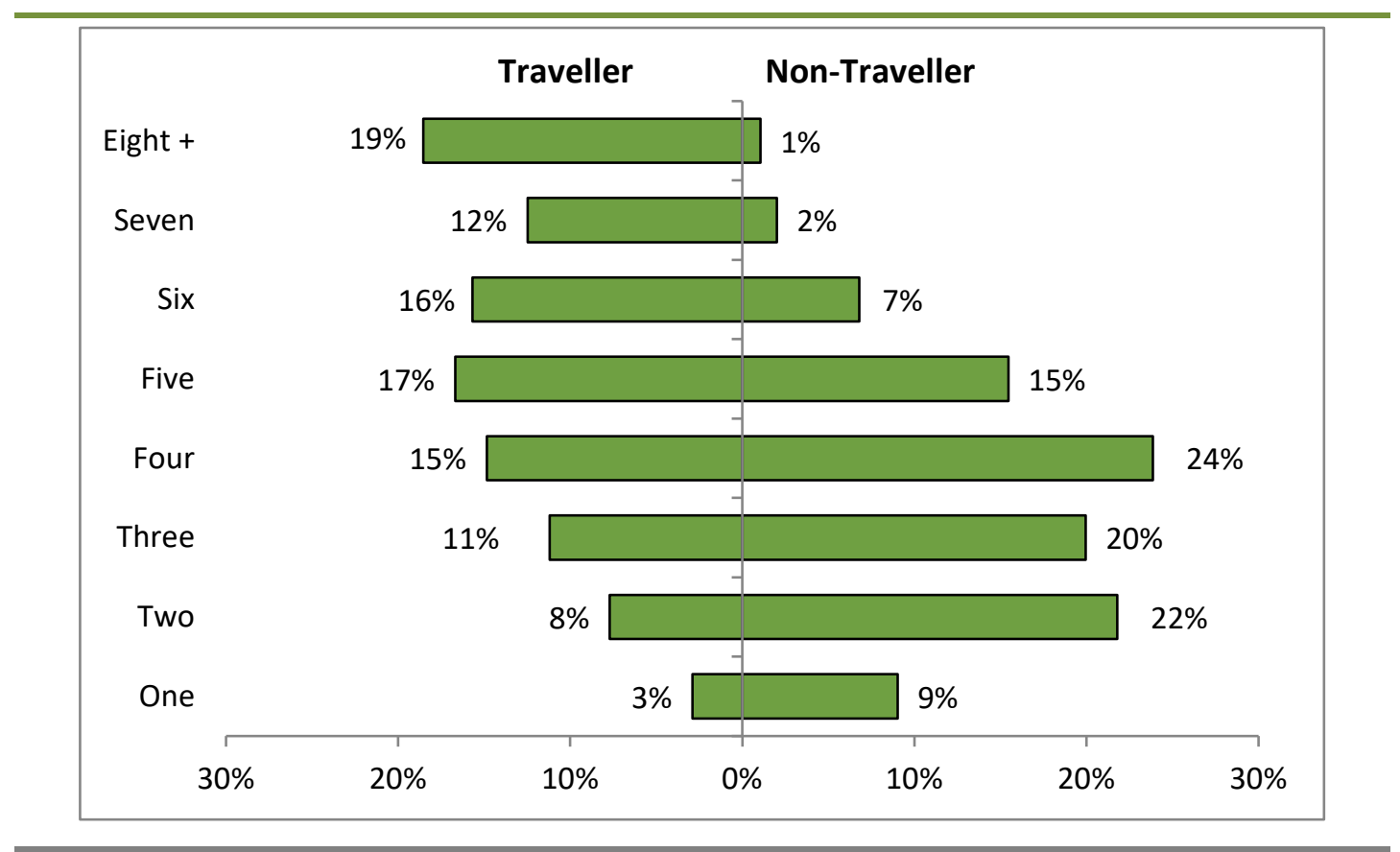

Source: Census of population micro-data files for 2011, analysis by authors.

\subsection{OUTLINE OF REPORT}

The next chapter examines the level of education of Travellers and nonTravellers and ask how the percentages completing lower levels of education would look if both groups had the same age distribution. Chapter three focuses on the labour market and work situation, examining how Travellers compare with the general population in terms of employment and unemployment. In chapter four, we turn to the accommodation situation of Travellers, with a particular emphasis on understanding differences in terms of access to permanent dwelling structures and accommodation that is large enough for the family's needs. Chapter five examines the health and disability status of Travellers and non-Travellers. Chapter six draws together the findings of the report, summarises the key points and suggests some implications for policy. 


\section{Chapter 2}

\section{Education}

\subsection{INTRODUCTION}

This chapter examines the educational attainment of Travellers and nonTravellers in Ireland. For this purpose, we focus on the population aged 25 and over, as the majority of those over 25 years will have completed their schooling. We begin the chapter with some descriptive results and then move on to the results of a statistical model that takes account of important differences between Travellers and non-Travellers in their age distribution. Since the typical levels of education have risen over time, younger adults will tend to have completed higher levels than older adults. We saw in the previous chapter that there are large differences in age between Travellers and non-Travellers, so it is important to statistically control for age differences when comparing the educational attainment of Travellers and non-Travellers.

\subsection{EDUCATION OF TRAVELLERS AND NON-TRAVELLERS}

\subsubsection{Age Education Ceased}

Figure 2.1 shows the age at which education ceased for Travellers and non-Travellers who are over 25 years according to Census 2011. There is a dramatic difference between the two groups regarding early school leaving, with 91 per cent of Travellers leaving school at age 16 or younger, compared to 25 per cent of non-Travellers. In fact, 28 per cent of Travellers leave before age 13, compared to 1 per cent of non-Travellers.

Figure 2.1 Age Education Ceased Among Those Aged 25 and Over, 2011

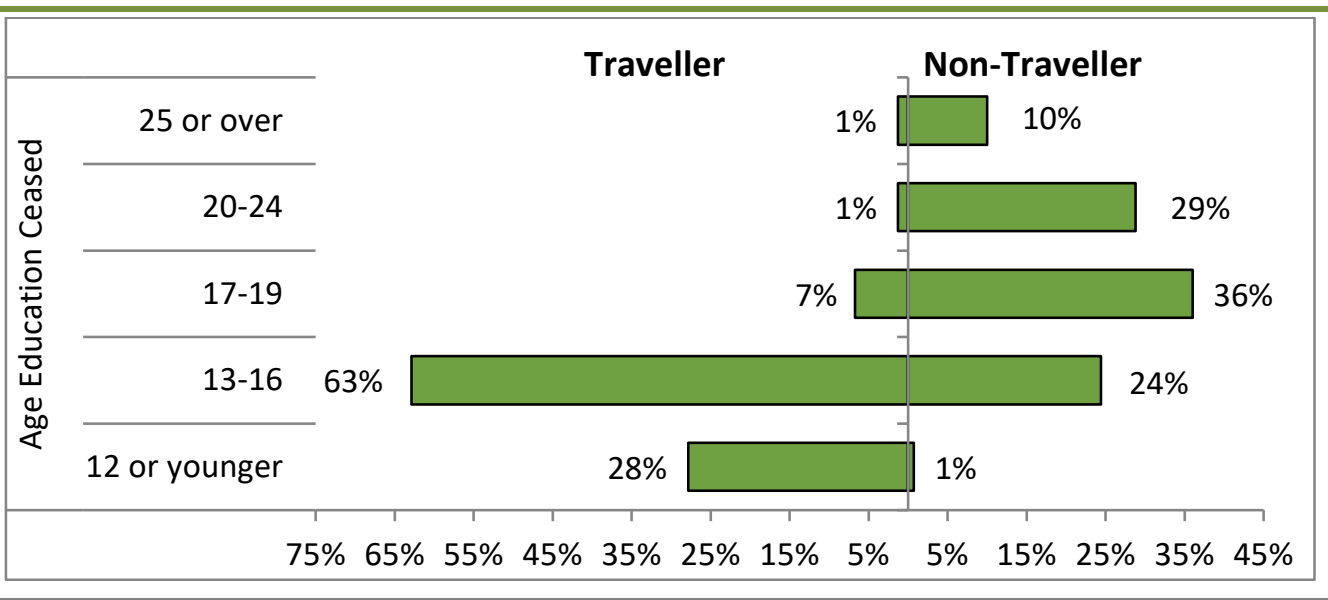

Source: Census of population micro-data for 2011; persons aged 25 and over in private households, analysis by authors. 
As we might expect, the differences between Travellers and nonTravellers in the age of leaving school is reflected in differences in educational attainment. Figure 2.2 shows the highest level of education achieved in 2011 by Travellers and non-Travellers. This time we focus on those of working age, again starting at age 25 , when most people have completed their education, and extending the range to age 64 .

Figure 2.2 Highest Level of Education Achieved, 25-64 Years, 2011

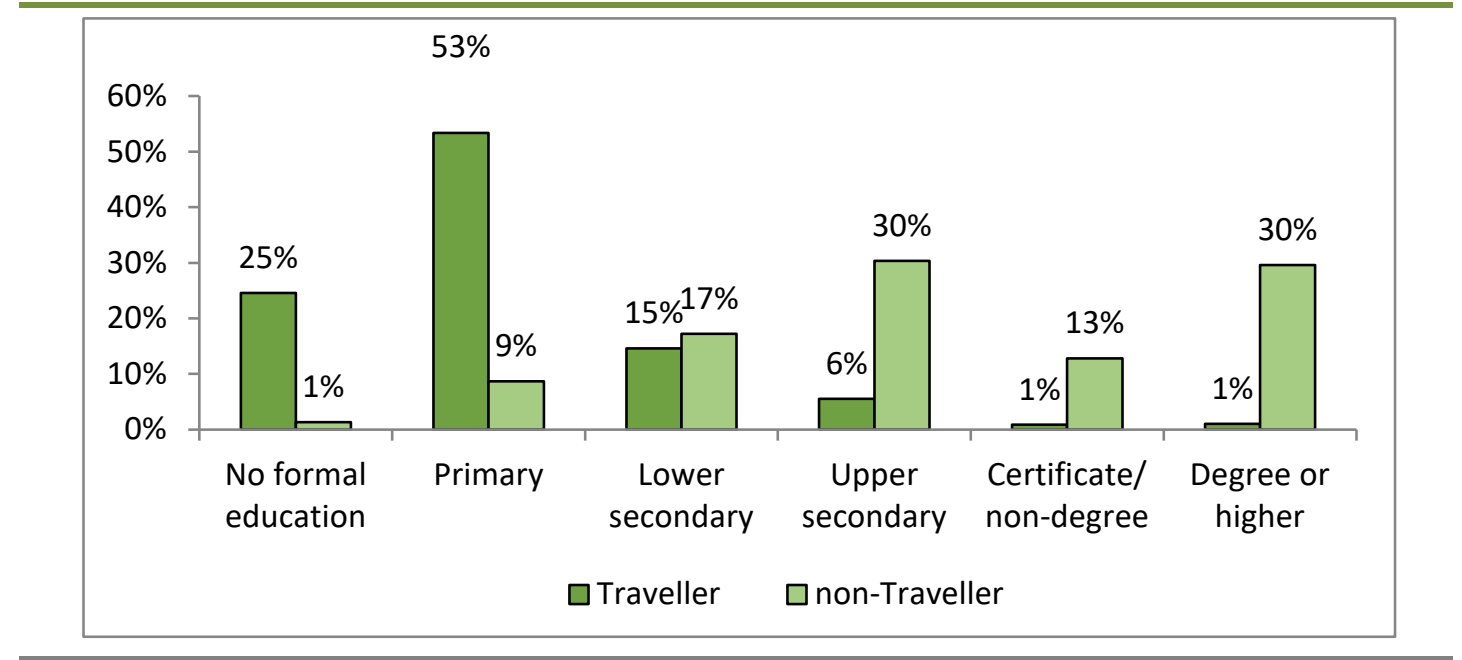

Source: Census of population micro-data files for 2011; persons aged 25-64 in private households, analysis by authors.

One-quarter of working-age Travellers have no formal education and 53 per cent have only primary education, compared to figures of 1 per cent and 9 per cent, respectively, for non-Travellers in the same age range. At the other end of the scale, only 8 per cent of working-age Travellers have completed second level education or above, compared to 73 per cent of non-Travellers. Only 1 per cent of Travellers have degree-level education compared to 30 per cent among non-Travellers.

\subsection{STATISTICAL MODEL OF EDUCATIONAL ATTAINMENT}

The differences reported so far do not take account of the age differences between the Traveller and other populations. As noted above, younger adults tend to have completed higher levels of education than older adults. We know from the previous chapter that Travellers tend to be younger than other adults. If Travellers had the same age profile as the general population, we would therefore expect the gap in educational attainment to be even larger. Statistical analysis can show how much larger this gap would be.

The statistical model is a way of asking how large the difference between the two groups would be if we could statistically control for age (and other differences; as well as age group, we take account of gender and 
region). The results of the analysis are shown in Table 2.1. The figures in the table are odds ratios for leaving school before completing second level. A ratio greater than one indicates a greater likelihood while a ratio less than one indicates a lower likelihood.

Model 1 shows the overall difference between Travellers and nonTravellers. In the 25 to 64 age group, Travellers have 33 times the odds of having left education without completing the Leaving Certificate or equivalent compared to non-Travellers. In model 2 , we can see how this changes when we add the controls for age group. The odds ratio increases to 51 times for Travellers. In other words, if Travellers had the same age distribution as the general population, their educational disadvantage would be seen to be even greater. They are younger, on average, than other adults and because younger adults tend to have better levels of education we might expect the position of Travellers to be more favourable. Their younger age profile hides some of the educational disadvantage experienced by Travellers.

There are substantial age differences because young people in more recent cohorts have tended to remain in school for longer, completing higher levels of education. Compared to adults aged 25-34 years, the odds of having finished school without full second level education are 1.7 times higher for adults aged 35-44 years, 3.3 times higher for adults aged 35-54 years and 6.4 times higher for adults aged 55-64 years.

Table 2.1 Odds Ratios for Finishing Education Without Completing Second Level, 25-64 Years, 2011

\begin{tabular}{|lccc}
\hline & Model 1 & Model 2 & Model 3 \\
\hline Traveller & 33.1 & 51.4 & 53.1 \\
\hline Female vs. male & & & 0.7 \\
\hline 35-44 vs. 25-34 years & & 1.8 & 1.7 \\
\hline 45-54 vs. 25-34 years & 3.3 & 3.3 \\
\hline 55-64 vs. 25-34 years & 6.4 & 6.4 \\
\hline Border vs. Dublin & & 1.6 \\
Midlands vs. Dublin & & 1.4 \\
\hline West vs. Dublin & & 1.0 \\
\hline Mid-East vs. Dublin & & & 1.1 \\
\hline Mid-West vs. Dublin & & & 1.2 \\
\hline South-East vs. Dublin & & & 1.4 \\
\hline South-West vs. Dublin & & & 1.1 \\
\hline Constant & 0.37 & 0.079 & 0.15 \\
\hline Nagelkerke R-squared & 0.007 & & 0.089 \\
\hline
\end{tabular}

Source: Census micro-data, 2011 analysis by authors. The table shows odds ratios for not completing second level education (i.e. finishing at the Junior Certificate or equivalent, or earlier). Odds ratios greater than one indicate a greater likelihood of finishing at this level while odds ratios less than one indicate a lesser likelihood. 
There are also some differences by gender and region, as can be seen in model 3. Women are less likely than men to have finished school without the Leaving Certificate or equivalent (odds ratio of 0.7).

Region refers to the eight regional authority areas. Note that this is the region where the person was living at the time of the census, which is not necessarily the place where they grew up and went to school or college. Compared to Dublin city and county, the odds of leaving without full second level education are higher for those living in most of the other regions, especially the Border region (odds ratio 1.6) and the Midlands and South-East regions (odds ratio 1.4 for each).

In Table 2.1, for simplification purposes, we made the assumption that the differences between the age groups, regions and genders were the same for Travellers as for the non-Traveller population. However, it might be the case that the age differences are larger or smaller among Travellers. To address this, we conducted another statistical analysis. The full model is shown in Table A2.1 (in the appendix), but the results are summarised in Figure 2.3. This figure draws on the results of the statistical model to present the adjusted percentages leaving education before completing the Leaving Certificate or equivalent. The adjusted percentages are shown separately for Travellers and non-Travellers and show the percentages we would expect if all other characteristics were the same for the groups being compared. For instance, the figure of 95 per cent for male Travellers tells us that we would expect to see 95 per cent of male Travellers finishing school without the Leaving Certificate if they were the same as non-Travellers in the population in terms of their age distribution and their distribution across regions.

As can be seen in Figure 2.3, for both males and females, across all age groups and regions, the differences between Travellers and nonTravellers remain very substantial. In general, however, the gap is largest between Travellers and non-Travellers for the most advantaged subgroup, by gender, age and region. For instance, the proportion leaving education before completing second level tends to be lower for females, younger adults and those living in Dublin, so females, younger adults and Dublin residents in the general population are more advantaged in this respect. The gap between Travellers and non-Travellers is somewhat larger for females than males, for younger adults than older adults and for Dublin residents than those living elsewhere. This is because the adjusted level of low education is above 90 per cent for Travellers in all subgroups, while there is more variation for non-Travellers. 
Figure 2.3 Adjusted Percentage Leaving Education Before Completing Second Level, 25-64 Years

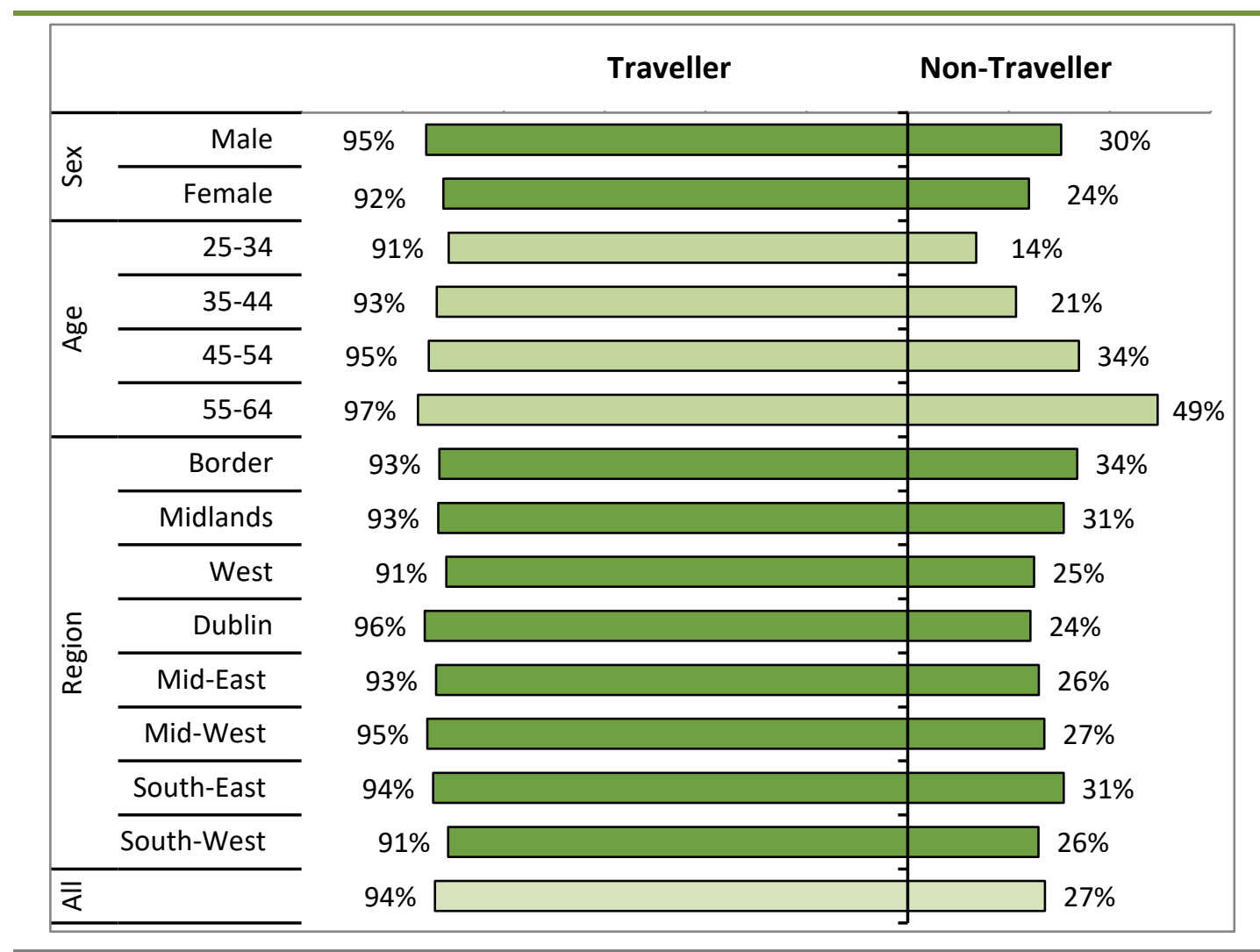

Source: Census of population micro-data files for 2011, analysis by authors. The figures are based on model 4 in Table A2.1 (appendix), which allows for interactions between being a Traveller and each of age, gender and region.

The differences by age are the most dramatic and are shown again in Figure 2.4. Here, in order to highlight the link between age and the time at which the person would have been roughly 'Leaving Certificate age', we show the adjusted percentage with Leaving Certificate or higher, by the year range in which the person was age 18 .

Figure 2.4 Adjusted Percentage with Leaving Certificate by Year in Which the Person was Age 18

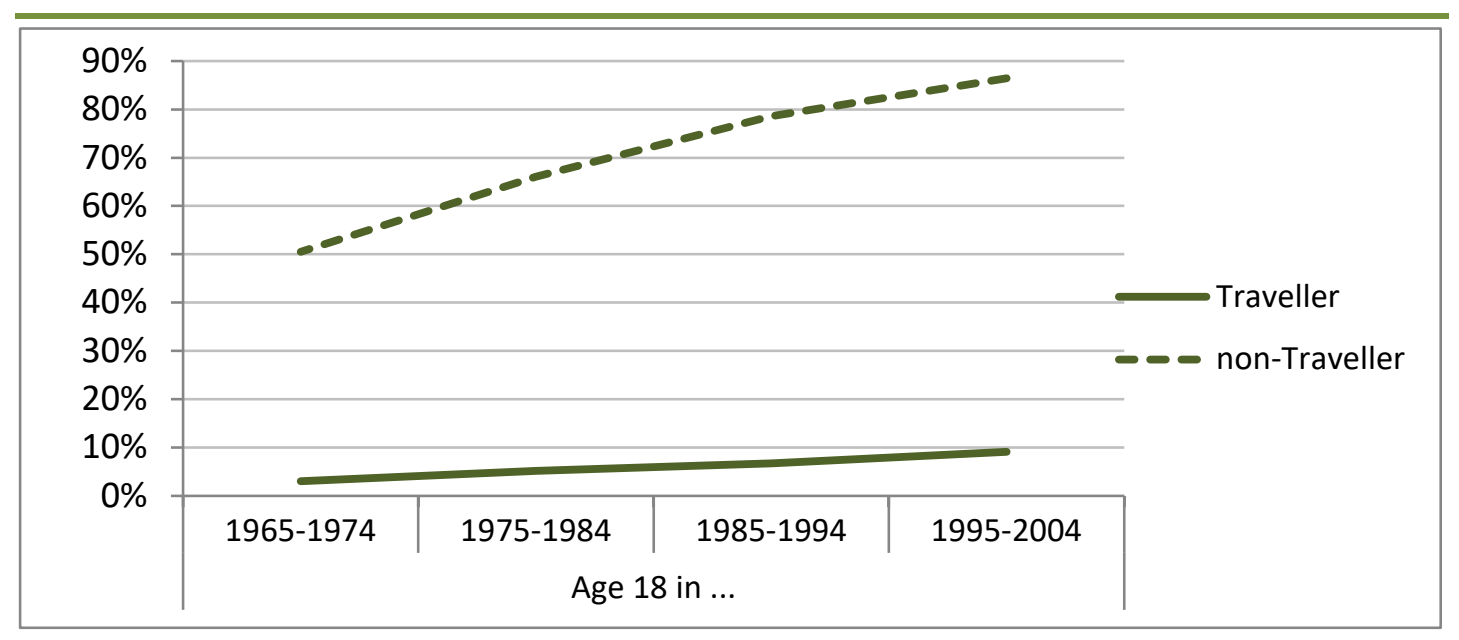

Source: Census of population micro-data files for 2011, analysis by authors. The figures are based on model 4 in Table A2.1 (appendix), which allows for interactions between being a Traveller and each of age, gender and region. 
Among those who turned 18 between 1965 and 1974, only 3 per cent of Travellers and 51 per cent of non-Travellers would have completed the Leaving Certificate. This rose to 9 per cent of Travellers and 86 per cent of non-Travellers for the cohort turning 18 between 1995 and 2004.

These patterns seem to suggest that improvements in education level across the general population have not been shared by Travellers. As a result, Travellers have been left farther behind in terms of their capacity to take advantage of employment opportunities and other advantages associated with improved levels of education. The gap was 48 percentage points for the oldest cohort examined here and 77 percentage points for the youngest cohort.

\subsection{SUMMARY}

In this chapter we drew on census data to examine the level of educational attainment among Travellers and non-Travellers in Ireland. We already knew that Travellers were more disadvantaged in this respect and the results from Census 2011 confirmed that only 9 per cent of Travellers aged 25-64 years stayed in school beyond the age of 16 (compared to 75 per cent of non-Travellers). The differences by age group, with other characteristics controlled, suggest that Travellers benefitted less from the general improvements in educational levels since the 1960s.

Although women are more likely to have completed second level education than men, Traveller women remain very disadvantaged in educational terms, with an estimated 92 per cent leaving school without having completed second level (with other characteristics controlled).

The next chapter examines the employment and unemployment situation of Travellers and non-Travellers. 


\section{Chapter 3}

\section{Work}

\subsection{INTRODUCTION}

This chapter examines the work situation of Travellers and non-Travellers in Ireland. We focus on the working-age population, beginning at age 25 when most people have completed their education and extending to age 64. We begin with some descriptive results and then move on to the results of a statistical model that takes account of important differences between Travellers and non-Travellers in their levels of education and their age distribution. We saw in the previous chapters that there are large differences in levels of education and age between Travellers and non-Travellers, so it is important to statistically control for these differences if we are to draw conclusions about the operation of the labour market.

\subsection{EMPLOYMENT OF TRAVELLERS AND NON-TRAVELLERS}

\subsubsection{Present Economic Status}

Figure 3.1 shows the present economic status of Travellers and nonTravellers, focusing on those aged 25-64 years and living in private households in 2011. There is a dramatic difference between the two groups in the percentages at work, with figures of only 11 per cent for Travellers compared to 66 per cent for non-Travellers. 
Figure 3.1 Present Economic Status, 25-64 Years, 2011

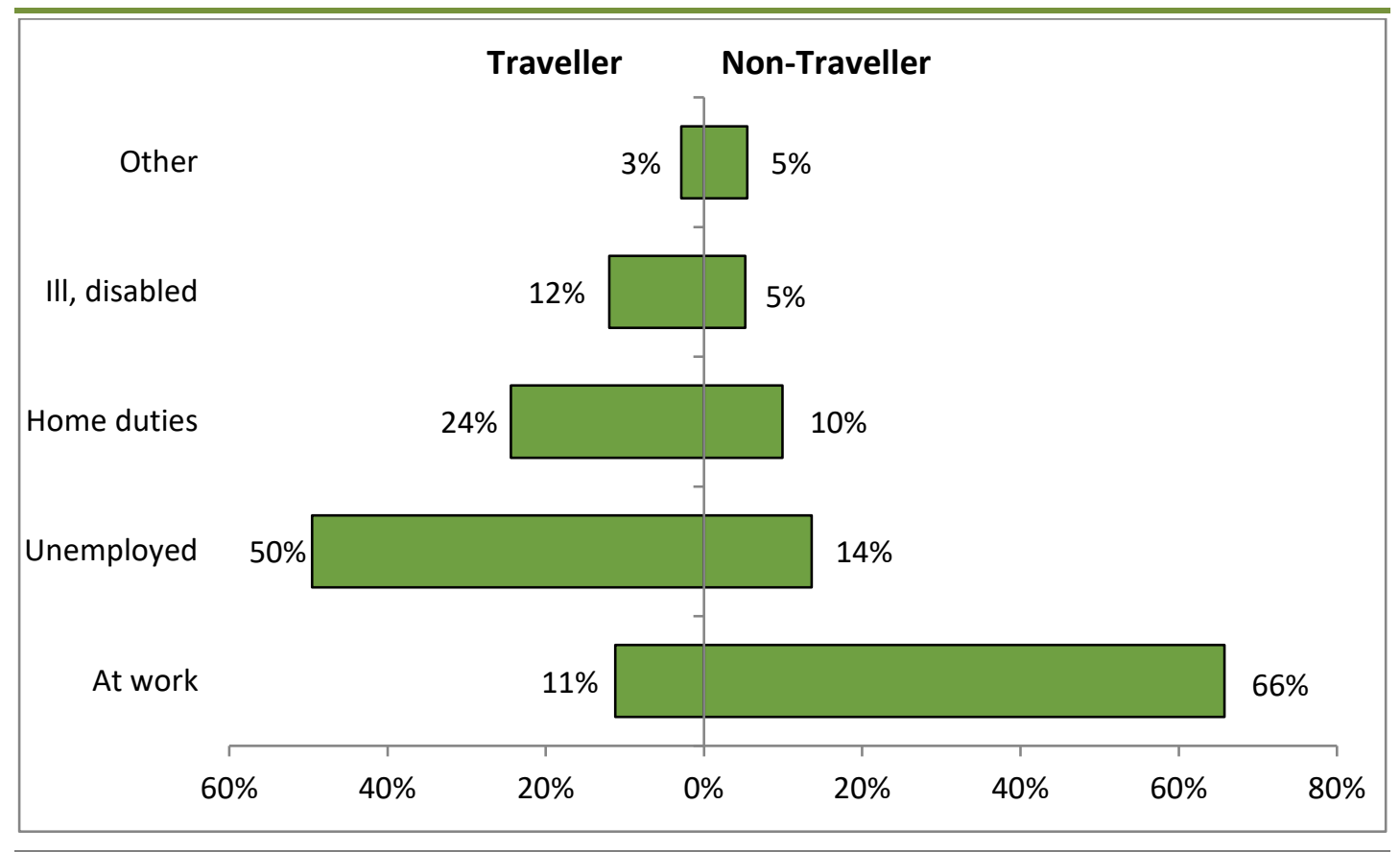

Source: Census of population micro-data files for 2011, analysis by authors.

For Travellers, the largest proportion is unemployed (50 per cent), compared to 14 per cent of non-Travellers. Nearly one-quarter of Travellers are engaged in home duties (24 per cent), compared to 10 per cent of non-Travellers. Twelve per cent of Travellers are unable to work due to illness or disability, compared to 5 per cent of non-Travellers.

Because the percentage of Travellers who are in employment is so low, the social class indicator is not very useful for this group. Social class is based on the current or most recent occupation of the householder. As can be seen in Table 3.1, for over eight out of ten Travellers, this is 'unknown'. The comparable figure for the other population is 16 per cent.

Table 3.1 Social Class, All Age Groups, 2011

\begin{tabular}{lcc|} 
& \multicolumn{2}{c}{$\begin{array}{c}\text { Non- } \\
\text { Traveller }\end{array}$} \\
& Traveller & \\
\hline Professionals & $0 \%$ & $7 \%$ \\
\hline Managerial, technical & $3 \%$ & $28 \%$ \\
\hline Non-manual & $2 \%$ & $18 \%$ \\
\hline Skilled manual & $4 \%$ & $16 \%$ \\
\hline Semi-skilled & $4 \%$ & $11 \%$ \\
\hline Unskilled & $2 \%$ & $4 \%$ \\
\hline Unknown & $84 \%$ & $16 \%$ \\
\hline
\end{tabular}

Source: Census of population micro-data files for 2011, analysis by authors. 
Figure 3.2 shows a number of other indicators related to the labour market: the participation rate, the employment rate and the unemployment rate. ${ }^{15}$ The participation rate is the percentage of adults aged 25-64 years who are active in the labour market - those who are either in employment or unemployed, as opposed to being 'inactive' in the labour market (caring for home and family, in education or unable to work because of illness or disability). The participation rate was 61 per cent for Travellers in 2011 with a figure of 79 per cent for non-Travellers.

The employment rate shows the percentage of adults aged 25-64 years in employment. This was 11 per cent for Travellers and 66 per cent for the other population. The employment rate is dramatically lower for Travellers than for other adults.

The unemployment rate (third category in Figure 3.2) concerns the percentage of those in the labour market who are unemployed. For those aged 25-64 in 2011, the unemployment rate was 82 per cent for Travellers aged 25-64 and 17 per cent for non-Travellers. The differences in the participation rate, while substantial, are not as large. The main driver of the low employment rate of Travellers is the high rate of unemployment among those seeking work.

Figure 3.2 Participation Rate, Employment Rate and Unemployment Rate, 25-64 Years, 2011

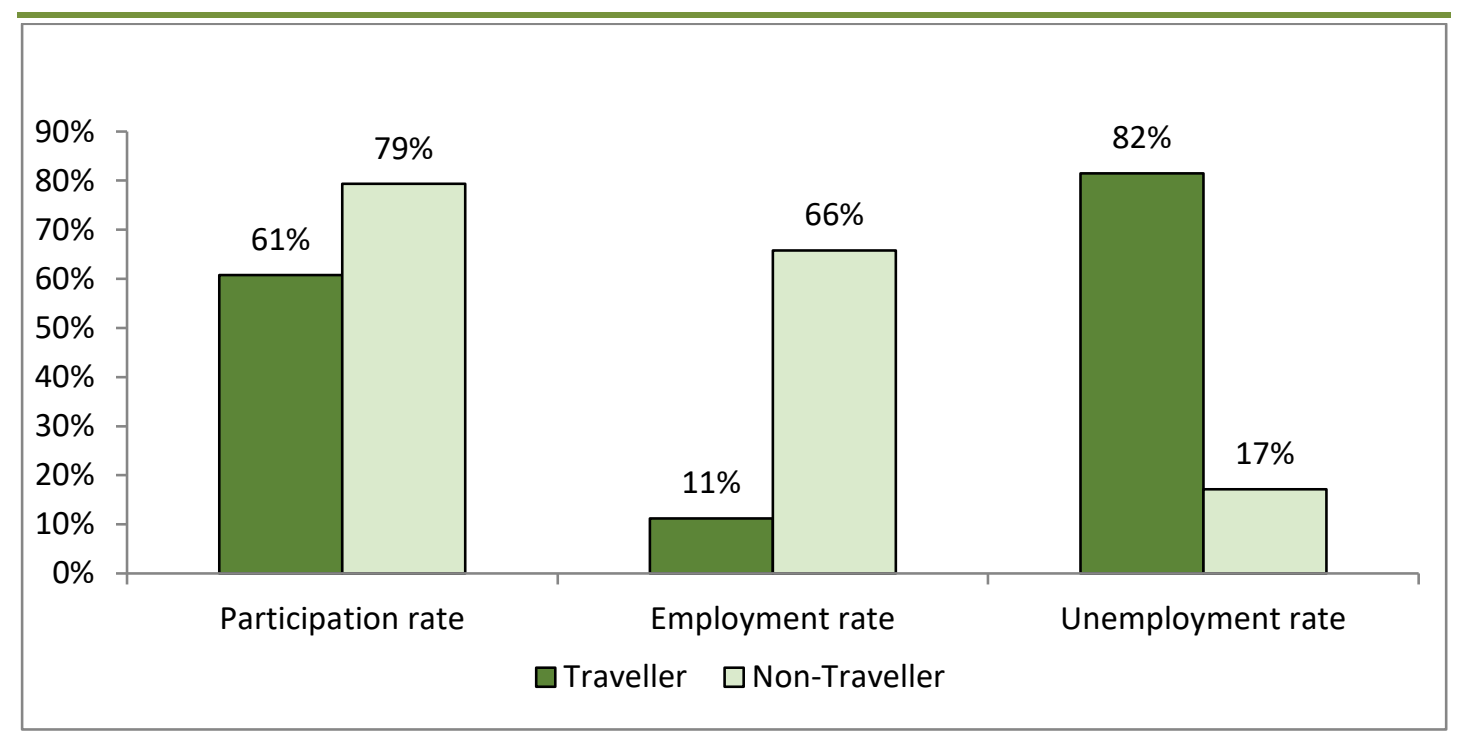

Source: Census of population micro-data files for 2011, analysis by authors.

\subsection{STATISTICAL MODEL OF EMPLOYMENT}

As in the previous chapter, we now draw on the results of a statistical model. This statistical model was constructed to examine how the

\footnotetext{
${ }^{15}$ Because of differences in measurement, these figures are not directly comparable to the official unemployment statistics from the Quarterly National Household Survey.
} 
employment rate of Travellers and non-Travellers vary by gender, region and age group. Education is also included in the analysis. This allows us to ask whether the lower employment rate of Travellers can be accounted for by their lower levels of education. Since employment rates differ by marital status for women, men and women are placed in three marital status categories: never married, married and formerly married (including divorced, separated and widowed). The presence of children under 15 separately is treated separately for men and women, as having children is likely to have different implications for the labour market participation of men and women.

In the previous tables in this chapter (except Table 3.1), we presented results for those aged 25-64 years in order to focus on those likely to have completed their education. For the statistical model, we take a different strategy: we include all of those aged 15 to 64, but exclude those still in education. We do this in order to be able to compare the employment situation of very young Travellers to that of their non-Traveller counterparts.

Table 3.2 shows the odds ratios for non-employment of Travellers compared to the general population, beginning with the overall ratio (model 1), adding controls for gender, marital status, age and region (model 2) and adding controls for education (model 3). 
Table 3.2 Odds of Not Being at Work for Adults 15-64 Years, Excluding Students

\begin{tabular}{|c|c|c|c|}
\hline & Model 1 & Model 2 & Model 3 \\
\hline Traveller & 19.0 & 22.2 & 8.5 \\
\hline Single men vs. married men & & 2.8 & 2.5 \\
\hline Formerly married men vs. married men & & 2.4 & 2.2 \\
\hline Single women vs. married men & & 1.6 & 1.7 \\
\hline Married women vs. married men & & 1.8 & 2.0 \\
\hline Formerly married women vs. married men & & 2.1 & 2.0 \\
\hline Female with child under 15 vs. no child & & 2.1 & 2.1 \\
\hline Male with child under 15 vs. no child & & 1.1 & 1.1 \\
\hline Age $15-24$ vs. $25-34$ years & & 2.1 & 1.8 \\
\hline Age $35-44$ vs. $25-34$ years & & 1.2 & 1.1 \\
\hline Age $45-54$ vs. $25-34$ years & & 1.7 & 1.2 \\
\hline Age $55-64$ vs. $25-34$ years & & 4.5 & 2.6 \\
\hline Border vs. Dublin & & 1.4 & 1.2 \\
\hline Midlands vs. Dublin & & 1.4 & 1.2 \\
\hline West vs. Dublin & & 1.1 & 1.1 \\
\hline Mid-East vs. Dublin & & 1.1 & 1.1 \\
\hline Mid-West vs. Dublin & & 1.2 & 1.1 \\
\hline South-East vs. Dublin & & 1.3 & 1.2 \\
\hline South-West vs. Dublin & & 1.1 & 1.1 \\
\hline Primary vs. third level education & & & 6.4 \\
\hline Lower second vs. third level education & & & 3.8 \\
\hline Upper second vs. third level education & & & 2.2 \\
\hline Constant & 0.49 & 0.12 & 0.08 \\
\hline Nagelkerke R-squared & 0.006 & 0.067 & 0.122 \\
\hline
\end{tabular}

Overall, before taking account of other characteristics (model 1), Travellers have 19 times the odds of being non-employed compared to the general population. The gap is larger (odds at 22 times higher) when we adjust for age. This is because Travellers tend to be younger and younger adults have a higher labour market participation rate than older adults (model 2). When we control for differences in level of education (model 3), the odds ratio is substantially reduced to 8.5 . The reduction in the odds ratio when we control for education suggests that over one half of the gap (expressed as an odds ratio) in employment between Travellers and non-Travellers is accounted for by their educational disadvantage. Nevertheless, even after taking education into account, the odds of not being at work are over eight times higher for Travellers than nonTravellers. This means that apart from their educational disadvantage, 
Travellers face further barriers in the labour market when it comes to employment.

The odds ratios reported in Table 3.2 assume that Travellers and nonTravellers are similar in terms of the relationship between being in employment and gender, age group, marital and family status, region and level of education. We now present the result of the statistical model in the form of 'adjusted percentages', that is, the percentage we would expect to see at work if Travellers and non-Travellers were the same in terms of other characteristics. For instance, if we are comparing the differences by age group, we ask what the age pattern would look like if Travellers and non-Travellers were similar in terms of their distribution by gender, marital status, region and education. The full model is shown in Table A3.1 in the appendix (see model 4) and the adjusted percentages are shown in Figure 3.3. Note that what we present in Figure 3.3 - the adjusted percentage in employment - is simply the inverse of the percentage non-employed as modelled in Table A3.1.

For both Travellers and non-Travellers, the biggest differences in employment rate were associated with education. In the general population, for instance, 80 per cent of those with third level education were in employment, compared to just 41 per cent of those with primary education or less. The differences were even more substantial for Travellers, ranging from just 9 per cent of those with primary education to 57 per cent of those with a degree or higher level.

The education pattern can be seen more clearly in Figure 3.4, which shows the percentage in employment by level of education as a line chart. The gap between Travellers and non-Travellers is somewhat narrower among those with education beyond second level. We may not wish to put too much weight on the narrowing of the gap for those with further or higher education because the number of Travellers in this group is relatively small. However, we can safely conclude that even though Travellers remain disadvantaged in terms of getting a job at all levels of education, their employment chances increase at least as much as those of non-Travellers with each increment in education.

Turning to differences by gender and marital status, as shown in Figure 3.3 , in the general population, married men are most likely to be at work (77 per cent), followed by single women (68 per cent). Among Travellers, the highest adjusted employment rate was for single men (40 per cent). 
Figure 3.3 Adjusted Percentage at Work, 15-64 years (Excluding Those in Education), 2011

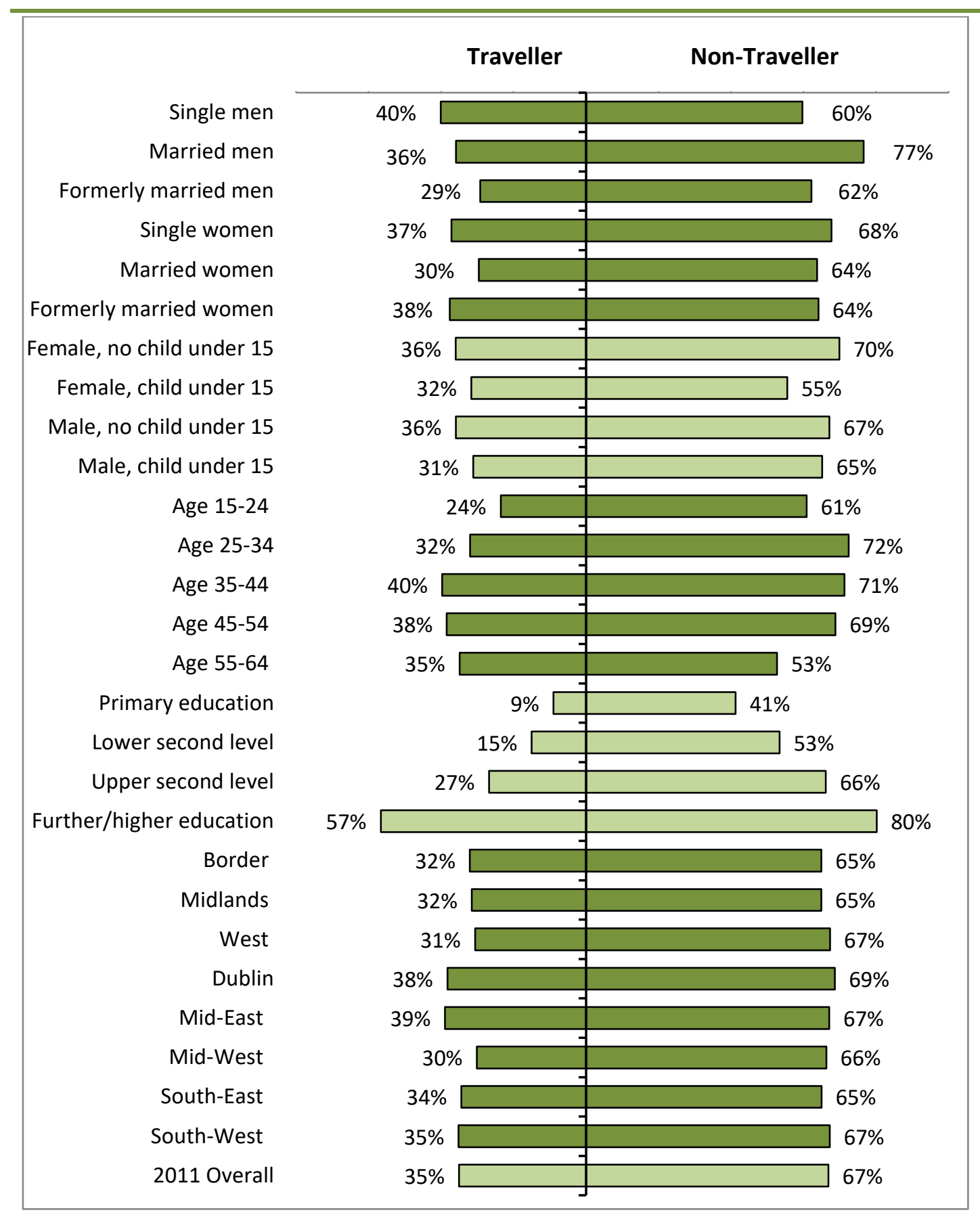

Source: Census of population micro-data files for 2011, analysis by authors. The figures are based on model 4 in Table A3.1 (appendix), which allows for the patterns to be different for Travellers and non-Travellers. 
Figure 3.4 Adjusted Percentage at Work by Level of Education, 2011

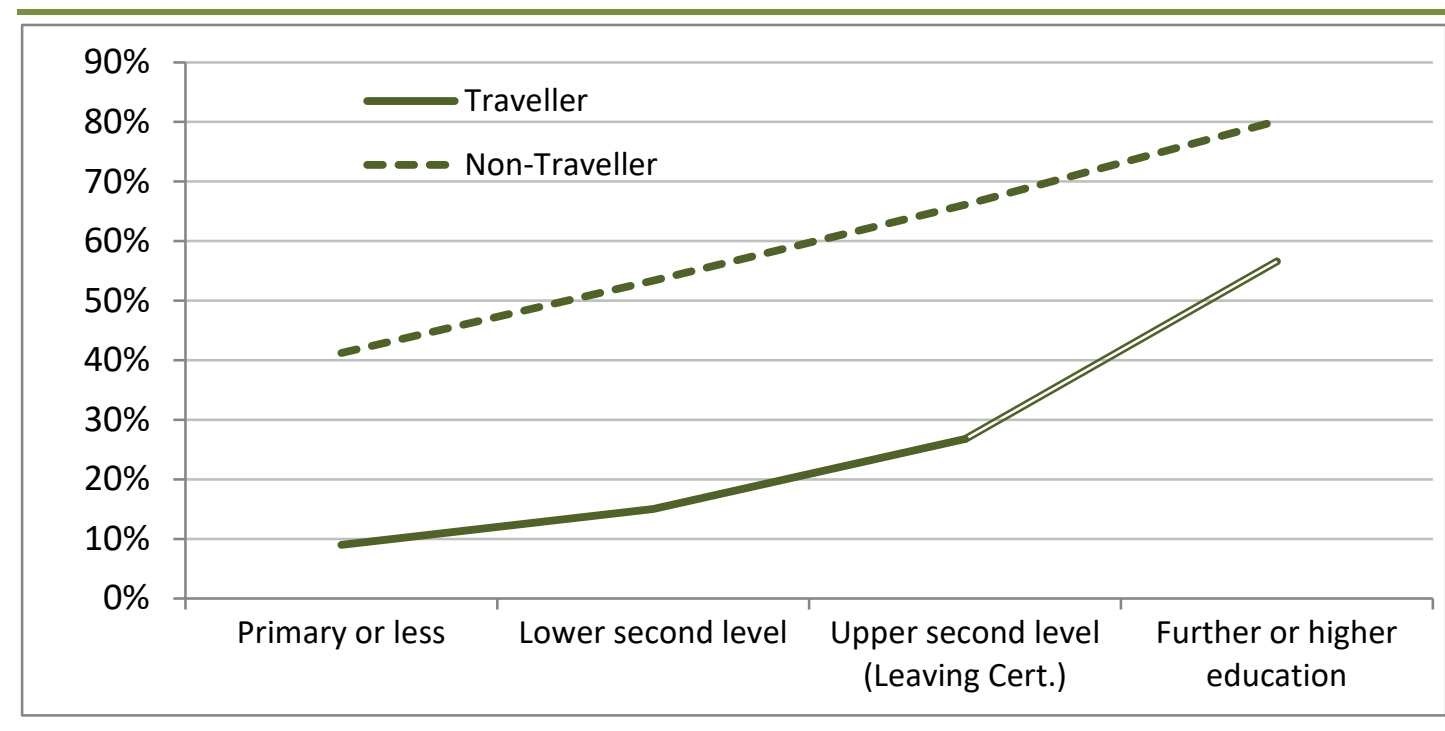

Source: Census of population micro-data files for 2011, analysis by authors. The figures are based on model 4 in Table A3.1 (appendix), which allows for the patterns to be different for Travellers and non-Travellers.

Among non-Travellers, the presence of children has a very substantial influence on women's employment. Among women with no child under 15 years, 70 per cent were at work compared to 55 per cent among women with at least one child under 15 years. The figures for men are less influenced by the presence of children (67 to 65 per cent). Among Travellers, women's employment is not quite as strongly affected by the presence of children, with a figure of 36 per cent for women with no children and 32 per cent for women with children. The figures for Traveller men are very similar to those for Traveller women. As a result, the employment gap between Traveller men with and without children under 15 is larger than that for non-Traveller men. This means that the employment of Traveller men is more strongly affected by the presence of children than the employment of non-Traveller men.

When it comes to age, the adjusted employment rate for non-Travellers is highest for those aged $25-44$ years (71-72 per cent), rising from 61 per cent for those aged 15-24 years and falling back to 53 per cent for those aged 55-64 years. The pattern for Travellers is similar, though not as pronounced, rising from 24 per cent for those aged 15-24 years, reaching 40 per cent for those aged 35-44 years and falling to 35 per cent for those aged $55-64$ years.

The adjusted percentage in employment varies little by region for nonTravellers but there are more significant regional differences among Travellers. Note that this refers to the region where the person is currently living and they may have moved to the region in search of work or to take up a job. Among Travellers, the adjusted employment rate is 
highest in the Mid-East (39 per cent) and is also high in Dublin (38 per cent) but lower in the Border, Midlands, West and Mid-West regions (3032 per cent).

\subsection{SUMMARY}

In this chapter we drew on census data to understand the large gap in employment levels between Travellers and non-Travellers. In 2011, the employment rate among those aged 25-64 years, not counting students, was 66 per cent for non-Travellers but only 11 per cent for Travellers.

We constructed a statistical model of employment for those aged 15-64 years, excluding students. If expressed as an odds ratio of nonemployment versus employment, the gap between Travellers and nonTravellers is reduced by more than one-half when differences in education are taken into account. Nevertheless, even after taking account of education, the odds of non-employment are over eight times higher for Travellers.

After adjusting for other characteristics, we saw a sharper increase in the employment level of Travellers with rising education (from 9 per cent to 57 per cent) than we observed for non-Travellers (from 41 per cent to 80 per cent).

In general, men were more likely than women to be in employment, with this pattern mainly driven by differences between married men and married women and by the fact that women with children are less likely than men with children to be in employment. However, the gender gap is smaller among Travellers and the employment of Traveller women is less affected by the presence of children. Of course, the rate of employment of both men and women among Travellers is low.

The next chapter turns to the differences in the quality of housing and housing amenities between Travellers and non-Travellers. 


\section{Chapter 4}

Housing

\subsection{INTRODUCTION}

This chapter examines the accommodation of Travellers and nonTravellers in Ireland. People of all ages are included in this analysis, unlike the previous two chapters, which focused on adults who were likely to have completed their education. We begin the chapter with some descriptive results and then move on to the results of a statistical model that takes account of important differences between Travellers and nonTravellers in their levels of education, age distribution, family circumstances and employment. In looking at the type of housing and the level of overcrowding, it is important to control for the age and family circumstances of Travellers.

\subsection{HOUSING OF TRAVELLERS AND NON-TRAVELLERS}

\subsubsection{Dwelling Characteristics}

In 2011, the most common housing type among Travellers was a semidetached house ( 32 per cent), detached house ( 25 per cent) or terraced house (22 per cent). Just 12 per cent lived in a caravan or mobile home. Compared to other members of the population, they were less likely to live in detached houses ( 25 per cent compared to 46 per cent) or apartments ( 5 per cent compared to 8 per cent).

The dominant tenure among Travellers is renting social housing. This is housing provided by the local authorities or social housing agencies. Almost one-half of Travellers are in this type of housing tenure (49 per cent). The second most common tenure type is 'other renting' - renting from a private landlord (29 per cent). Compared to non-Travellers, Travellers are much less likely to own a property outright (10 per cent versus 30 per cent) or to own one with a mortgage ( 6 per cent versus 42 per cent). Together, these two homeowner categories account for over 70 per cent of tenure types among the other population.

The number of rooms in a dwelling is the count of living rooms and bedrooms; bathrooms, hallways and kitchenettes too small to sit in are excluded. The number of rooms available to Travellers tends to be lower than the number available to non-Travellers. In 2011, 30 per cent of 
Travellers lived in accommodation with three rooms or less, compared to only 6 per cent of non-Travellers.

Figure 4.1 Housing Characteristics of Travellers and Non-Travellers (Private Households), 2011

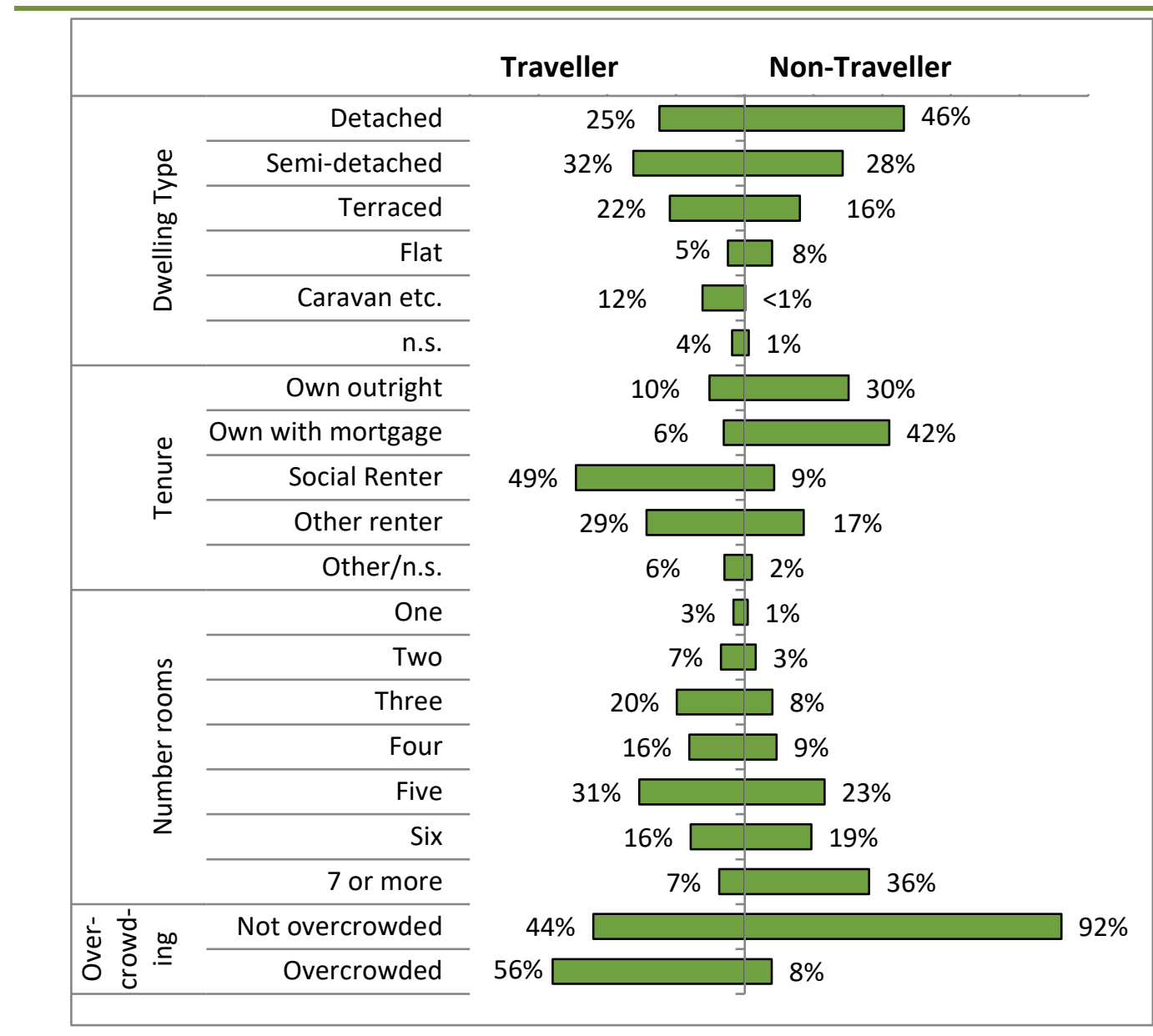

Source: Census of population micro-data files for 2011, analysis by authors.

Note: $\quad$ n.s. $=$ not specified .

Overcrowding is measured in terms of living in accommodation where there is more than one person per room, as per the above description of 'rooms'. Since Traveller households tend to be larger, we would expect the smaller number of rooms available to them to lead to overcrowding; in 2011, 56 per cent of Travellers lived in overcrowded accommodation compared to just 8 per cent of non-Travellers.

Figure 4.2 shows the amenities available in the accommodation. Most Travellers had some type of central heating (only 3 per cent did not). The main type of heating was oil or gas (56 per cent) but they were more likely than the general population to have heating based on coal or peat ( 25 per cent compared to 9 per cent).

Most Travellers live in accommodation with access to water and sewerage facilities (only 2-3 per cent do not). On the other hand, most 
Travellers do not have access to the internet; only 24 per cent have internet access compared to 82 per cent of non-Travellers.

Figure 4.2 Housing Amenities of Travellers and Non-Travellers (Private Households), 2011

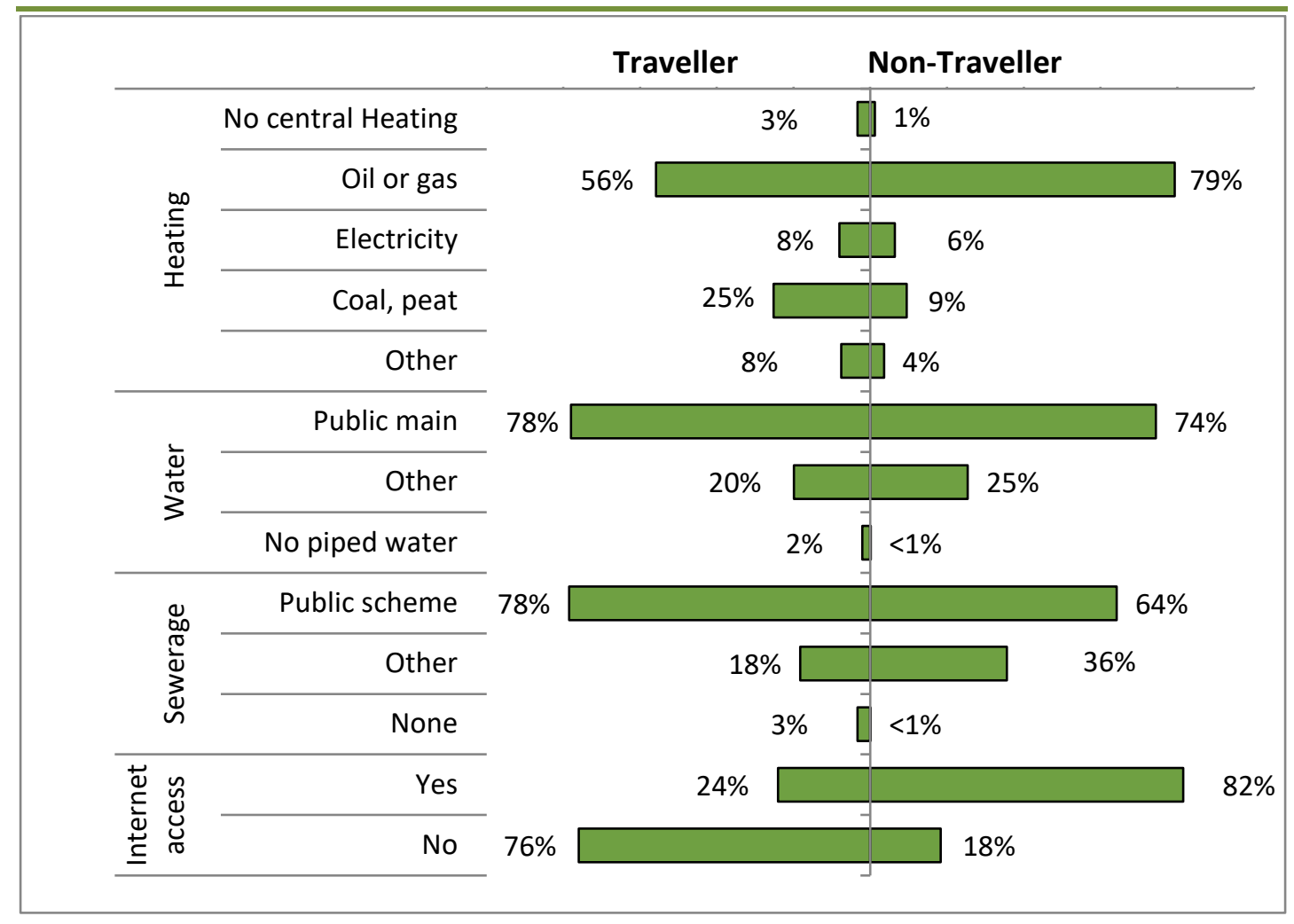

Source: Census of population micro-data files for 2011, analysis by authors.

\subsection{TRAVELLERS LIVING IN MOBILE HOMES OR CARAVANS}

\subsubsection{Amenities in Mobile Homes or Caravans}

Figure 4.3 shows that many problems with accommodation among Travellers are more severe among those living in caravans or mobile homes. People living in these forms of accommodation are more likely to lack central heating (13 per cent), piped water (19 per cent) or sewerage facilities (29 per cent).

They are also much more likely to experience overcrowding ( 84 per cent), and to lack internet access (91 per cent). Both of these problems are also relatively common among Travellers living in standard accommodation, with 53 per cent experiencing overcrowding and 74 per cent lacking internet access. 
Figure 4.3 Housing Amenities of Travellers by Type of Dwelling (Private Households), 2011

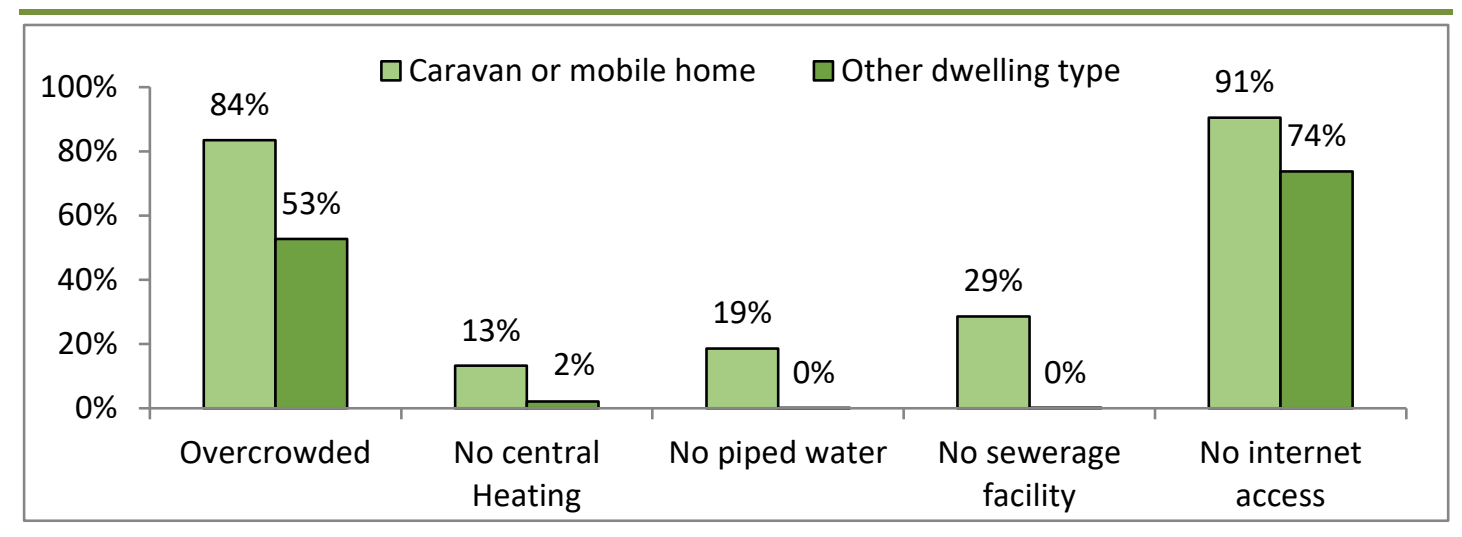

Source: Census of population micro-data files for 2011 for Travellers, analysis by authors.

\subsubsection{Which Travellers Live in Mobile Homes or Caravans?}

This section considers which groups of Travellers are more likely to live in caravans and mobile homes and whether this varies by age, level of education and employment status. Figure 4.4 presents the adjusted percentages of Travellers living in a caravan or mobile home, based on a statistical model - model 2; see Table A4.1 in the appendix - that allows us to isolate the associations with gender, marital status, age, education, work status and region. 
Figure 4.4 Adjusted Percentage of Travellers Living in a Caravan or Mobile Home, 2011

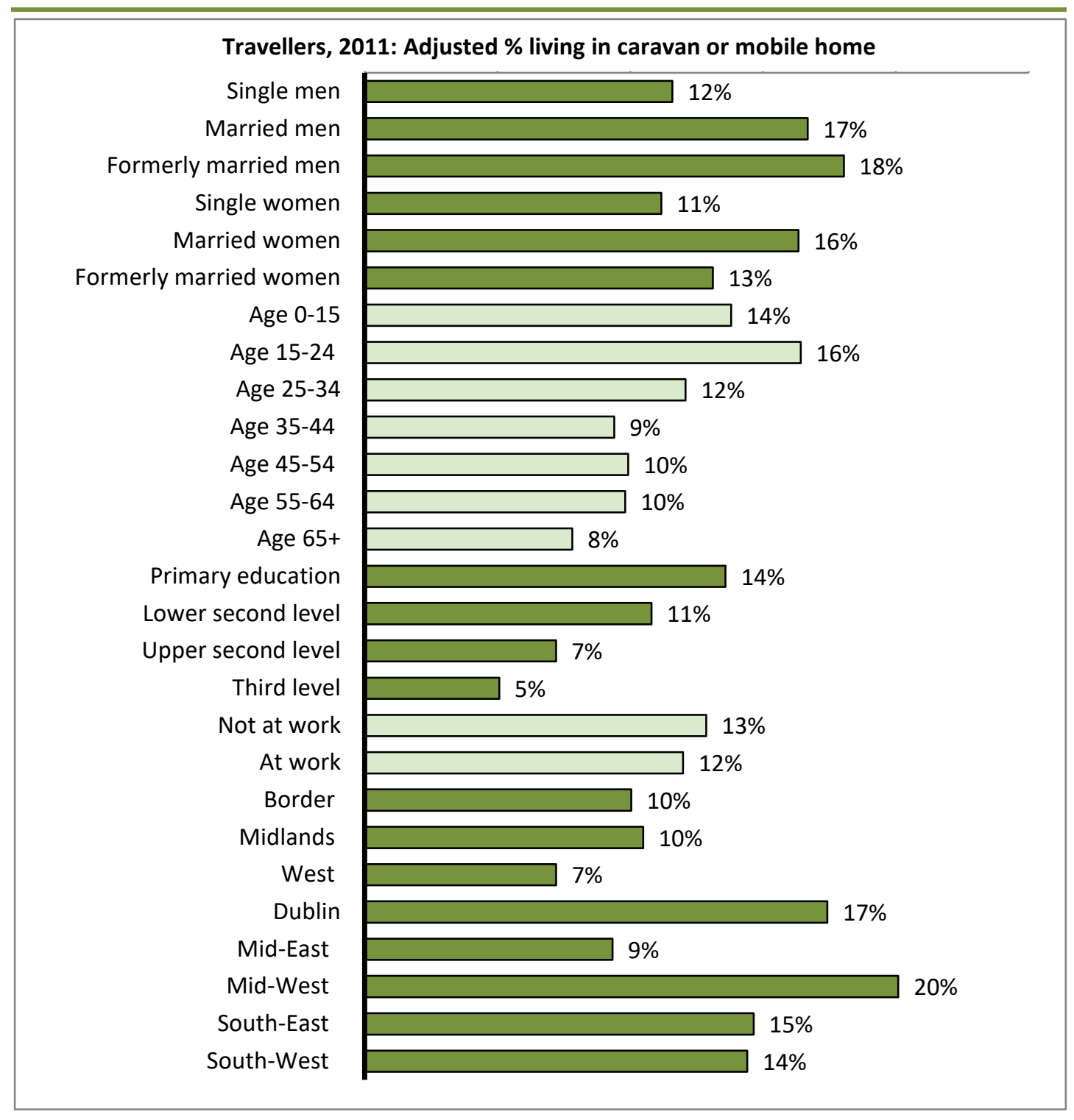

Source: Census of population micro-data for 2011, analysis by authors, based on model 2 in Table A4.1 (appendix).

There are some clear differences. Living in a caravan or mobile home is more common among married couples or formerly married adults; among children and young adults; among those with lower levels of education and those living in the Mid-West region (20 per cent) and Dublin (17 per cent). The adjusted percentages are much lower among those with further/higher education ( 5 per cent), those living in the West ( 7 per cent) and those living in the Mid-East (9 per cent).

\subsection{TRAVELLERS LIVING IN OVERCROWDED ACCOMMODATION}

We saw above that Travellers are more likely than the general population to live in overcrowded accommodation (56 per cent versus 8 per cent). This section examines the characteristics associated with overcrowding, 
for both Travellers and non-Travellers. Figure 4.5 presents the adjusted rate of overcrowding, based on a statistical model that allows us to isolate the differences by gender, marital status, age, education, work status, region and year - model 3 (see Table A4.2 in the appendix).

From Figure 4.5 we can see that the adjusted percentage of people living in overcrowded accommodation is higher for Travellers across all categories of age, gender by marital status, education, work, region and dwelling type.

It is also clear from the figure that the biggest differences in the adjusted rate of overcrowding are between those living in a caravan or mobile home and standard accommodation ( 66 versus 34 per cent for Travellers and 34 versus 8 per cent for non-Travellers).

Looking at the differences by marital status, we see that overcrowding is high for Travellers who are married or single and lower for those who are formerly married (including widowed and divorced or separated). Among non-Travellers, the adjusted overcrowding rate is also higher for married adults, but is low for single as well as formerly married adults.

When it comes to age group, the highest adjusted rates of overcrowding among Travellers are found at the family life-cycle stages, with rates of 49 per cent among children under 15 years and 43 per cent among adults aged 35-44 years, where the family is likely to be complete but still living at home. The rate of overcrowding declines after age 45 , falling to 10 per cent for Travellers aged 65 and over. However, given the youth of the Traveller population, the numbers in the older age groups represent a relatively small proportion of all Travellers. As noted above, the rate of overcrowding for the non-Traveller population tends to be highest in early adulthood, at 14-15 per cent between the ages of 15 and 35 years. 
Figure 4.5 Adjusted Percentage Living in Overcrowded Accommodation, 2011

\begin{tabular}{|c|c|c|c|}
\hline & & Traveller & Non-Traveller \\
\hline \multirow{6}{*}{ 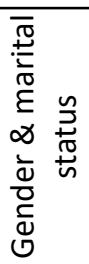 } & Single men & $34 \% \square$ & $76 \%$ \\
\hline & Married men & $37 \% \square$ & $14 \%$ \\
\hline & Formerly married men & $20 \%$ & 9\% \\
\hline & Single women & $34 \% \square$ & 6\% \\
\hline & Married women & $36 \% \square$ & $12 \%$ \\
\hline & Formerly married women & $25 \%$ & $10 \%$ \\
\hline \multirow{7}{*}{ 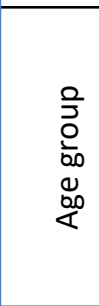 } & Age 0-14 & $49 \% \square$ & $11 \%$ \\
\hline & Age 15-24 & $36 \% \square$ & 14\% \\
\hline & Age $25-34$ & $34 \% \square$ & 15\% \\
\hline & Age 35-44 & $43 \% \square$ & $9 \%$ \\
\hline & Age 45-54 & $28 \% \square$ & $75 \%$ \\
\hline & Age 55-64 & $15 \%$ & $2 \%$ \\
\hline & Age 65+ & $10 \%$ & $1 \%$ \\
\hline \multirow{4}{*}{$\begin{array}{l}\stackrel{ }{0} \\
\stackrel{7}{0} \\
\stackrel{0}{J} \\
\stackrel{0}{0}\end{array}$} & Primary education & $41 \% \square$ & $12 \%$ \\
\hline & Lower second level & $39 \% \square$ & $7 \%$ \\
\hline & Upper second level & $37 \%$ & $7 \%$ \\
\hline & Third level & $20 \%$ & $\square \%$ \\
\hline \multirow{2}{*}{$\frac{1}{3}$} & Not at work & $38 \% \square$ & $9 \%$ \\
\hline & At work & $28 \%$ & $\square 6 \%$ \\
\hline \multirow{8}{*}{ 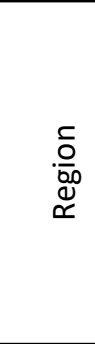 } & Border & $28 \%$ & 6\% \\
\hline & Midlands & $32 \% \square$ & $7 \%$ \\
\hline & West & $39 \% \square$ & $\square 6 \%$ \\
\hline & Dublin & $36 \% \square$ & $12 \%$ \\
\hline & Mid-East & $33 \%$ & $7 \%$ \\
\hline & Mid-West & $39 \% \square$ & $7 \%$ \\
\hline & South-East & $31 \%$ & $\square 6 \%$ \\
\hline & South-West & $33 \% \square$ & $\square$ 6\% \\
\hline \multirow{2}{*}{ 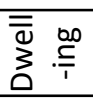 } & Permanent dwelling & $34 \%$ & $8 \%$ \\
\hline & Caravan/mobile home & $66 \%[$ & $34 \%$ \\
\hline
\end{tabular}

Source: Census of population micro-data files for 2011, analysis by authors. Based on statistical model 4 in Table A4.2.

For both Travellers and non-Travellers, the adjusted rate of overcrowding is lower among those in employment and among those with higher levels of education. Among Travellers, there is regional variation, with higher rates of overcrowding in the West and Mid-West (39 per cent) and lower rates in the Border region (28 per cent). Among non-Travellers, the rate of overcrowding is highest in Dublin, at 12 per cent, but there is less variation between other regions with the rate ranging between 6 and 8 per cent.

\subsection{SUMMARY}

In this chapter, we examined the housing circumstances of Travellers and non-Travellers, drawing on the census data. Most Travellers enumerated in Census 2011 lived in houses (79 per cent) and only 12 per cent lived in caravans or mobile homes. More than 95 per cent had central heating, piped water and a connection to a sewerage system, but the percentages 
lacking these facilities tended to be higher among those living in caravans or mobile homes. Overcrowding is a more common problem among Traveller households. It affects 84 per cent of Travellers living in a caravan or mobile home and 53 per cent of those living in other types of housing.

Among Travellers, living in a mobile home or caravan was more common among those with lower levels of education, adults not at work, those living in the Dublin region and younger adults and children (under 24 years). Apart from its link to living in a caravan or mobile home, overcrowding was more common among Travellers with children under age 15, adults not at work, with lower levels of education and those living in the West and Mid-West regions. Apart from being less common among those 65 years and over, the overcrowding pattern was somewhat different for non-Travellers, being most frequent among teens and young adults.

The next chapter examines the health status of Travellers and nonTravellers and looks at the impact of type of dwelling and overcrowding on health, as well as the health impact of other characteristics. 


\section{Chapter 5}

\section{Health}

\subsection{INTRODUCTION}

This chapter examines the health and disability status of Travellers and non-Travellers in Ireland. People of all ages are included in this analysis. As in earlier chapters, we first present some descriptive results and then move on to the results of a statistical model that takes account of the same important differences between Travellers and non-Travellers but that also includes their housing situation. In looking at health, it is important to control for age and economic circumstances and the statistical model allows us to do this. As before, we focus on 2011 when analysing the census data.

In this chapter we also draw on relevant data on Travellers from the All Ireland Traveller Health Study (AITHS), as well as data on the general population from the 2007 Survey of Lifestyle, Attitudes and Nutrition (SLÁN). The SLÁN survey provides data on the general health, health behaviours and health service use of adults aged 18 years or over living in Ireland. Conducted in 2007, it was based on face-to-face interviews with adults, interviewed at home. A total of 10,364 adults, including nonIrish nationals, were surveyed, representing a 62 per cent response rate. The data were weighted to correspond with the general population on variables such as gender, age, marital status and ethnicity and was found to match the Census 2006 population on these and other variables very closely (Morgan et al., 2008).

\subsection{GENERAL HEALTH OF TRAVELLERS AND NON-TRAVELLERS}

Figure 5.1 shows the health status of Travellers and non-Travellers, drawing on a new census question asked for the first time in 2011. This includes people of all ages, children as well as adults. Most Travellers describe their health as very good ( 59 per cent) or good ( 28 per cent). The corresponding figures for reporting very good or good health among the general population are slightly higher, however, at 62 per cent and 29 per cent, respectively. At the other end of the scale, 12 per cent of Travellers describe their health as fair, bad or very bad compared to 9 per cent of non-Travellers. 
While we do see some differences here between Travellers and nonTravellers, they are not as large as we might have expected. This is because there is a strong association between age and poor health; as shown in chapter one, Travellers tend to be younger than non-Travellers. When all Travellers are compared to all non-Travellers, as in Figure 5.1, the comparison is between two groups with very different age profiles.

Figure 5.1 General Health of Travellers and Non-Travellers, All Ages, 2011

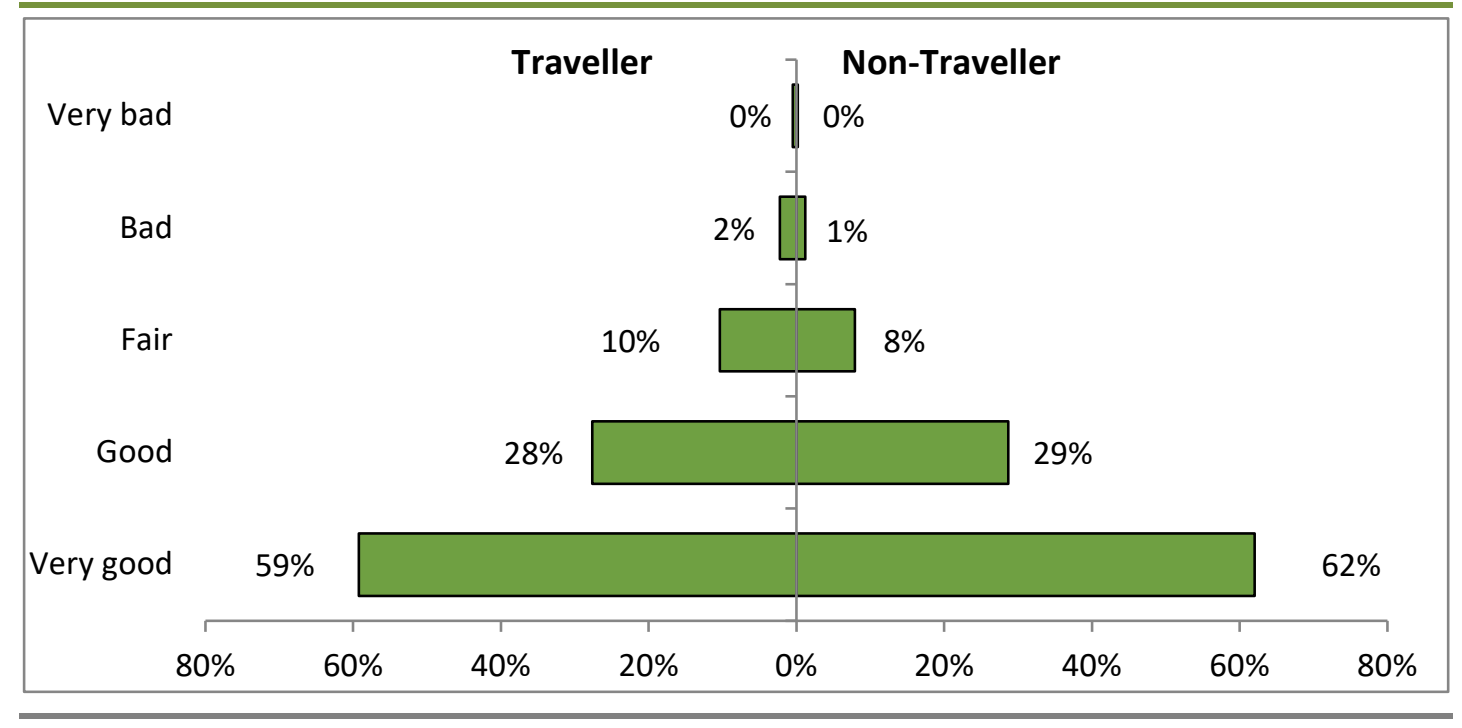

Source: Census of population micro-data files for 2011; all ages, in private households, analysis by authors.

We can see the differences between Travellers and non-Travellers more clearly if we focus on a narrower age range (35-54 years), as we do in Figure 5.2. We have removed some of the differences that arise due to the fact that Travellers are much more likely than non-Travellers to be aged 18 years or lower, and much less likely to be 65 years or over?

Figure 5.2 General Health of Travellers and Other Adults, 35-54 Years, 2011

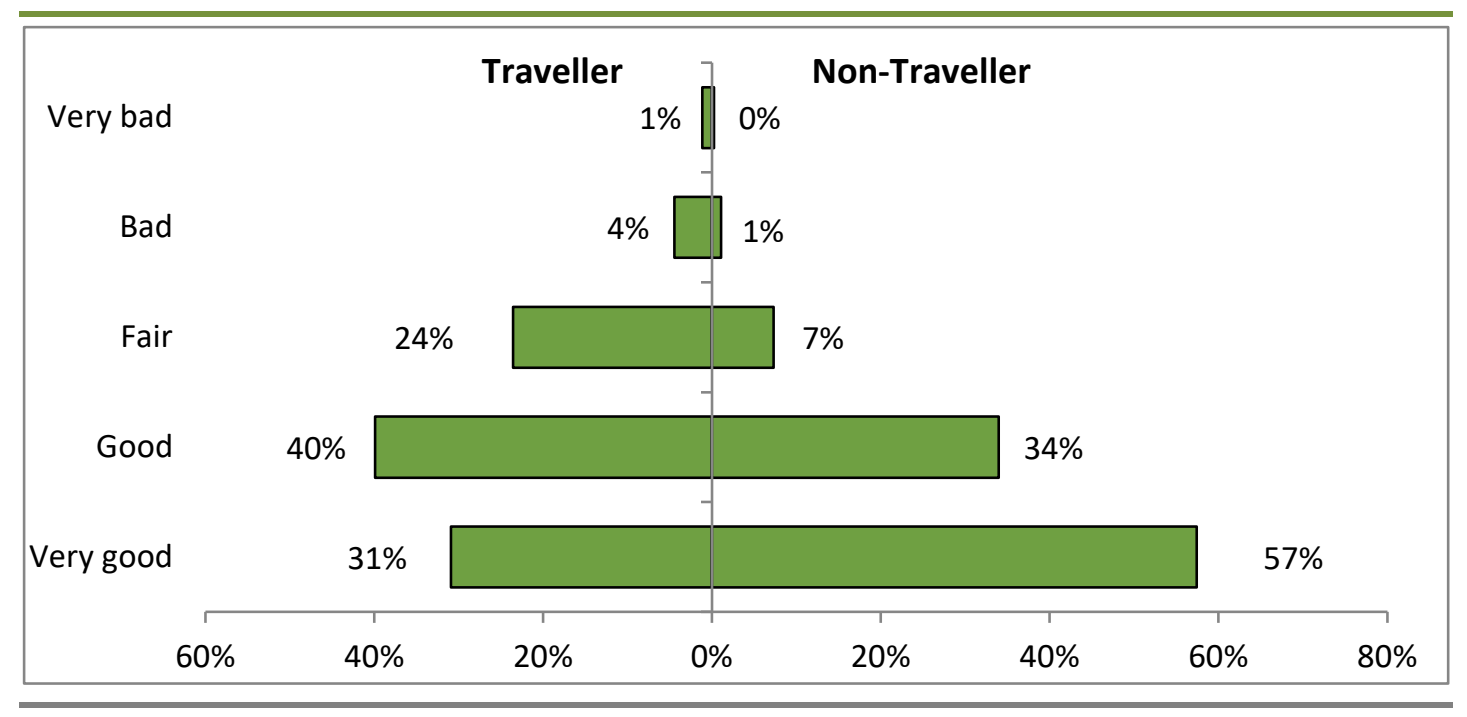

Source: Census of population micro-data files for 2011; persons aged 35-54 years, in private households, analysis by authors. 
The differences between the two groups are clearer: 57 per cent of nonTravellers have health that is 'very good' compared to only 31 per cent among Travellers. At the other end of the scale, 29 per cent of Travellers in this age group have health that is described as 'fair', 'bad' or 'very bad' compared to only 8 per cent of non-Travellers.

\subsection{NATURE OF HEALTH PROBLEMS}

In this section, we compare the nature of the health problems reported by Travellers in the AITHS to those reported by the general population in the 2007 Survey of Lifestyle, Attitudes and Nutrition (SLÁN).

Results from the AITHS data are compared with published results from the SLÁN report (Morgan et al., 2008), including the analyses of that data in One Island - One Lifestyle? (Ward et al., 2009), Smoking Patterns in Ireland (Brugha et al., 2009), Dietary Habits of the Irish Population (Harrington et al., 2008) and Alcohol Use in Ireland (Morgan et al., 2009).

The SLÁN survey provides data on the general health, health behaviours and health service use of adults aged 18 years or over living in Ireland. The study, conducted in 2007, was the third of its kind and used face-toface interviews with adults, interviewed in their home (the previous two studies in 1998 and 2002 used postal questionnaires). It was also weighted to adjust for groups that are typically underrepresented in surveys; for example, men and younger, single adults (Morgan et al., 2008).

The comparison of estimates presented here is tentative due to differences between the design of SLÁN 2007, which is a survey of a representative sample of the population, and AITHS 2008, which is a health survey of randomly chosen adults from the Traveller population. In the AITHS, adults were only chosen to take part in the 'adult health survey' if they had no children who were eligible to complete the 'child health survey' - i.e. aged five, nine or 14 years. This means that although adults were chosen randomly, no parents with children of the specified ages would have been included. There are other differences between these two studies, including the order and wording of questions and variation in the response categories. These differences are noted where relevant and caution should be exercised when interpreting the results. Nonetheless, the results presented here are illustrative of the potential value in further investigating the nature of health differences between the Traveller and general population in Ireland.

Both surveys included a question on chronic illness. The questionnaire for the SLÁN study asked, 
'Have you had any of the following in the last 12 months?' This was followed by a list of health conditions. After this came the supplementary question: 'If yes, was this condition diagnosed by a doctor?' (Morgan et al., 2008).

However, the reported results relate only to the initial part of the question. The AITHS asked,

'In the last 12 months, has a doctor diagnosed that you have any of the following?' A list of health conditions followed.

Table 5.1 shows the percentage of self-reported chronic illnesses in the SLÁN population and general practitioner (GP) diagnosed chronic illnesses for the AITHS respondents. Only those illnesses that were listed on both questionnaires are included. It shows that, Apart from cancer, Travellers more often report each kind of chronic illness. The difference is substantial in some cases: 13-14 percentage points for urinary/bladder problems and back conditions; 8 percentage points for reported chronic bronchitis and 6 percentage points for asthma. Further analysis shows that, overall, 38 per cent of respondents reported at least one chronic illness in the SLÁN survey, with a higher rate for women than men (40 per cent compared to 35 per cent). By contrast, 59 per cent of Travellers reported at least one chronic illness, with a gender pattern similar to that of the general population - 61 per cent of women compared to 56 per cent of men (Morgan et al., 2008; authors' analysis of AITHS data).

Table 5.1 Percentage of Adults Reporting Different Types of Chronic Illness

\begin{tabular}{|l|c|c|}
\hline Chronic illness in last $\mathbf{1 2}$ months & $\begin{array}{c}\text { General population } \\
\text { (SLÁN, self-report) }\end{array}$ & $\begin{array}{c}\text { Travellers (AITHS, } \\
\text { doctor-diagnosed) }\end{array}$ \\
\hline Back condition & $16 \%$ & $29 \%$ \\
\hline Asthma & $6 \%$ & $12 \%$ \\
\hline Osteoarthritis / Rheumatoid arthritis & $11 \%$ & $12 \%$ \\
\hline Diabetes & $3 \%$ & $6 \%$ \\
\hline Urinary/bladder problems & $3 \%$ & $17 \%$ \\
\hline Chronic bronchitis & $3 \%$ & $11 \%$ \\
\hline Angina & $2 \%$ & $4 \%$ \\
\hline Cancer & $1 \%$ & $1 \%$ \\
\hline Heart attack & $<1 \%$ & $2 \%$ \\
\hline Stroke & $<1 \%$ & $1 \%$ \\
\hline Other & $4 \%$ & $13 \%$ \\
\hline
\end{tabular}

Note: $\quad$ This table shows the percentage of self-reported chronic illnesses in the SLÁN population and general practitioner (GP) diagnosed chronic illnesses for the AITHS respondents. Only those illnesses that were listed on both questionnaires are included.

Source: Morgan et al., 2008, p. 37; AITHS data, analysis by authors. SLÁN n=10,184; AITHS $n=1,610$. Based on sample sizes and allowing for design effects, the differences are statistically significant for back condition, asthma, diabetes, urinary/bladder problems, chronic bronchitis, angina and 'other' problems. 


\subsection{HEALTH SERVICE USAGE}

Both the SLÁN and AITHS studies asked respondents about the frequency of visits to their GP and about usage of hospital services.

The SLÁN questionnaire asked, 'When was the last time you consulted a GP or family doctor for your own health or health related needs?'

The AITHS questionnaire asked, 'Which, if any, of the following services have you used in the last 12 months?' The list of services included GP.

Overall, 74 per cent of SLÁN respondents had attended their GP between one and 12 months prior to the interview. A similar but slightly higher proportion of AITHS participants reported attending a GP in the previous 12 months (77 per cent).

Figure 5.3 Percentage Visiting a GP in the Past 12 Months by Whether Traveller and Age Group

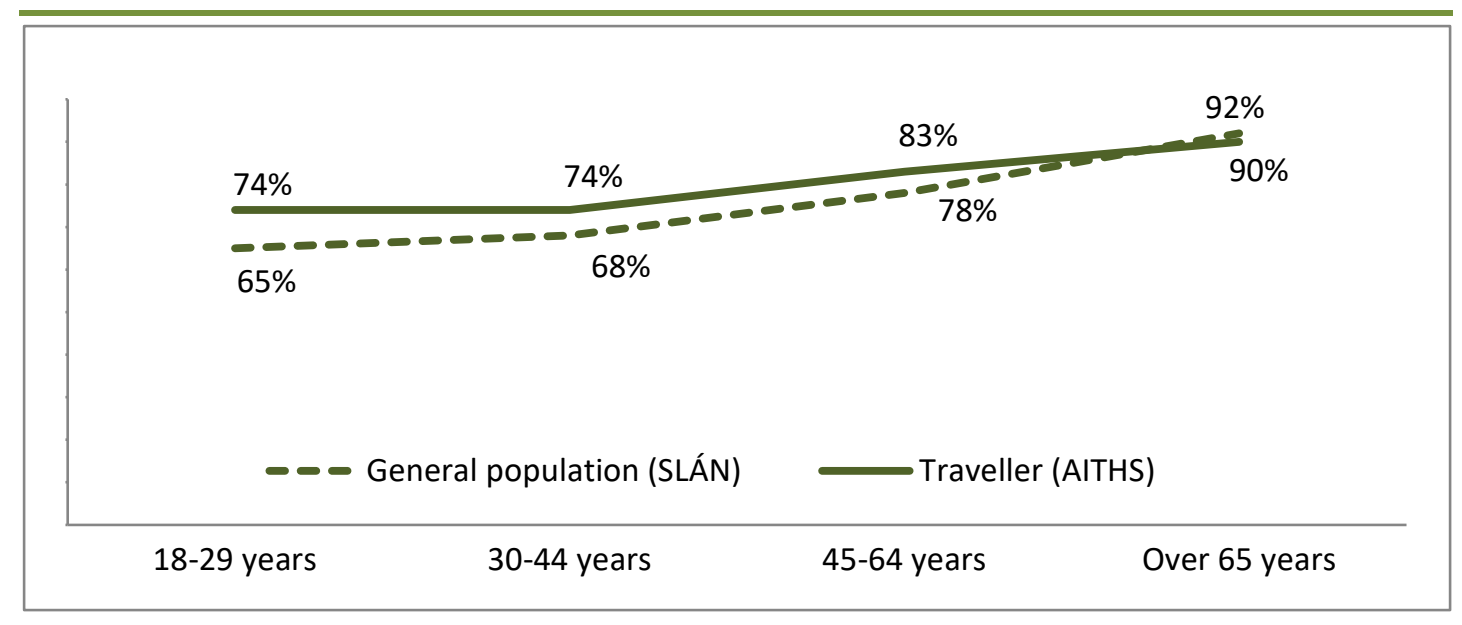

Source: Ward et al., 2009, p. 31; AlTHS data, analysis by authors. SLÁN n=10,256; AITHS $n=1,656$. Given the sample size and allowing for the design effects, the differences are statistically in the 18-29 and 30-44 age groups but not in the older age groups.

In the SLÁN survey, a higher percentage of women (80 per cent) reported attendance in the previous 12 months compared to men (67 per cent) (Ward et al., 2009). While the same pattern is found in the AITHS study, the gap is slightly narrower (79 per cent of women and 73 per cent of men).

Overall then, GP attendance rates are quite high for both groups and the rates are higher for women than for men. But the sizeable gender difference in attendance that was found in the general population is less marked among Travellers.

There is a pattern of increased usage of GP services with increasing age in both populations. However, there is a steadier rise in GP usage by age in the SLÁN population, as shown by the dashed line in Figure 5.3. This 
reflects the fact that GP usage among the Traveller population begins and remains relatively high, regardless of age. The difference is statistically significant in the 18-29 and 30-44 age groups, with a higher GP visiting rate among Travellers, except the older two age groups.

Both the SLÁN and AITHS studies also have data on hospital usage. The SLÁN questionnaire asked, 'During the past 12 months, have you been in hospital as an in-patient, that is overnight or longer, or for a day procedure?' In-patient and day procedures were recorded separately. The AITHS questionnaire asked, 'Which, if any, of the following services have you used in the last 12 months?' The options listed included 'hospital as an in-patient ("KEPT IN")' and 'hospital as a day patient ("IN BED FOR A DAY")'.

In total, 10 per cent of respondents in the SLÁN survey reported that they had been in hospital during the previous 12 months as an in-patient (Ward et al., 2009), while more than twice this number (26 per cent) of Travellers reported having been a hospital in-patient (authors' analysis of AITHS data). More females reported in-patient hospital stays compared to males in the SLÁN study (9 per cent of men and 11 per cent of women) while a higher number of men were hospital in-patients in the AITHS (27 per cent of men compared to 25 per cent of women). When this information is analysed by age band, a much sharper increase in the over 65 -year age band is noticeable among the Traveller population compared to the general population.

\subsection{DISABILITY OF TRAVELLERS AND NON-TRAVELLERS}

Census 2011 had two questions on disability; these related to having one or more of a range of long-lasting conditions and the impact of this on daily activities. These questions are shown in Figure 5.4, while Figure 5.5 shows responses for Travellers and non-Travellers aged 35-54 years. As above, by focusing on a narrower age range, we are removing some of the age patterns that would distort the comparison due to the fact that Travellers, on average, are younger than non-Travellers. 
16. Do you have any of the following long-lasting conditions or difficulties?

(a) Blindness or a serious vision impairment;

(b) Deafness or a serious hearing impairment;

(c) A difficulty with basic physical activities such as walking, climbing stairs, reaching, lifting or carrying;

(d) An intellectual disability;

(e) A difficulty with learning, remembering or concentrating;

(f) A psychological or emotional condition;

(g) A difficulty with pain, breathing, or any other chronic illness or condition.

17. If 'Yes' to any of the categories specified in Question 16, do you have any difficulty in doing any of the following?

(a) Dressing, bathing or getting around inside the home;

(b) Going outside the home alone to shop or visit a doctor's surgery;

(c) Working at a job or business or attending school or college;

(d) Participating in other activities, for example leisure or using transport.

Source: Census of population micro-data files for 2011, Questions 16 and 17.

In Figure 5.5, the disadvantage experienced by Travellers is very clear:

they are nearly three times as likely as non-Travellers in the 35-54 age group to experience any difficulty or disability (31 per cent versus 11 per cent). The differences in risk are apparent across all disability types and across all the different kinds of difficulty. In total, 9 per cent of Travellers aged 35-54 years have a psychological or emotional disability, compared to 3 per cent of their non-Traveller counterparts. There is a similar difference in the rate of having mobility limitations with the figure for Travellers more than three times higher than that for nonTravellers (13 per cent versus 4 per cent).

Figure 5.4 Disability or Difficulty with Everyday Activities by Whether Traveller, 35-54 Years

\begin{tabular}{|c|c|c|c|c|}
\hline & & & Traveller & Non-Traveller \\
\hline \multirow{7}{*}{ 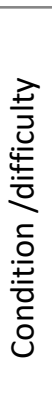 } & \multicolumn{2}{|l|}{ Blindness } & $2 \%$ & $1 \%$ \\
\hline & \multicolumn{2}{|l|}{ Deafness } & $3 \%$ & $1 \%$ \\
\hline & \multicolumn{2}{|l|}{ Mobility limitation } & $13 \%[$ & $4 \%$ \\
\hline & \multicolumn{2}{|l|}{ Intellectual disability } & $5 \%$ & $1 \%$ \\
\hline & \multicolumn{2}{|l|}{ Learning disability } & $10 \%[$ & $2 \%$ \\
\hline & \multicolumn{2}{|l|}{ Psychological/emotional disability } & $9 \%$ & $3 \%$ \\
\hline & \multicolumn{2}{|l|}{ Other disability } & $15 \%$ & $6 \%$ \\
\hline \multirow{5}{*}{ 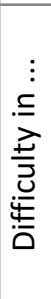 } & Dressing, bathing & & $5 \%$ & $1 \%$ \\
\hline & Going outside & & $7 \%$ & $2 \%$ \\
\hline & Attending work, school etc. & & $11 \%$ & $4 \%$ \\
\hline & Other difficulty & \multirow[b]{2}{*}{$31 \%$} & $9 \%$ & $3 \%$ \\
\hline & Any condition or difficulty & & & $11 \%$ \\
\hline
\end{tabular}

Source: Census of population micro-data for 2011, analysis by authors. 
There is a slightly different indicator of health-related activity limitations available in both the AITHS and SLÁN studies. The following question was asked in both surveys:

'Is your daily activity [or work, in AITHS] limited by a long term illness, health problem or disability?'

There were different response categories between the two surveys; in SLÁN responses were limited to 'yes' or 'no', while in the AITHS a third response was offered: 'do not have any of the above'. This differs from the census question on disability by specifically mentioning 'health'; a disability is not necessarily going to be seen as a 'health' condition. In addition, it does not mention the range of conditions or difficulties included in the census question.

The SLÁN survey found that 11 per cent of the general population reported that their daily activity was limited by a long-term illness, health problem or disability (Morgan et al., 2008); however, our analysis of the AITHS data shows that 16 per cent of Travellers report limited activity due to illness or disability. When the age band is limited to $35-54$ years as above, to compensate for the younger profile of Travellers, the AITHS data shows that 25 per cent of Travellers in this age range report that their daily activities are limited by illness or disability.

Both surveys show that more men than women report limited daily activity, but the gap is larger for Travellers (19 per cent of Traveller men versus 14 per cent of Traveller women) than in the general population (11 per cent and 10 per cent, respectively). Analysis of these data by age shows sharper increases among Travellers in the prevalence of limitations with increasing age, as shown in Figure 5.6. 
Figure 5.5 Daily Activities Limited by Illness, Health Problem or Disability, by Whether Traveller

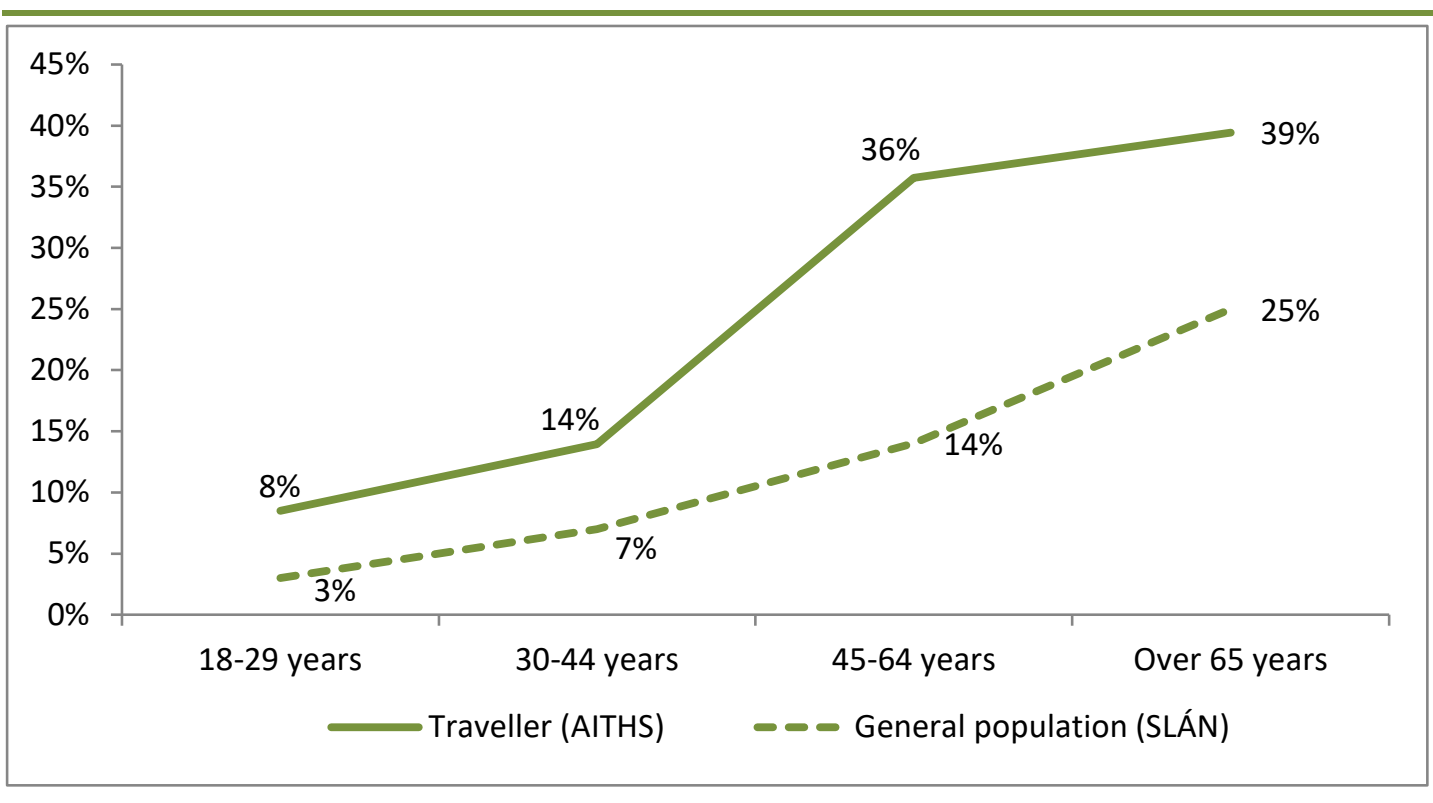

Source: Morgan et al., 2008, p. 35.; AITHS, analysis by authors. SLÁN $n=10,526 ;$ AITHS $n=1622$. Given the sample sizes and allowing for design effects, the differences between Travellers and the general population are statistically significant in all age groups.

\subsection{FACTORS ASSOCIATED WITH POOR HEALTH}

We have seen that age is a very important factor in accounting for health differences in the population and that if we do not take account of the age differences between Travellers and the general population, the two groups appear more similar than they really are in terms of health status. We now turn to an examination of the association between a number of factors and poor health. Our goal here is to examine whether differences in health in the Traveller population follow a similar pattern by age and other characteristics to that found in the general population. As in previous chapters, we include gender and marital status, level of education and region. We also examine whether there are differences in the prevalence of poor health by accommodation type (standard permanent housing, such as a house or apartment, compared to temporary housing such as a caravan or mobile home) and by whether the accommodation is overcrowded. Figure 5.7 presents the adjusted percentages with poor health - that is, health that is fair, bad or very bad. These percentages are adjusted for all of the other characteristics in the analysis so that when we look at differences by age, for instance, we are looking at the age differences in health that we would expect to see if the two groups were similar in terms of gender, marital status, education, region and housing. The adjusted percentages shown in Figure 5.7 are based on statistical model 4 in Table A5.1 (appendix).

Poor health is more common among single or formerly married people than among those who are married. It is also more common among older 
than younger people; and among those with lower levels of education and those living in a caravan or mobile home.

Figure 5.6 Adjusted Percentage with Poor Health, 2011

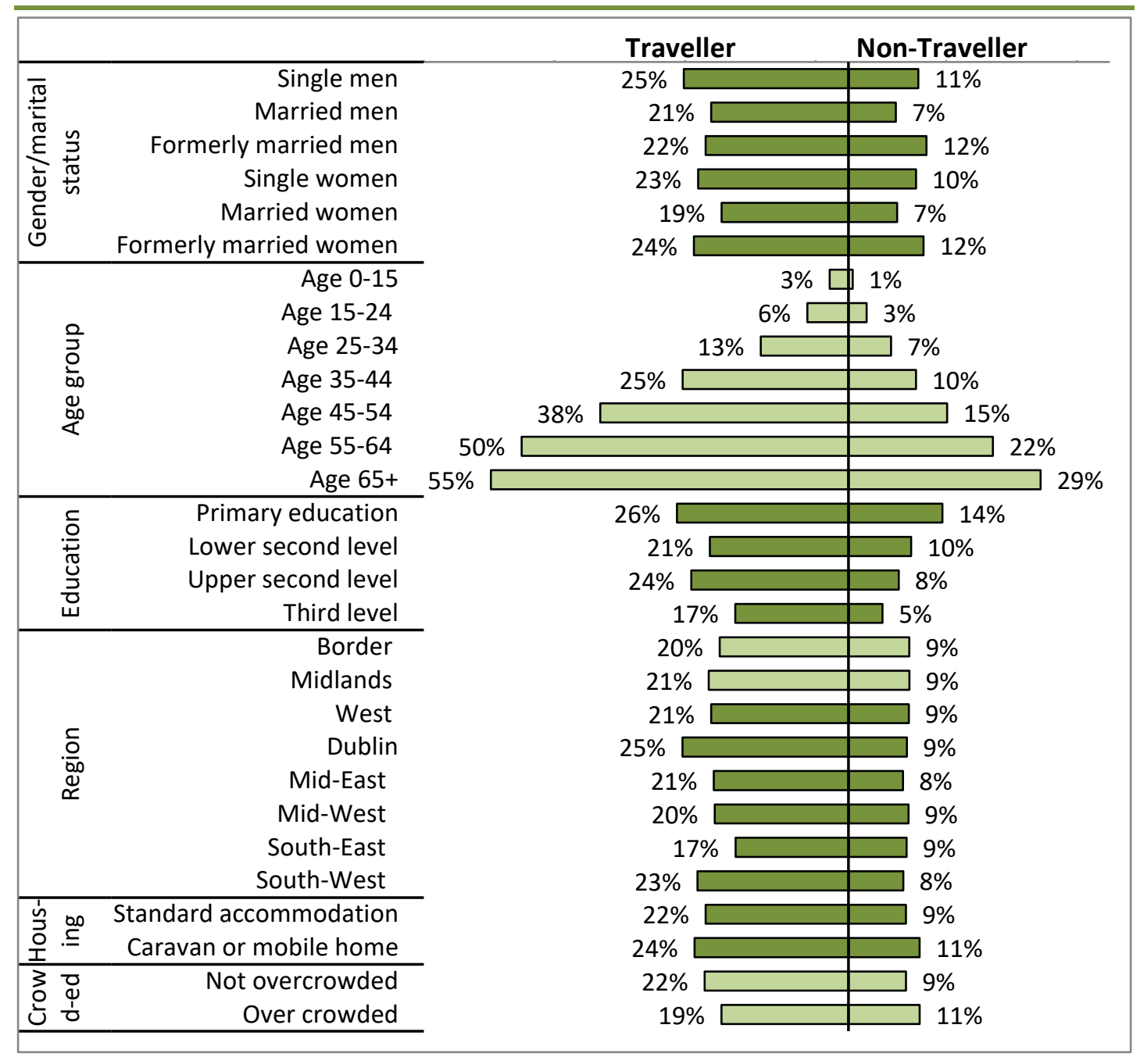

Source: Census of population 2011 micro-data analysis by authors. Based on statistical model 4 in Table A5.1 (appendix).

The increase in poor health with age is sharper for Travellers, however. This can be seen more clearly in Figure 5.8. At all ages, Travellers are more likely than non-Travellers to experience poor health. There is a sharper increase in poor health with age for Travellers, especially between 35 and 64 years. As a result, the gap in poor health between Travellers and nonTravellers is smaller in childhood and early adulthood but increases very rapidly after 35 years. This pattern of an increasing gap with age has also been found for other minority ethnic groups (see, for example, Ferraro, Farmer and Wybraniec, 1997; Heiss, Venti and Wise, 2014). This parallels the gap between the two populations, shown in Figure 5.6 (drawing on AITHS and SLÁN), regarding limitations on activities. 
Figure 5.7 Adjusted Percentage with Poor Health by Age Group, 2011

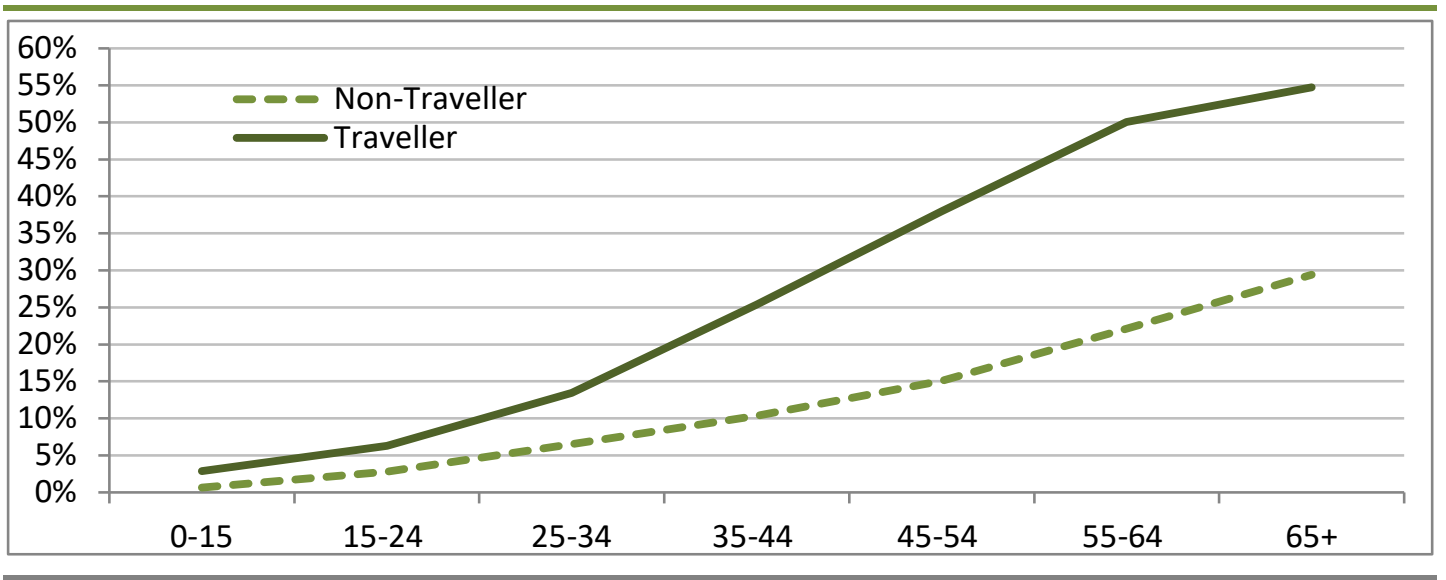

Source: Census of population micro-data files for 2011 analysis by author, from model 4 in Table A5.1 (appendix).

The increasing health disadvantage as the life course progresses is a characteristic of cumulative disadvantage, a process whereby early experiences shape trajectories in the long-term, with the effects accumulating over the life course, resulting in a larger gap in later life (Elder, 1985). The gap shown in Figure 5.8 is even more striking when we remember the higher mortality rate of Travellers; those still living in the older age groups are a healthier subgroup than the entire cohort.

Returning to Figure 5.7, we see that there is more regional variation in the health of Travellers (with age and other characteristics held constant) than for the general population. Travellers in Dublin (adjusted percentage is 25 per cent) and in the South-West (23 per cent) are more likely to report poor health than those living elsewhere. The lowest reported rates of poor health among Travellers are found in the South-East (17 per cent). The regional variation for the non-Traveller population is very slight once we remove the influence of age and other characteristics, ranging from 8 to 9 per cent.

We might expect that living in a caravan or mobile home would be associated with poor health, since this type of accommodation is less likely to have facilities such as hot water or central heating, as noted in the previous chapter. The results in Figure 5.7 show that, with other characteristics controlled, the relationship is in the expected direction for both Travellers and non-Travellers, although the effect is not large: for both groups, the incidence of poor health is increased by two percentage points among those living in a caravan/mobile home compared to standard housing. Although the proportion of non-Travellers living in a caravan or mobile home is very low (less than 1 per cent as we saw in Figure 4.1), it is associated with an increase in poor health for this group, as well as for Travellers. 
Among non-Travellers, we find a similar, plausible pattern for overcrowding, with a higher prevalence of poor health for those living in overcrowded accommodation. This relationship is absent for Travellers, however; in fact, there is a slightly lower prevalence of poor health in overcrowded accommodation (19 per cent versus 22 per cent). Overcrowded accommodation may have a negative impact on health, but this finding may mean that those with bad health apply for accommodation that is not overcrowded. An alternative explanation is that living within a large family group may come with added social supports, which can have a positive impact on health.

\subsection{HEALTH-RELATED BEHAVIOUR OF TRAVELLERS AND NON- TRAVELLERS}

Diet and the use of tobacco and alcohol are well recognised as important factors, among others, in influencing health outcomes. This section compares the health behaviour of Travellers and the general population using these indicators. Results are reported in Figure 5.9.

Rates of current tobacco smoking among both populations were determined using the following question formats:

'Have you yourself smoked at least 100 cigarettes in your entire life? (If yes) Do you now smoke every day, some days, or not at all?' (SLÁN)

'Do you smoke cigarettes now?' (Yes, regularly / Yes, occasionally / No) (AITHS)

Our analysis found that 50 per cent of Travellers, compared to only 29 per cent of other respondents, reported being current smokers (Brugha et al., 2009). When analysis is confined to the $35-54$ year age group, as above, the proportion of current smokers among Travellers rises to 54 per cent.

In both populations, the rate of smoking declined with age, albeit more sharply among the general population, where the rate was higher for men (31 per cent) than for women (27 per cent). However, the gender difference was not statistically significant among Travellers, at 51 per cent of men and 49 per cent of women.

Diet also has an important influence on health. Current healthy eating guidelines advocate limiting the intake of fatty foods. ${ }^{16}$ In both surveys, the following question was asked:

${ }^{16}$ See http://www.safefood.eu/Healthy-Eating/What-is-a-balanced-diet/The-Food-Pyramid.aspx 


\section{'How often do you eat fried food?'}

The percentage of respondents who reported consuming fried foods more than four times per week was 9 per cent among the general population (Harrington et al., 2008), but over three times this figure among Travellers (29 per cent; authors' analysis of AITHS data). In both populations, a higher percentage of men reported consuming fried foods on more than four occasions per week when compared to women; 14 per cent of men compared to 6 per cent of women in the general population and 36 per cent of men compared to 24 per cent of women in the Traveller population.

Figure 5.8 Smoking, Consumption of Fried Food and Use of Alcohol by Whether Traveller

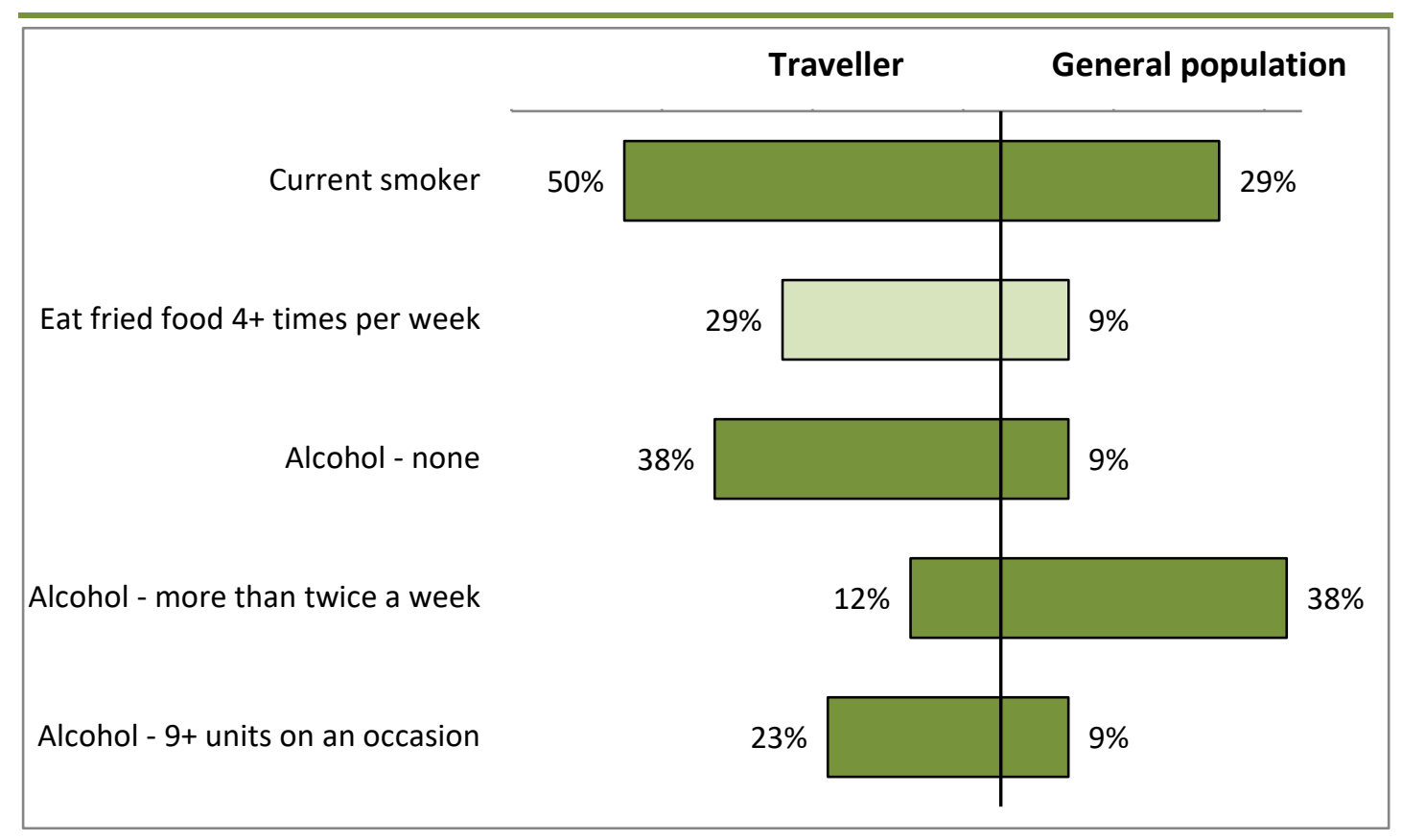

Source: Brugha et al., 2009, p. 5; Harrington et al., 2008, p. 59; Morgan et al., 2009, p. 12; and AITHS data, analysis by authors. SLÁN $n=10,313$ and 7,736 for alcohol use; AITHS $n=981-1,655$. Given the sample sizes, and allowing for design effects, the differences between Travellers and the general population are statistically significant.

Both surveys used the same question format to establish frequency of alcohol consumption:

\section{'How often do you have a drink containing alcohol?'}

Our analysis of the AITHS data found that Travellers are much more likely to report never drinking alcohol compared to the general population, as reported in Morgan et al. (2009): 38 per cent compared to 19 per cent. In addition, Travellers are much less likely to report drinking alcohol more than twice a week (12\% compared to $38 \%$ ). Analysis by gender showed that the less frequent and non-use of alcohol among Travellers is mainly 
driven by Traveller women (see Figure 5.10). In both populations, the proportion of those who report never drinking alcohol increases with age, although a relatively high percentage of 18-24-year-old Travellers also report never drinking alcohol.

A follow-up question on both surveys, using slightly different formats, was designed to determine the typical amount of alcohol consumed on a drinking occasion:

\section{'How many drinks containing alcohol do you have on a typical day when you are drinking?' (SLÁN)'How much alcohol would you normally consume on average?' (AITHS)}

Despite reporting less frequent alcohol use, analysis of the follow-up question about the amount of alcohol taken on a typical occasion finds that Travellers are more likely to consume a larger number of alcoholic drinks at one time. For example, only 14 per cent of the general population report consuming more than nine standard drinks on a typical drinking occasion (Morgan et al., 2009), compared to 23 per cent of Travellers. Men are more likely to consume more than nine standard drinks than women in both surveys ( 23 per cent of men and 4 per cent of women in the general population and 34 per cent of men compared to 14 per cent of women among Travellers). However, the steep decline with age, after age 30 , in consumption of more than nine standard units of alcohol seen in the general population is not reflected in the Traveller population (see Figure 5.11). There is, however, a sharp decline among Travellers over age 65 who drink nine or more units at a time.

Figure 5.9 Frequency of Alcohol Consumption by Gender among Travellers and Non-Travellers

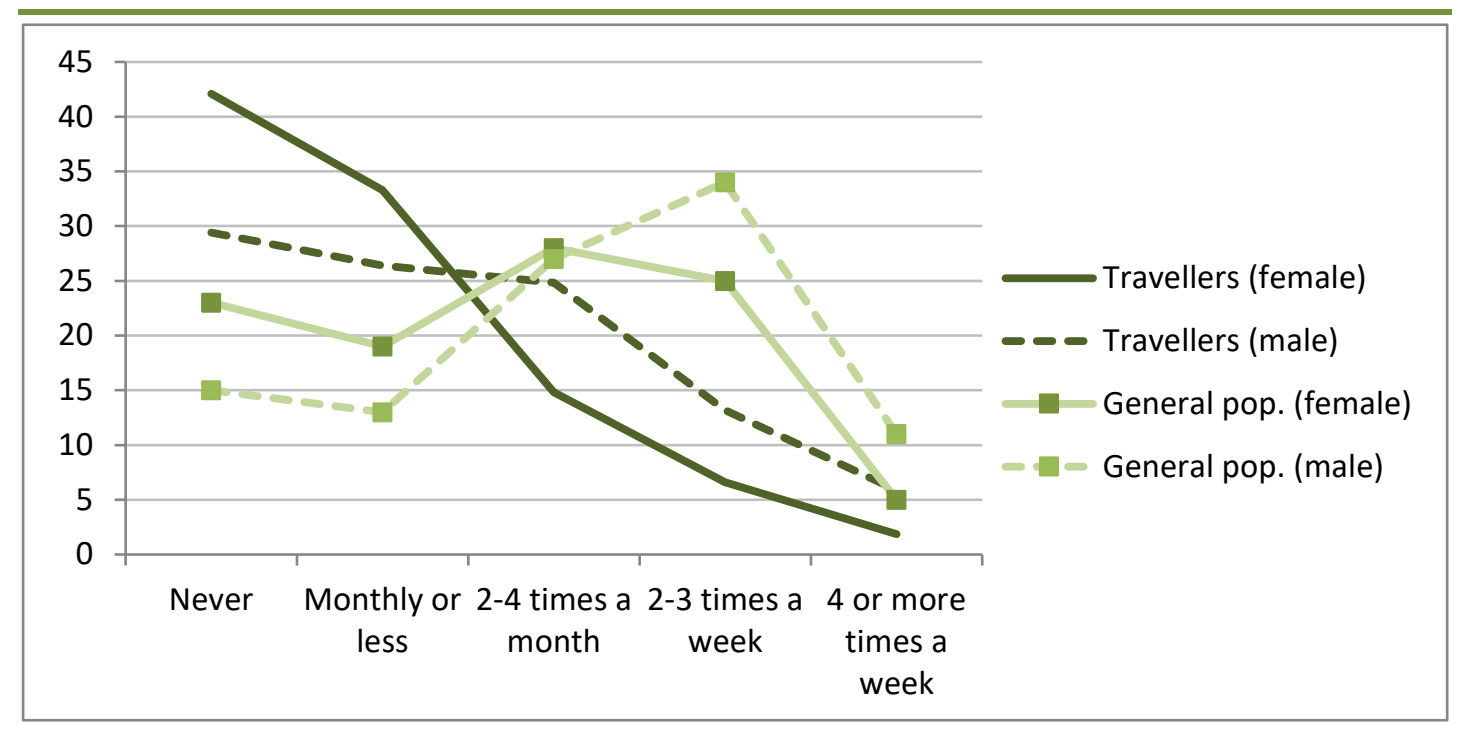

Source: Morgan et al., 2009, p. 10; AITHS data, analysis by authors. SLÁN $n=10,313 ;$ AITHS $n=1,650$. Given the sample size and allowing for design effects, the maximum margin of error is about 2 per cent for male and female Travellers and 5.6 per cent for males and females in the general population. 
Figure 5.10 Typically Consuming more than Nine Units of Alcohol by Whether Traveller

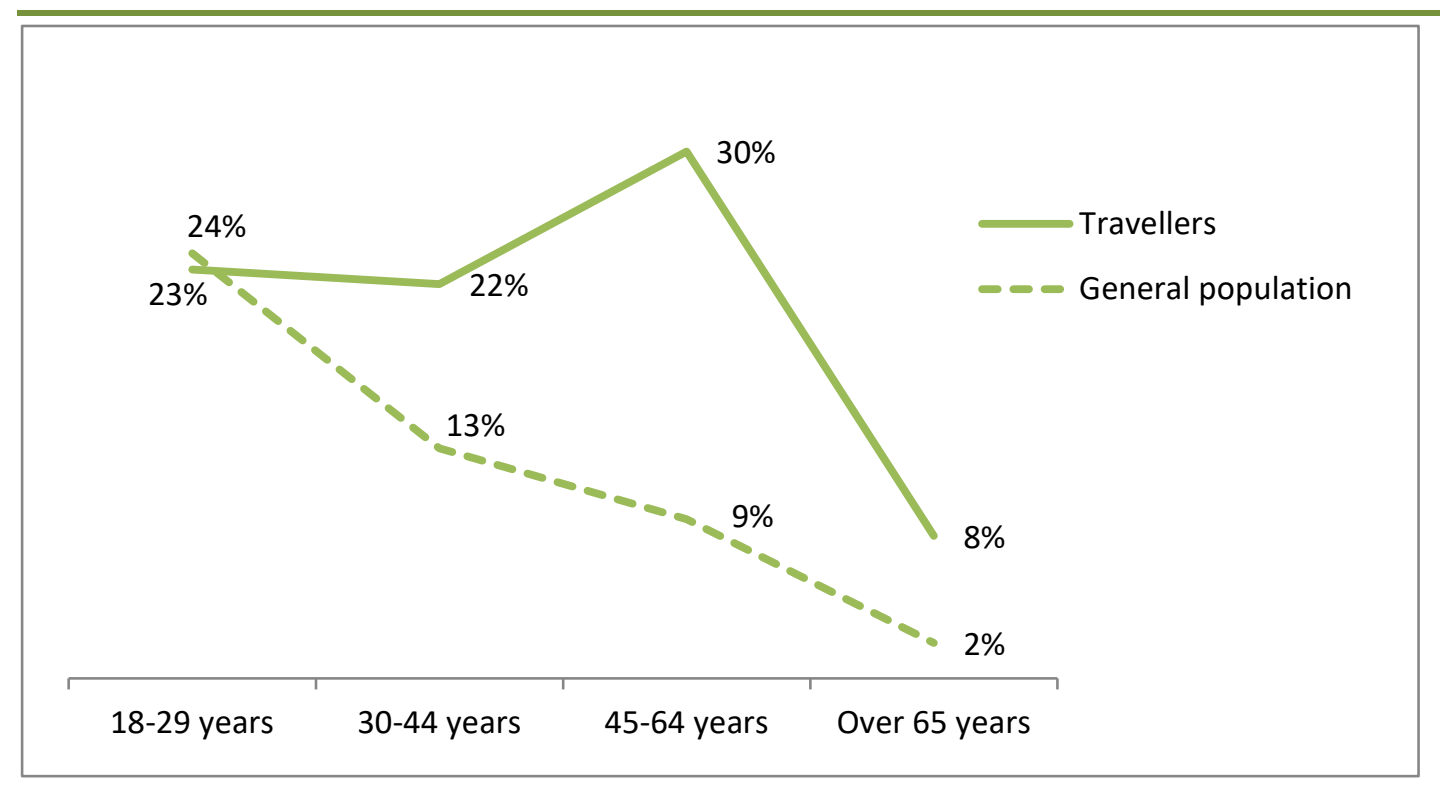

Source: SLAN survey, Morgan et al., 2009, p. 12; AITHS data, analysis by authors. SLÁN n=7,736; AITHS $n=981$. Given the sample size and allowing for design effects, the maximum margin for error for Travellers is about 4 per cent and the maximum for the general population is about 1.4 per cent.

\subsection{SUMMARY}

In this chapter, we examined the rates of poor health and disability among Travellers and non-Travellers, drawing mainly on Census 2011. We saw the importance of taking into account age differences when comparing the two groups, because of the strong association between health and age. When we compare Travellers and non-Travellers in the 35-54 age group, we see that Travellers are about three times as likely to have poor health or some type of difficulty or disability. The statistical model showed that there were some differences in the patterns of poor health between Travellers and non-Travellers. In particular, there was a sharper rise with age in poor health among Travellers, especially between the ages of 35 and 64 years. There was also more regional variation in the prevalence of poor health among Travellers, with higher rates in Dublin and the South-West than in the South-East. As with all regional patterns, it is worth noting that this refers to the region where people currently live, rather than the region where they lived at the time they first became ill.

Men and women are quite similar in terms of the prevalence of poor health, with other characteristics controlled, and this is true of Travellers as well as non-Travellers. GP attendance rates are quite high and the rates are higher for women than for men, but the sizeable gender difference in attendance found in the general population is less marked among Travellers. In the general population, somewhat more women than men 
reported being a hospital in-patient in the previous 12 months, while there was almost no gender difference among Travellers. In terms of health-related behaviour, women are more likely than men to report never drinking or infrequent drinking (monthly or less often), but the gender gap in never drinking is larger for Travellers than for the general population. 


\section{Chapter 6}

\section{Conclusions and Implications}

\subsection{INTRODUCTION}

In this chapter, we draw together the findings of the study in order to answer the research questions and explore the implications for policy. We began this research project against the background of research evidence on the extreme disadvantage of Travellers in a number of life domains - education, employment, housing and health. Travellers have also faced high levels of prejudice and discrimination in Ireland (MacGréil's work, 2010 and 2011). By analysing a very large dataset, the census of population for 2011, we sought to add to this body of knowledge by systematically testing whether the disadvantage experienced by Travellers tends to cumulate across domains or is driven by their disadvantage in one domain, such as education. This accumulation of the effects across domains and across the life course is cumulative disadvantage and it would be expected to result in a larger gap between Travellers and non-Travellers later in life.

We also sought to understand whether the variations in disadvantage among Travellers follow a similar pattern to the variations in disadvantage in the general population. If the patterns are different, then this would signal that some subgroups of Travellers are more disadvantaged than non-Travellers, which could have important implications for understanding the factors that exacerbate or ameliorate their disadvantage. These findings have implications for how policy might be designed to improve the lives of Travellers.

The research findings are considered in the four domains of education, employment, housing and health, followed by an exploration of the implications of these findings.

\subsection{EDUCATION}

Chapter two focused on how the educational attainment of Travellers compared to that of the general population and whether educational variations by gender, age group and region were similar to those of the non-Traveller population. This analysis focused on adults aged 25-64 years. The differences between Travellers and non-Travellers were dramatic: 78 per cent of Travellers had completed no more than primary 
education compared to 10 per cent of non-Travellers. At the other end of the educational scale, only 1 per cent of Travellers had a degree or higher, compared to 30 per cent of non-Travellers.

The odds of leaving school without having completed second level (the Leaving Certificate or equivalent) were 33 times higher for Travellers than for non-Travellers. When we take account of the fact that Travellers are younger than the general population, and that younger adults tend to stay longer in education than their older counterparts, the odds are over 50 times higher for Travellers than non-Travellers. In other words, compared to non-Travellers, Travellers are over 50 times more likely to leave school without the Leaving Certificate or equivalent than we would expect based on their age distribution and other characteristics.

The adjusted percentage of people who leave school without completing second level takes account of differences in age profile. This figure was 95 per cent for Traveller men and 92 per cent for Traveller women, compared to 30 per cent for men and 24 per cent women among nonTravellers. For both groups, males were more likely than females to leave school without completing second level, but the gender gap was less noticeable among the Traveller population.

The age pattern also differed between Travellers and non-Travellers. For both groups, the percentage leaving before the end of second level increased with age, because the older cohorts were more likely to have left school at an earlier age. However, the age pattern is much stronger for the non-Traveller population, where we see 14 per cent of those aged 25-34 years leaving before the end of second level, compared to 49 per cent aged 55-54 years. The corresponding figures for Travellers are 91 per cent and 97 per cent, respectively. As a result, the education gap is more marked for the younger cohort of Travellers than for the older cohort. Travellers have benefitted much less than non-Travellers from the general increase in educational level that began in the 1960 s.

There are some regional differences in the percentage of non-Travellers who had left school before the end of second level, with the highest percentages leaving early in the Border (34 per cent), Midlands (31 per cent) and South-East (31 per cent) regions and the lowest figure in the West ( 25 per cent) and Dublin ( 24 per cent). It should be noted that these figures relate to the regions where respondents lived at the time of the survey in question; where they grew up may be different. Many people with higher levels of education are likely to move to urban areas to take up jobs in professions and public service. The rates of early leaving are high for Travellers across all regions, with only small regional differences 
(ranging from 91 per cent in the West and South-West to 96 per cent in Dublin.)

In general, the patterns across age groups suggest that while levels of education improved for Travellers as well as non-Travellers, the improvement happened more slowly for Travellers. As a result, the educational gap has tended to increase over time.

\subsection{EMPLOYMENT}

In chapter three, we turned our attention to the employment situation of the working-age population. We examined the differences between Travellers and non-Travellers, and asked whether the same factors (such as level of education, gender and family status) accounted for differences in employment rates for both groups. In particular, we were interested in how much of the difference between Travellers and non-Travellers in the employment rate could be accounted for by differences in their levels of educational attainment.

Focusing on those aged 25-64 years (to exclude the age group where many are still in education), we found that in 2011 only 11 per cent of Traveller adults were in employment, compared to 66 per cent of nonTravellers. Travellers had a lower labour market participation rate than non-Travellers: 61 per cent of Travellers were participating in the labour market in 2011 (i.e. either at work or unemployed), compared to 79 per cent of non-Travellers. About one half of Traveller adults identified their main status as 'unemployed', compared to a figure of 14 per cent for nonTravellers.

We used a statistical model to estimate the importance of differences in the level of education in accounting for the employment gap between Travellers and non-Travellers. For the statistical model, we focused on those aged 15-64 years, but excluded students. Overall, before taking account of other characteristics, Travellers were about 19 times more likely than non-Travellers to not be at work. The gap grows to Travellers being 22 times more likely to not be at work when we adjust for age, because Travellers tend to be younger and younger adults have a higher labour market participation rate than older adults. When we control for differences in level of education, the odds ratio is substantially reduced; it falls to Travellers being nine times more likely to not be at work. This suggests that nearly two-thirds of the gap in employment between Travellers and non-Travellers is accounted for by educational disadvantage. Nevertheless, it is striking that even after taking education 
into account, the odds of not being at work remain nearly nine times higher for Travellers than for non-Travellers.

We asked whether the employment rate for Travellers and non-Travellers was affected in the same way by age, gender, region and level of education.

The strongest predictor of being at work was level of education. The adjusted percentage at work increased even more sharply by level of education for Travellers than non-Travellers, but even at degree-level education, the adjusted percentage at work was only 57 per cent for Travellers compared to 80 per cent for non-Travellers. Marital status, gender and the presence of children had more of an impact on the employment levels of non-Travellers than of Travellers. In addition, the fall in employment levels after age 55 was not as marked for Travellers as for non-Travellers. Regional differences in the employment rate were stronger for Travellers, with the highest adjusted employment rates in Dublin and the Mid-East (38-39 per cent).

Overall, then, the relationship between education and employment was stronger for Travellers than for the general population. This suggests that Travellers may face a bigger penalty for lower levels of education. However, it also shows that increasing levels of education have at least as much impact on the employment levels of Travellers as of nonTravellers.

\subsection{HOUSING}

In examining housing, we saw that along a range of dimensions, the situation of Travellers was less favourable than that of the general population.

In 2011, nearly eight out of ten Travellers lived in a house, while just 5 per cent lived in an apartment and 12 per cent lived in a caravan or other temporary structure. In 4 per cent of cases, the type of accommodation was not stated on the census form.

Travellers are more likely than non-Travellers to live in crowded accommodation, with 56 per cent having more than one person per room compared to just 8 per cent of non-Travellers. Most Travellers had central heating in their accommodation in 2011 and the vast majority of Travellers have access to piped water and are connected to a sewerage scheme. However, the proportion of Travellers lacking these heating and sanitary facilities is higher than it is for the general population, with 2 per cent of Travellers having no piped water and 3 per cent not having a 
sewerage connection. Over three-quarters of Travellers do not have internet access in their accommodation, compared to just 18 per cent of the general population.

Some groups of Travellers are more likely to live in caravans or mobile homes. Those living in such housing are somewhat more likely to: be married; be aged 15-24 years; have lower levels of education; and be living in Dublin or the Mid-West. The regional differences were quite strong and are likely to be related to the type of accommodation made available to Travellers. In Dublin and the Mid-West, for instance, the percentages living in caravans or mobile homes are twice as high as in the Mid-East or West.

\subsection{HEALTH}

All of the evidence points to poorer health among Travellers than the general population. A question on self-rated health was added to Census 2011, which allowed us to compare the responses of Travellers to those of the general population. Most Travellers describe their health as very good (59 per cent) or good ( 28 per cent), with just 12 per cent describing their health as bad or very bad. When compared to non-Travellers, however, and especially when we take account of the fact that Travellers tend to be younger, we can see large differences. Focusing on those in the 35-54 age group, 29 per cent of Travellers have health that is 'fair', 'bad' or 'very bad' compared to only 9 per cent of non-Travellers.

We can compare Travellers to the general population in terms of the type of chronic illness they experience by drawing on the All Ireland Traveller Heath Survey for Travellers and the SLÁN 2007 survey for the general population. The comparison suggests a higher prevalence among Travellers of most of the specific illnesses identified, with the exception of cancer, despite the fact that Travellers tend to be younger. Travellers have a broadly similar rate of having visited a GP in the last 12 months compared to the general population but are about twice as likely to have been hospitalised (26 per cent versus 10 per cent).

Travellers also have a higher rate of disability than the general population. Drawing on questions from Census 2011 on the presence of a long-standing condition or difficulty with everyday activities, we saw that Travellers aged 35-54 years are nearly three times as likely to be affected (31 per cent versus 11 per cent).

We examined the factors associated with poor health for both Travellers and non-Travellers, again using Census 2011 data. For both groups, the biggest differences occurred between age groups, but the increase in ill- 
health with age was steeper for Travellers, especially in the 35-64 years age range. There was also a greater degree of regional variation in the health of Travellers, with those living in Dublin and the South-West reporting poorer health than those living in other regions.

We anticipated that those living in temporary dwellings such as caravans or mobile homes would experience poorer health because of the greater overcrowding and lack of facilities in this type of accommodation. While the pattern was as expected, the difference is small once we take account of overcrowding.

\subsection{LIMITATIONS AND FURTHER RESEARCH}

The present analysis drew largely from Census 2011 data. With census data, we are only able to look at the situation at one point in time. As a result, it is difficult to answer some questions, such as whether poor health leads to a change in accommodation type or accommodation characteristics are associated with poor health. This is also the case when examining regional differences. For instance, if we observe regional differences in levels of education, it is important to keep in mind that the person may have gone to school in a different region.

Another issue to keep in mind when comparing different data sources is the issue of coverage. As noted in chapter one, there appears to have been a big improvement in the self-identification of Travellers on the census form by 2011. This is evident in the 32 per cent increase in the number of Travellers identified. It also appears that Travellers living in conventional housing were more likely to identify themselves, in 2011, as being Travellers. As a result, we need to exercise caution in interpreting any apparent change over time, because the coverage was less complete in 2006. In the future, if the improved coverage of 2011 is maintained into 2016, it should be possible to compare the two data sources in order to assess change over time.

In general, because of the severity of the disadvantage experienced by Travellers across a range of outcomes, adding an ethnic identifier to administrative data should be made a priority so that the circumstances of Travellers can be monitored over time. This is particularly important for Travellers: because of the small size of the group, sample surveys will rarely provide enough cases to permit the group to be identified. This means that the census and administrative data sources are particularly important in monitoring their outcomes and access to state services.

While the census data are useful, they have limitations in terms of the range or depth of coverage of certain topics. For instance, the coverage 
of health is very general and the issue of mental health is touched on only briefly in the context of the disability question. A strong case could be made for a repeat of the All Ireland Traveller Health Study (AITHS) in order to address these and other issues in more depth.

\subsection{IMPLICATIONS}

The findings point to a level of extreme disadvantage experienced by Travellers across the domains of education, employment, housing and health, with evidence of a widening gap in health over the life course. The increasing disadvantage in terms of health as the life course progresses is a characteristic of cumulative disadvantage, a process whereby early adverse experiences shape the long-term trajectory, with the effects accumulating over the life course resulting in a larger gap in later life (Elder, 1985).

A new National Traveller/Roma Inclusion Strategy is being developed currently, under the auspices of the Department of Justice and Equality. Coordinated through a national steering group, it involves consultation with Traveller and Roma representative organisations and will cover the period 2016 to 2020 . The findings reported here have implications for the strategy in a number of areas. Perhaps the most general finding is that improving the situation of Travellers poses a challenge to policy: because of the very great scale of disadvantage and discrimination, is it possible for mainstream policies in the areas of education, employment, housing and health to meet the needs of this very disadvantaged population? If tailored policies are required, how are these to be implemented in a way that respects the cultural identity of Travellers and includes them rather than contributing to their marginalisation? According to Pavee Point, 'policies deemed as "neutral" can lead to indirect discrimination of Travellers and Roma when they impose additional barriers for Travellers and Roma because of their situation' (2014a, p.8). In other words, mainstreaming policies may not always be the best way to achieve inclusion and may have the effect of excluding Travellers by not being sensitive to their special circumstances. The consultation with Traveller organisations that is part of the development of this new strategy will be important in addressing this issue.

The tension between mainstreaming and targeting is reflected in The 10 Common Basic Principles on Roma Inclusion. This seeks to balance explicit but not exclusive targeting in the context of an intercultural approach that avoids assimilation, with the eventual goal of mainstreaming in order to avoid segregation (Pavee Point, 2015). 
The Joint Oireachtas Committee on Justice, Equality and Defence (2014) has recommended the full recognition of Irish Travellers as an ethnic group. This has also been recommended in the Concluding Observations of the Committee on the Elimination of Racial Discrimination (CERD, 2011), since Travellers satisfy the internationally recognised criteria for an ethnic group. This recommendation has not yet been realised. The results reported here do not directly address the issue of recognition of Travellers as an ethnic group; however, the magnitude of the gap between Travellers and non-Travellers across a range of outcomes clearly suggests that something beyond a mainstream policy response is needed. Recognition of Travellers as a distinct ethnic group could provide the basis for such a response. Along with affirming the distinct cultural identity of Travellers, recognition of Traveller ethnic identity would create a positive platform for engagement by Travellers and public authorities together in addressing key issues facing the community on the basis of mutual respect. This recognition would also automatically include Travellers in all state anti-racism and intercultural policies, programmes and actions.

Promoting positive images of Traveller identity will continue to be important, not only to build confidence among Travellers but also to increase the willingness of the general population to include them in their activities.

\subsubsection{Education}

There are very large differences between Travellers and non-Travellers in the level of education completed. The pattern by age suggests that although there have been improvements in Traveller education over time, these improvements have been less rapid than in the general population, so the gap in educational terms has widened. The labour market disadvantage of Travellers is largely linked to this educational disadvantage, although a gap remains even after taking account of education. When Travellers complete higher levels of education, we see a dramatic improvement in their chances of being in employment. Addressing educational disadvantage, then, needs to be a priority.

The tension that exists between the mainstreaming approach and one that tailors policies to the needs of Travellers is likely to be particularly acute in the area of education. While an approach that seeks to meet the needs of individual children has merit in its emphasis on equality of treatment, it ignores the fact that a child's attitude to school is formed in their family and community. Although some Traveller-specific educational and training policies and segregated educational provision may have had unintended negative consequences, there are particular 
challenges faced by Traveller children that point to the need for tailored policies. The depth of educational disadvantage experienced by Travellers means that specific, targeted additional supports will be required in order for them to participate in mainstream education on equal terms. The challenges that need to be addressed include: the intergenerational character of educational disadvantage; larger family size, often living in crowded accommodation, which may reduce the opportunity to study; and discrimination in employment and in wider society, which is likely to undermine educational ambition.

The fact that Traveller parents are likely to be educationally disadvantaged means that they will need support in order to engage with schools and with their children's school work. This is recognised in the Department of Education and Science's recommendations regarding the need to address the educational needs of parents, the need to involve parents in the school life of their children and the proposal to establish a network of Traveller community education workers (DES, 2006). It also has implications for how schools communicate with parents, some of whom may have literacy issues.

In order to combat the negative experiences of Traveller children in schools, teachers and early years' practitioners need to be provided with training on the Traveller and Roma culture, and approaches to embracing intercultural diversity should be a compulsory component of initial education and continuous professional development. Traveller and Roma culture and history should be embedded in the formal curriculum (Harmon, 2015).

After-school study clubs, particularly where they involve parents, are likely to be important to children living in crowded conditions and to be particularly significant for Traveller children. In addition, other afterschool opportunities for participation in extra-curricular activities, such as sport, music, drama and art, could contribute to greater inclusion of Traveller pupils. Cuts in the School Completion Programme between 2008 and 2015 have curtailed after-school and holiday provision and are likely to have had an adverse impact on Traveller students (Smyth et al., 2015a). Given the paid nature of many out-of-school activities, particularly cultural activities, supports for economically vulnerable families, including many Travellers, are particularly important, as such participation is likely to have implications for their longer term cognitive, educational and social development (McCoy, Quail and Smyth, 2012).

School admission policies also need to be scrutinised to ensure they do not discriminate against Travellers. Pavee Point made a number of 
recommendations in this regard, including the need to standardise procedures and deadlines, the need for an appeals process and the need to facilitate transition from primary to post-primary schools (Pavee Point, 2013). The Education (Admission to Schools) Bill 2016, which is due to be enacted in 2017, will go some way to meeting these concerns by explicitly banning discrimination and the use of waiting lists that favour long-term residents of an area; by ensuring that admissions policies are published; and by requiring that schools that are not oversubscribed admit all pupils who apply.

\subsubsection{Employment}

Since low employment levels among Travellers are likely to undermine the ambition to succeed in school in order to get a good job, addressing this is likely to have knock-on benefits for education. The link between education and future employment prospects is also noted by the DES (2006).

However, not all of the labour market disadvantage of Travellers is linked to lower levels of education. Even when Travellers have similar levels of education to non-Travellers, their chances of being in employment are much lower. This means that the employment disadvantage must also be addressed separately. We know from other research that Travellers face extreme prejudice and discrimination in Irish society, and this has an impact on their employment chances as well as on their self-confidence in applying for employment.

Since 2008, employment supports for Travellers have been mainstreamed (Harvey, 2013). However, the challenges faced by Travellers in this area are more complex than for the long-term unemployed generally. In particular, the discrimination and prejudice faced by this group is more severe than that facing most other long-term unemployed people. Mainstreaming employment services in a context where prejudice and educational disadvantage persist may well be premature.

There are some mainstream services that may be particularly beneficial to Travellers. In particular, there is scope to build on the Traveller tradition of self-employment and enterprise. The Department of Social Protection's Back to Work Enterprise Allowance scheme allows the retention of part of a social welfare payment for up to two years for those starting their own business. This has the potential to be an important route to independence and economic security for Travellers (see Peelo, O'Connor and O'Toole, 2008). 


\subsubsection{Housing}

Most Travellers in 2011 lived in conventional housing and the vast majority had access to basic services such as heating, piped water supply and sewerage facilities. Among the one in eight living in caravans or mobile homes, however, there was a lower rate of access to these basic facilities so there is clearly a need for improvement here.

A problem affecting over one half of Travellers is overcrowding and this is an issue that needs attention. Given the larger Traveller family size, average-sized housing does not have enough space. Data on the accommodation of Travellers show the increasing reliance on privately rented accommodation in recent years. Such accommodation is unlikely to be adequate for larger families.

One factor likely to be contributing to this overcrowding is the practice of sharing accommodation or doubling up on halting site bays. This, together with location on unauthorised sites, masks what might otherwise be a homelessness problem in the Traveller community, which is linked to inadequate provision of suitable accommodation.

The government needs to be more proactive in ensuring that local authorities are meeting their obligation to provide adequate Travellerspecific accommodation. The fact that funding for this has been provided but not spent points to a systemic failure in existing processes and structures. In order to achieve the accommodation objectives, further action is necessary. The challenge clearly goes beyond the funding issue and includes the need to enforce local responsibility and to address local opposition to the provision of Traveller-specific housing.

\subsubsection{Health}

In some respects, health can be seen as the embodiment of disadvantage across the other areas studied here - education, employment, housing and the prejudice that is a big part of the underlying story, although we are not able to measure it directly using the census data. The health gap between Travellers and non-Travellers widens with age. This suggests that a process of cumulative disadvantage operates over time, whereby a lifetime of more challenging experiences combines to produce poorer outcomes (Ross and $\mathrm{Wu}, 1996)$. This points to the importance of preventive interventions that extend to the broader social context of poverty, low education and discrimination and that address these issues at all stages of the life course. The health problems of Travellers have their roots in the social context and this must be addressed in order to bring about an improvement. The problem cannot be solved purely in 
terms of clinical health services, although ensuring access to such services is important.

There have been some successes in the area of Traveller health policy, as reflected in the good access to health services by Travellers (AITHS, 2010). However, areas that still need to be addressed include the quality of the consultation experience, attendance at outpatient appointments and involvement with preventive services. In addition, cuts in provision of healthcare services during the recession are likely to have had a particularly negative impact on disadvantaged and marginalised groups such as Travellers (IHREC, 2015). The equality impact of service cuts during the recession has not been adequately assessed.

Health policy has seen a greater level of recognition than other policy areas of the need for Traveller-specific services, including the establishment of Traveller health units and Traveller primary health care projects. Nevertheless, there is concern that a move in the direction of a mainstreaming approach to health service delivery would ignore inequalities in health outcomes (Pavee Point, 2014b).

Given the higher prevalence of disability among Travellers than among the general population, there is also a need to ensure that access to disability-related services is available to Travellers to maximise their capacity to participate in everyday activities. The types of services needed will depend on the nature of the disability. Other research has pointed to the importance of physiotherapy services and walking aids for people with mobility disability; counselling, psychiatric and other therapies for people with emotional, psychological and mental health disability; and pain management for people with pain disability (Watson, Banks and Lyons, 2015). These services and supports are important for maximising participation and enhancing quality of life for people with a disability.

\subsubsection{Data and Monitoring Progress}

Given the importance of the census as a data source for examining education, employment, housing and the health situation of small minorities who are not captured in sufficient numbers in most other national sources, it is particularly important to ensure adequate coverage of these groups and their correct identification on the census form.

In addition, in order to monitor access to public services and progress in promoting equality, an ethnic identifier should be included in all routine administrative systems. This should be based on the census question and identify both Traveller and Roma populations in order to ensure compatibility. This is important in the context of the public sector duty 
specified in the Irish Human Rights and Equality Commission Act 2014, which requires public bodies to

have regard to the need to; (a) eliminate discrimination, (b) promote equality of opportunity and treatment of its staff and the persons to whom it provides services, and (c) protect the human rights of its members, staff and the persons to whom it provides services. (Government of Ireland, 2014) 


\section{References}

All Ireland Traveller Health Study Team (2010). All Ireland Traveller Health Study. Our Geels. Summary of Findings, Dublin: UCD School of Public Health and Population Science, available at https://www.ucd.ie/t4cms/AITHS SUMMARY.pdf.

Bambra, C., M. Gibson, A. Sowden, K. Wright, M. Whitehead and M. Petticrew (2010). 'Tackling the Wider Social Determinants of Health and Health Inequalities: Evidence from Systematic Reviews', Journal of Epidemiology and Community Health, Vol. 64, No. 4, pp. 284-291.

Barnett, E. C. (2004). 'Women and Multiple Roles: Myth and Reality', Harvard Review of Psychiatry, Vol. 12, No. 3, pp. 158-164.

Barry, M. M., E. Van Lente, M. Molcho, K. Morgan, H. McGee, R. Conroy, D. Watson, E. Shelley and I. Perry (2009). SLÁN 2007: Survey of Lifestyle, Attitudes and Nutrition in Ireland. Mental Health and Social Well-being Report, Department of Health and Children, Dublin: The Stationery Office.

Benyamini, Y. and E. L. Idler (1999). 'Community Studies Reporting Association Between Self-rated Health and Mortality', Research on Ageing, Vol. 21, No. 3, pp. 392-401.

Berkel, R. van and I. H. Møller (2002). Active Social Policies in the EU: Inclusion Through Participation? Bristol: Policy Press.

Bolin, K., B. Lindgren and P. Lundborg (2007). 'Your Next of Kin or your Own Career? Caring and Working among the 50+ of Europe', Journal of Health Economics, Vol. 27, No. 3, pp. 718-738.

Brugha, R., N. Tully, P. Dicker, E. Shelley, M. Ward and H. McGee (2009). SLÁN 2007: Survey of Lifestyle, Attitudes and Nutrition in Ireland. Smoking Patterns in Ireland: Implications for Policy and Services, Department of Health and Children, Dublin: The Stationery Office.

Byrne, D., S. McCoy and D. Watson (2008). 2007 School Leavers' Survey Report, Dublin: Department of Education and Science and The Economic and Social Research Institute.

Byrne, D. and E. Smyth (2010). No Way Back? The Dynamics of Early School Leaving, Dublin: The Economic and Social Research Institute and the Liffey Press.

Central Statistics Office (2007). Census 2006 Volume 5 - Ethnic or Cultural Background (including The Irish Traveller Community), Dublin: Stationery Office.

Central Statistics Office (2009). Standard Report on Quality and Methodology for Census of Population (Census 2006), available at http://www.cso.ie/en/media/csoie/surveysandmethodologies/surveys/ populations/documents/pdfdocs/COP quality report.pdf. 
Central Statistics Office (2012a). Census 2011 Profile 7 - Religion, Ethnicity and Irish Travellers, Dublin: Stationery Office.

Central Statistics Office (2012b). Statistical Yearbook of Ireland, Dublin: Stationery Office

Central Statistics Office (2007a). Census 2006 Principle Demographic Results, Dublin: Stationery Office.

Committee to Monitor and Co-Ordinate the Implementation of the Recommendations of the [1995] Task Force on the Travelling Community (2005) Second Progress Report, Dublin: Department of Justice, Equality and Law Reform, available at (http://justice.ie/en/JELR/TaskForceRpt2.pdf/Files/TaskForceRpt2.pdf).

Committee on the Elimination of Racial Discrimination (2011). Concluding observations of the Committee on the Elimination of Racial Discrimination - Ireland. (78th sess., 14/2-11/3, 2011, CERD/C/IRL/CO/34), available at:

http://www2.ohchr.org/english/bodies/cerd/docs/co/Ireland AUV.pdf.

Costello, L. (2014). Travellers in the Irish Prison System: A Qualitative Study, Dublin: Irish Penal Reform Trust.

Crowley, U. and R. Kitchin (2007). 'Paradoxical Spaces of Traveller Citizenship in Contemporary Ireland', Irish Geography, Vol. 40, No. 2, pp. 128-145.

Denis C. and D. C. Bracken (2014). 'Probation Practice with Travellers in the Republic of Ireland', Irish Probation Journal, Vol. 11, pp. 44-62.

Department of Children and Youth Affairs (2016). State of the Nation's Children, 2014, Dublin: Department of Children and Youth Affairs.

Department of Education and Science (2005). Survey of Traveller Education Provision, Dublin: Department of Education and Science.

Department of Education and Science (2006). Report and Recommendations for a Traveller Education Strategy, Dublin: Department of Education and Science.

Department of Health and Children (2002). Traveller Health: A National Strategy 2002-2005, Dublin: Department of Health and Children.

Department of Justice and Equality (2011). Ireland's National Traveller / Roma Integration Strategy. Available at:

http://ec.europa.eu/justice/discrimination/files/roma_ireland_strategy_ en.pdf

Department of Justice, Equality and Law Reform (2005). Second Progress Report of the Committee to Monitor and Coordinate the Implementation of the Recommendations of the Task Force on the Travelling Community, Dublin: The Stationery Office.

Department of Social Welfare (1963). Report of the Commission on Itinerancy, Stationery Office; Dublin. 
Department of the Environment (2015). Annual Count of Traveller Families 2014, available at www.environment.ie.

DeSalvo, K., V. Fan, M. McDonnell and S. Fihn (2005). 'Predicting Mortality and Healthcare with a Single Question', Health Services Research, Vol. 40, No. 4, pp. 1234-1247.

Elder, G. H. Jr. (1985). Life-Course Dynamics, Ithaca, NY: Cornell University Press.

Elder, G.H. Jr (1994). 'Time, Human Agency, and Social Change: Perspectives on the Life Course', Social Psychology Quarterly, Vol. 57, pp. 4-15.

European Commission (2012). National Roma Integration Strategies: A First Step in the Implementation of the EU Framework, $\operatorname{COM(2012)226~final,~}$ Brussels: European Commission.

European Commission (2013). Steps Forward in Implementing National Roma Integration Strategies, $\operatorname{COM}(2013) 454$ final, Brussels: European Commission.

European Commission (2014). Report on the Implementation of the EU Framework for National Roma Integration Strategies, COM(2014)209 final, Brussels: European Commission.

European Commission (2009). Vademecum - The 10 Common Basic Principles on Roma Inclusion, available at http://www.coe.int/t/dg4/youth/Source/Resources/Documents/2011 1 o Common Basic Principles Roma Inclusion.pdf.

European Committee of Social Rights (2016). Decision on The Merits of the European Roma Rights Centre (ERRC) v. Ireland; Complaint No. 100/2013.

Fahey, T. and D. Watson (1995). An Analysis of Social Housing Need, Research Series No. 168, Dublin: The Economic and Social Research Institute.

Ferraro, K. F., M. M. Farmer and J. A. Wybraniec (1997). 'Health Trajectories: Long-Term Dynamics Among Black and White Adults', Journal of Health and Social Behavior, Vol. 38, No. 1, pp. 38-54.

Gorby, S., S. McCoy and D. Watson (2005). Report on the PLC Sector, 2004 Annual School Leavers' Survey of 2002/2003, Dublin: Department of Education and Science and The Economic and Social Research Institute.

Government of Ireland (1998). Employment Equality Act, Dublin: The Stationery Office

Government of Ireland (1998). Housing (Traveller Accommodation) Act, Dublin: The Stationery Office.

Government of Ireland (2000). Equal Status Act, Dublin: The Stationery Office.

Government of Ireland (2004). Housing (Miscellaneous provisions) Act, Dublin: The Stationery Office.

Government of Ireland (2014). Irish Human Rights and Equality Commission Act 2014, Dublin: The Stationery Office. 
Harmon, H. (2015). Irish Traveller and Roma Children: A Response to Ireland's Consolidated Third and Fourth Report to the UN Committee on the Rights of the Child, Dublin: Pavee Point Traveller and Roma Centre.

Harrington, J., I. Perry, J. Lutomski, K. Morgan, H. McGee, E. Shelley, S. Watson and M. Barry (2008). SLÁN 2007: Survey of Lifestyle, Attitudes and Nutrition in Ireland. Dietary Habits of the Irish Population, Department of Health and Children, Dublin: The Stationery Office.

Harvey, B. (2013). 'Travelling with Austerity': Impacts of Cuts on Travellers, Traveller Projects and Services, Dublin: Pavee Point Publications.

Heiss, F., S.F. Venti and D. Wise (2014). 'The Persistence and Heterogeneity of Health among Older Americans,' NBER Working Paper No. 20306.

Houses of the Oireachtas Joint Committee on Health and Children (2016). Report on Affordable and Quality Childcare, available at http://www.oireachtas.ie/parliament/media/committees/healthandchil dren/health2015/Health-Committee-Report-on-Quality-Childcare.pdf.

Houses of the Oireachtas Joint Committee on Justice, Defence and Equality (2014). Report on the Recognition of Traveller Ethnicity, available at http://www.oireachtas.ie/parliament/media/committees/justice/Report -onTraveller-Ethnicity.pdf.

Kelleher, C., J. Whelan, L. Daly and P. Fitzpatrick (2012). 'Socio-demographic, Environmental, Lifestyle and Psychosocial Factors Predict Self Rated Health in Irish Travellers, A Minority Nomadic Population', Health \& Place, Vol. 18, pp. 330-338.

Kelly, C., A. Gavin, M. Molcho and S. Nic Gabhainn (2012). The Irish Health Behaviour in School-aged Children (HBSC) Study 2010, Dublin and Galway: National University of Ireland, Galway and Department of Health.

Kotowska I.E., A. Matysiak, A. Pailhé, A. Solaz, M. Styrc and D. Vignoli (2010). Second European Quality of Life Survey: Family Life and Work, European Foundation for the Improvement of Living and Working Conditions, Office for Official Publications of the European Communities, Luxembourg.

KW Research and Associates and S. Williams (2014). Why Travellers Leave Traveller-specific Accommodation? A Research Report, Dublin: National Traveller Accommodation Consultative Committee and The Housing Agency.

MacGréil, M. (2010). Emancipation of the Travelling People, NUI Maynooth.

MacGréil, M. (2011). Pluralism and Diversity in Ireland. Prejudice and Related Issues in Early 21st Century Ireland, Dublin: Columbia Press.

McCann, M., S. Ó'Síocháin and J. Ruane (eds.) (1994). Irish Travellers: Culture and Ethnicity, Belfast: Institute of Irish Studies, The Queen's University of Belfast for the Anthropological Association of Ireland. 
McCoy, S., A. Quail and E. Smyth (2012). Influences in 9-year-olds Learning: Home, School and Community, Growing Up in Ireland, Child Cohort Report 3, Dublin: Department of Children and Youth Affairs.

McCoy, S., E. Smyth, D. Watson and M. Darmody (2014). Leaving School in Ireland: A Longitudinal Study of Post-School Transitions, Dublin: Economic and Social Research Institute.

Marmot, M. (2015). The Health Gap: The Challenge of an Unequal World, London: Bloomsbury.

Morgan, K., H. McGee, D. Watson, I. Perry, M. Barry, E. Shelley, J. Harrington, M. Molcho, R. Layte, N. Tully, E. Van Lente, M. Ward, J. Lutomski, R. Conroy and R. Brugha (2008). SLÁN 2007: Survey of Lifestyle, Attitudes and Nutrition in Ireland. Main Report, Department of Health and Children, Dublin: The Stationery Office.

Morgan, K., H. McGee, P. Dicker, R. Brugha, M. Ward, E. Shelley, E. Van Lente, J. Harrington, M. Barry, I. Perry and D. Watson, D. (2009). SLÁN 2007: Survey of Lifestyle, Attitudes and Nutrition in Ireland. Alcohol use in Ireland: A Profile of Drinking Patterns and Alcohol-Related Harm from SLÁN 2007, Department of Health and Children, Dublin: The Stationery Office.

Nolan, B. and B. Maître (2008). A Social Portrait of Communities in Ireland, Dublin: Department of Social and Family Affairs.

Pavee Point (2013). Submission to the Oireachtas Joint Committee on Education and Social Protection on the Draft General Scheme of an Education (Admission to Schools) Bill 2013, available at http://www.paveepoint.ie/wp-content/uploads/2010/08/PaveePoint Submission-to-Joint-Committee-on-Education-and-SocialProtection -Admissions-Bill.pdf.

Pavee Point (2014a). Submission to Department of Justice and Equality regarding its Statement of Strategy, available at: http://www.paveepoint.ie/wp-content/uploads/2013/11/Pavee-PointSubmission-to-Department-of-Justice-and-Equality-with-execsummary.pdf.

Pavee Point (2014b). Submission to Dept. of Health Statement of Strategy, available at http://www.paveepoint.ie/document/submission-to-thedepartment-of-health-regarding-its-strategy-statement/.

Pavee Point (2015). Towards a National Traveller and Roma Integration Strategy 2020, Dublin: Pavee Point.

Pavee Point (2016a). Counting Us In - Human Rights Count! Policy and Practice in Ethnic Data Collection and Monitoring, Dublin: Pavee Point.

Pavee Point (2016b). Presentation to the Oireachtas Committee on Housing and Homelessness - Thursday 19th May, 2016, Dublin: Pavee Point.

Peelo, D., A. O'Connor and G. O'Toole (2008). Positive Action for Traveller Employment, Dublin: Equality Authority. 
Task Force on the Travelling Community (1995) Report of the Task Force on the Travelling Community, Dublin: Stationery Office.

Travelling People Review Body (1983) Report of the Travelling People Review Body, Dublin: Stationery Office.

Ross, C. E. and C-L Wu (1996). 'Education, Age, and the Cumulative Advantage in Health', Journal of Health and Social Behavior, Vol. 37, No. 1, pp. 104120.

Russell, H., F. McGinnity, T. Callan and C. Keane (2009). A Woman's Place: Female Participation in the Irish Labour Market, Dublin: The Equality Authority and The Economic and Social Research Institute.

Skinner, C.J., D. Holt and T.M.F. Smith (eds.) (1989). Analysis of Complex Surveys, New York: Wiley.

Smyth, E., M. Darmody, F. McGinnity and D. Byrne (2009). Adapting to Diversity: Irish Schools and Newcomer Students, Dublin: Economic and Social Research Institute.

Smyth, E., J. Banks, A. Whelan, M. Darmody and S. McCoy (2015a). Review of the School Completion Programme, Research Series Number 44, Dublin: Economic and Social Research Institute.

Smyth, E., S. McCoy and G. Kingston (2015b). Learning from the Evaluation of DEIS, Research Series No. 39, Dublin: The Economic and Social Research Institute.

StataCorp (2013a). Stata: Release 13. Statistical Software, College Station, TX: StataCorp LP.

StataCorp (2013b). Stata Survey Data Reference Manual, Release 13, College Station, TX: StataCorp LP.

Tormey, R. and J. Gleeson (2012). 'Irish Post-primary Students' Attitudes Towards Ethnic Minorities', Irish Educational Studies, Vol. 31, No. 2, pp. 157-173.

Treas, J. and S. Drobnič (eds.) (2010). Dividing the Domestic: Men, Women, and Household Work in Cross-National Perspective, Stanford: Stanford University Press.

Ward, M., H. McGee, K. Morgan, E. Van Lente, R. Layte, M. Barry, D. Watson, and I. Perry (2009). SLÁN 2007: Survey of Lifestyle, Attitudes and Nutrition in Ireland. 'One Island - One Lifestyle?' Health and lifestyles in the Republic of Ireland and Northern Ireland: Comparing the Population Surveys SLÁN 2007 and NIHSWS 2005, Department of Health and Children, Dublin: The Stationery Office.

Watson, D., P. Lunn, E. Quinn and H. Russell (2011). Multiple Disadvantage in Ireland: An Analysis of Census 2006, Dublin: Equality Authority and Economic and Social Research Institute.

Watson, D., J. Banks and D. Lyons (2015). Educational and Employment Experiences of People with a Disability in Ireland: An Analysis of the 
National Disability Survey, Research Series No. 41, Dublin: Economic and Social Research Institute.

Weir, S. and P. Archer (with A. O'Flaherty and L. Gilleece) (2011). A Report on the First Phase of the Evaluation of DEIS. Report to the Department of Education and Skills, Dublin: Educational Research Centre.

Wilkin, A., C. Derrington, R. White, K. Martin, B. Foster, K. Kinder and S. Rutt (2010). Improving the Outcomes for Gypsy, Roma and Traveller Pupils: Final Report. London: Department for Education.

Williams, R. (2012). 'Using the Margins Command to Estimate and Interpret Adjusted Predictions and Marginal Effects', Stata Journal, Vol. 12, pp. 308-331. 


\section{Appendix 1}

\section{Additional Figures and Tables}

Figure A1.1 Age Distribution of Irish Travellers in Census 2011 and AITHS 2008 Data

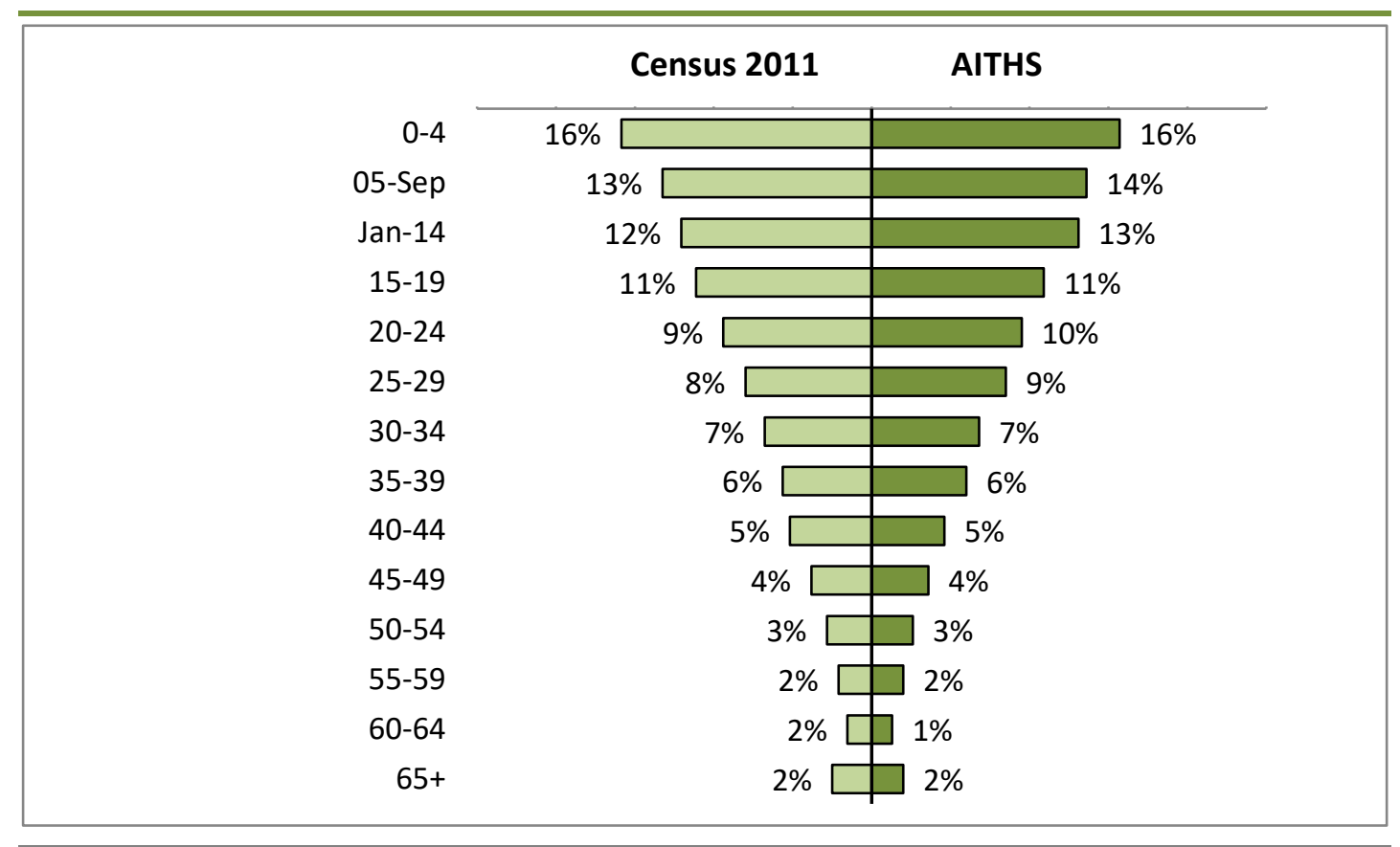

Source: Census 2011 micro-data and AITHS, analysis by authors

Figure A1.2 Education Level of Irish Travellers in Census 2011 and AITHS 2008 Data

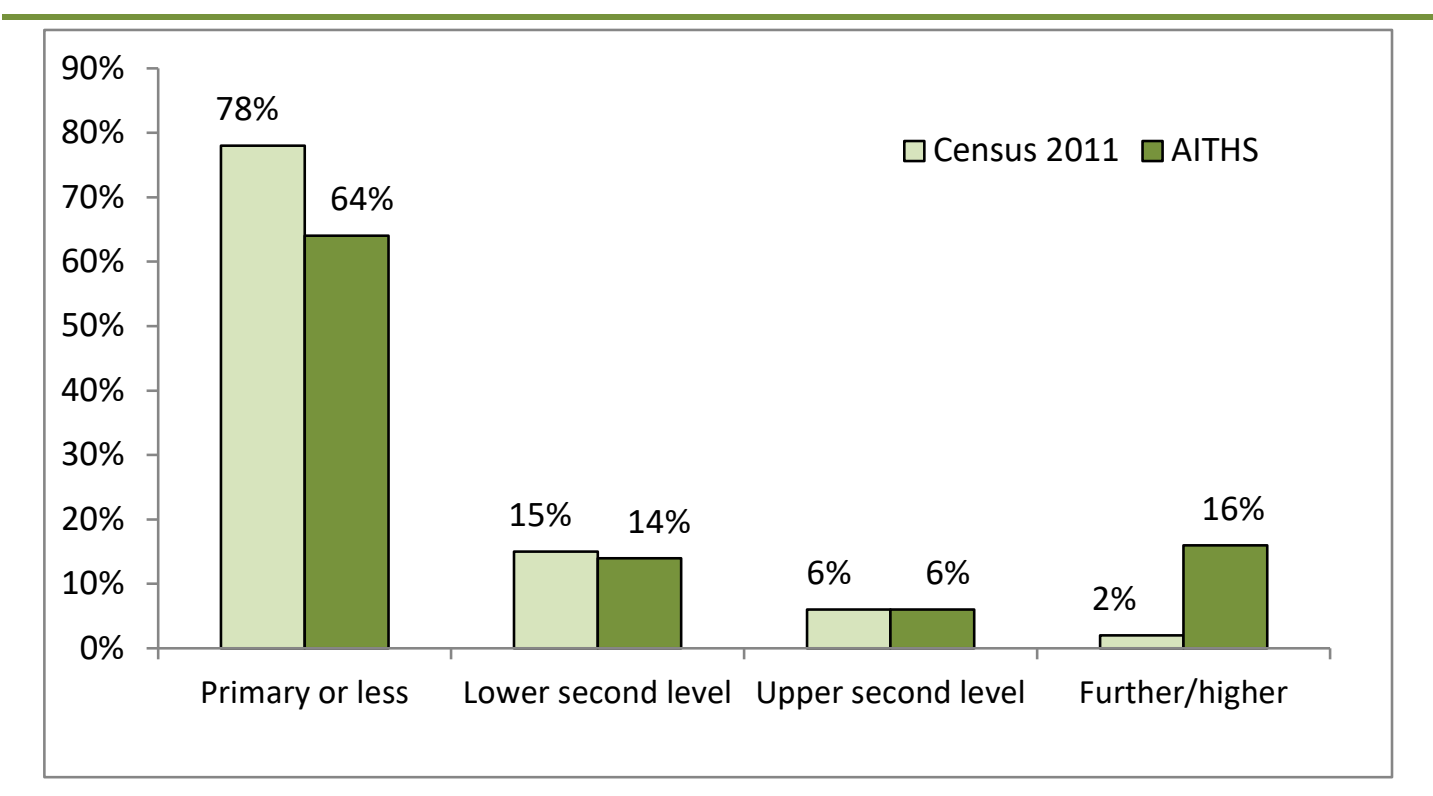

Source: Census 2011 micro-data and AITHS, analysis by authors (both surveys select adults aged 25 to 64). In AlTHS the question asked 'what level of education do you have' while in the Census the question asks 'What is the highest level of education (full/part time) that you have completed to date?' 
Figure A1.3 Main Economic Status of Irish Travellers in Census 2011 and AITHS 2008 Data

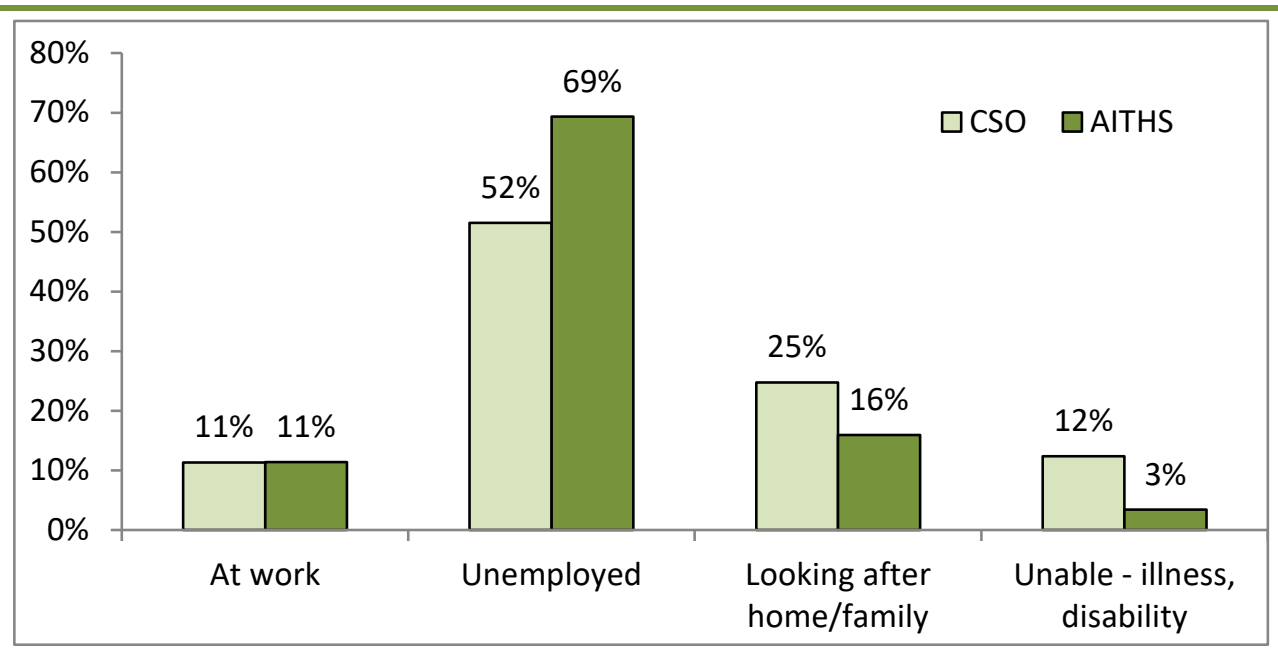

Source: Census 2011 micro-data and AITHS, analysis by authors. Includes adults aged 25-64 years.

Figure A1.4 Labour Market Statistics for Irish Travellers in Census 2011 and AITHS 2008 Data

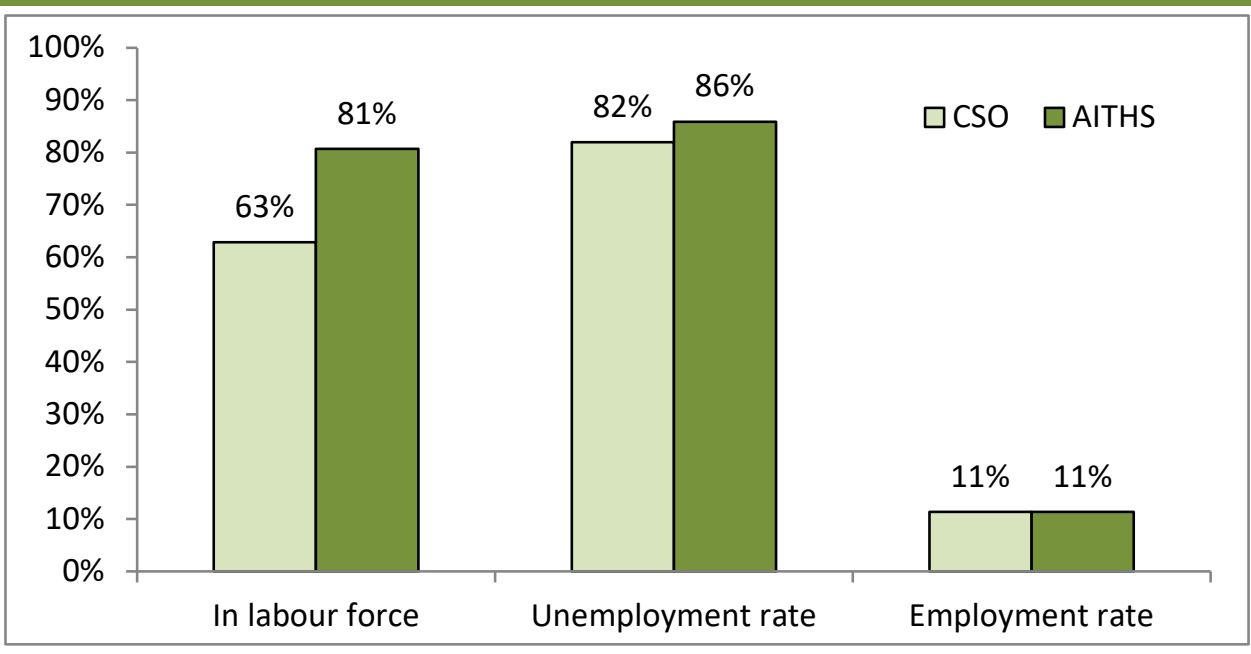

Source: Census 2011 micro-data and AITHS, analysis by authors. Includes adults aged 25-64 years.

Figure A1.5 Housing Type and Tenure of Irish Travellers in Census 2011 and AITHS 2008 Data

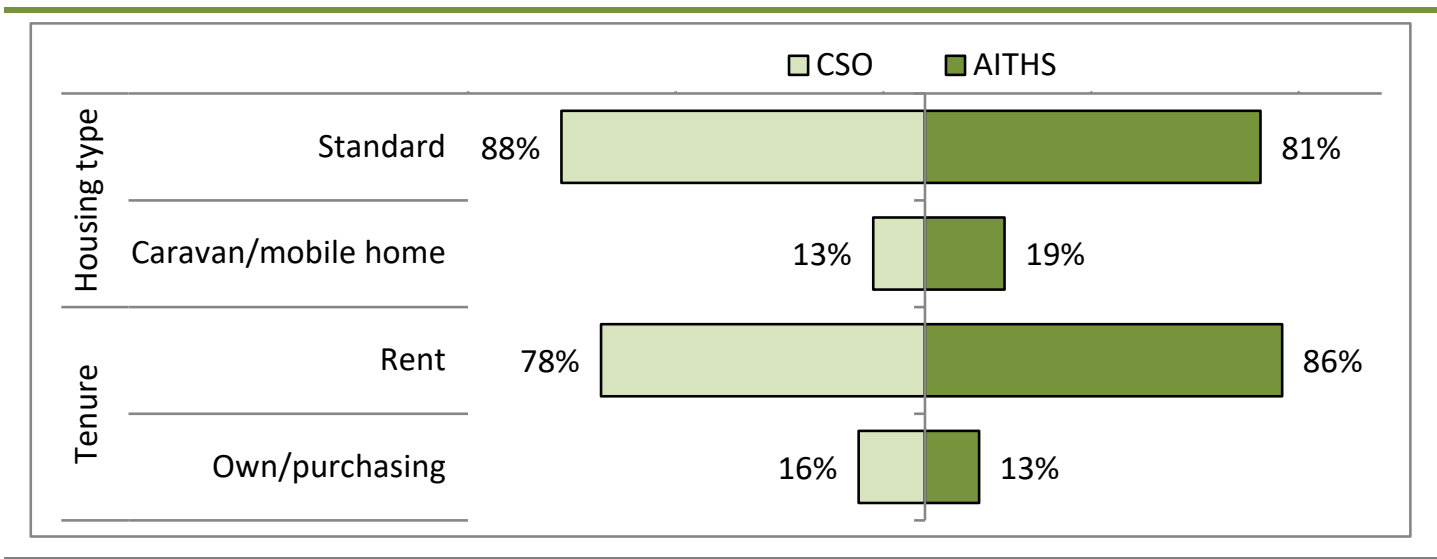

Source: Census 2011 micro-data and AITHS, analysis by authors. Includes people of all ages. 
Table A2.1 Odds Ratios for Finishing Education Without Completing Second Level (2011 Census), Adults in Private Households, 25-64 Years

\begin{tabular}{|c|c|c|c|c|c|}
\hline & \multirow[t]{2}{*}{ Model 1} & \multirow[t]{2}{*}{ Model 2} & \multirow[t]{2}{*}{ Model 3} & \multicolumn{2}{|c|}{ Model 4} \\
\hline & & & & $\begin{array}{c}\text { Main } \\
\text { effects }\end{array}$ & $\begin{array}{c}\text { Inter- } \\
\text { actions }\end{array}$ \\
\hline Traveller & 33.1 & 51.4 & 53.1 & 133.2 & \\
\hline Female vs. male & & & 0.7 & 0.7 & 0.8 \\
\hline $35-44$ vs. $25-34$ & & 1.8 & 1.7 & 1.7 & 0.8 \\
\hline 45-54 vs. $25-34$ & & 3.3 & 3.3 & 3.3 & 0.6 \\
\hline 55-64 vs. $25-34$ & & 6.4 & 6.4 & 6.4 & 0.5 \\
\hline Border vs. Dublin & & & 1.6 & 1.6 & 0.4 \\
\hline Midlands vs. Dublin & & & 1.4 & 1.4 & 0.4 \\
\hline West vs. Dublin & & & 1.0 & 1.0 & 0.5 \\
\hline Mid-East vs. Dublin & & & 1.1 & 1.1 & 0.6 \\
\hline Mid-West vs. Dublin & & & 1.2 & 1.2 & 0.8 \\
\hline South-East vs. Dublin & & & 1.4 & 1.4 & 0.5 \\
\hline South-West vs. Dublin & & & 1.1 & 1.1 & 0.4 \\
\hline Constant & 0.37 & 0.15 & 0.16 & & \\
\hline Nagelkerke R-squared & 0.007 & 0.079 & 0.089 & & \\
\hline
\end{tabular}


Table A3.1 Odds of Not Being at Work for Adults, 15-64 Years, Excluding Students, 2011

\begin{tabular}{|c|c|c|c|c|c|}
\hline & Model 1 & Model 2 & Model 3 & \multicolumn{2}{|c|}{ Model 4} \\
\hline & & & & $\begin{array}{l}\text { Main } \\
\text { effect }\end{array}$ & $\begin{array}{l}\text { Inter- } \\
\text { actions }\end{array}$ \\
\hline Traveller & 19.0 & 22.2 & 8.5 & 8.4 & \\
\hline Single men vs. married men & & 2.8 & 2.5 & 2.5 & 0.3 \\
\hline Formerly married men vs. married men & & 2.4 & 2.2 & 2.2 & 0.7 \\
\hline Single women vs. married men & & 1.6 & 1.7 & 1.7 & 0.6 \\
\hline Married women vs. married men & & 1.8 & 2.0 & 2.0 & 0.7 \\
\hline $\begin{array}{l}\text { Formerly married women vs. married } \\
\text { men }\end{array}$ & & 2.1 & 2.0 & 2.0 & 0.5 \\
\hline Female with child under 15 vs. no child & & 2.1 & 2.1 & 2.1 & 0.6 \\
\hline Male with child under 15 vs. no child & & 1.1 & 1.1 & 1.1 & 1.2 \\
\hline Age $15-24$ vs. $25-34$ & & 2.1 & 1.8 & 1.8 & 0.9 \\
\hline Age $35-44$ vs. $25-34$ & & 1.2 & 1.1 & 1.1 & 0.6 \\
\hline Age $45-54$ vs. $25-34$ & & 1.7 & 1.2 & 1.2 & 0.6 \\
\hline Age $55-64$ vs. $25-34$ & & 4.5 & 2.6 & 2.7 & 0.3 \\
\hline Border vs. Dublin & & 1.4 & 1.2 & 1.2 & 1.1 \\
\hline Midlands vs. Dublin & & 1.4 & 1.2 & 1.2 & 1.2 \\
\hline West vs. Dublin & & 1.1 & 1.1 & 1.1 & 1.4 \\
\hline Mid-East vs. Dublin & & 1.1 & 1.1 & 1.1 & 0.9 \\
\hline Mid-West vs. Dublin & & 1.2 & 1.1 & 1.1 & 1.4 \\
\hline South-East vs. Dublin & & 1.3 & 1.2 & 1.2 & 1.0 \\
\hline South-West vs. Dublin & & 1.1 & 1.1 & 1.1 & 1.1 \\
\hline Primary vs. third level education & & & 6.4 & 6.4 & 2.2 \\
\hline Lower 2 nd vs. 3rd level education & & & 3.8 & 3.8 & 2.0 \\
\hline Upper 2 nd vs. 3rd level education & & & 2.2 & 2.2 & 1.7 \\
\hline Constant & 0.49 & 0.12 & 0.08 & 0.08 & \\
\hline Nagelkerke R-squared & 0.006 & 0.067 & 0.122 & 0.123 & \\
\hline
\end{tabular}

Source: Census micro-data, 2011 and 2006 analysis by authors. The table shows odds ratios for not being in employment. Odds ratios greater than one indicate a greater likelihood of not working while odds ratios less than one indicate a lesser likelihood. The interactions show how the pattern is different for Travellers. In model 4, the odds ratio for Travellers is the product of the 'main effect' ratio and the 'interaction' ratio. 
Table A4.1 Odds of Living in a Caravan or Mobile Home, Travellers

\begin{tabular}{lll}
\hline & Model $\mathbf{1}$ & Model $\mathbf{2}$ \\
\hline Single men vs. married men & & \\
\hline Formerly married men vs. married men & 0.6 & 0.6 \\
\hline Single women vs. married men & 1.0 & 1.1 \\
\hline Married women vs. married men & 0.6 & 0.6 \\
\hline Formerly married women vs. married & 1.0 & 1.0 \\
\hline men & & \\
\hline Age 0-14 vs. 25-34 & 0.7 & 0.7 \\
\hline Age 15-24 vs. 25-34 & 1.4 & 1.2 \\
\hline Age 35-44 vs. 25-34 & 1.3 & 1.4 \\
\hline Age 45-54 vs. 25-34 & 0.7 & 0.8 \\
\hline Age 55-64 vs. 25-34 & 0.9 & 0.8 \\
\hline Age 65+ vs. 25-34 & 0.8 & 0.8 \\
\hline Border vs. Dublin & 0.7 & 0.6 \\
\hline Midlands vs. Dublin & 0.5 & 0.5 \\
\hline West vs. Dublin & 0.6 & 0.6 \\
\hline Mid-East vs. Dublin & 0.4 & 0.4 \\
\hline Mid-West vs. Dublin & 0.5 & 0.5 \\
\hline South-East vs. Dublin & 1.2 & 1.2 \\
\hline South-West vs. Dublin & 0.8 & 0.8 \\
\hline Primary vs. third level education & 0.8 & 0.8 \\
\hline Lower 2nd vs. 3rd level education & & 3.0 \\
\hline Upper 2nd vs. 3rd level education & & 2.3 \\
\hline At work vs. not at work & 0.03 & 0.03 \\
\hline Constant & & 0.9 \\
\hline Nagelkerke R-squared & & 0.1 \\
\hline & & \\
\hline
\end{tabular}

Source: Census micro-data, 2011 and 2006 analysis by authors. The table shows odds ratios for living in a caravan or mobile home. Odds ratios greater than one indicate a greater likelihood of not working while odds ratios less than one indicate a lesser likelihood. The interactions show how the pattern is different between 2006 and 2011. 
Table A4.2 Odds of Living in Overcrowded Accommodation, 2011

\begin{tabular}{|c|c|c|c|c|}
\hline & \multirow[t]{2}{*}{ Model 1} & \multirow[t]{2}{*}{ Model 2} & \multicolumn{2}{|c|}{ Model 3} \\
\hline & & & $\begin{array}{l}\text { Main } \\
\text { effect }\end{array}$ & $\begin{array}{l}\text { Inter- } \\
\text { action }\end{array}$ \\
\hline Traveller vs. non-Traveller & 10.9 & 7.6 & 1.2 & \\
\hline Single men vs. .married men & 0.5 & 0.4 & 0.4 & 2.3 \\
\hline Formerly married men vs. married men & 0.7 & 0.5 & 0.6 & 0.7 \\
\hline Single women vs. married men & 0.5 & 0.4 & 0.4 & 2.3 \\
\hline Married women vs. married men & 0.9 & 0.8 & 0.8 & 1.2 \\
\hline Formerly married women vs. married men & 0.8 & 0.6 & 0.6 & 0.8 \\
\hline Age $0-14$ vs. $25-34$ & 2.2 & 0.7 & 0.7 & 2.9 \\
\hline Age $15-24$ vs. $25-34$ & 1.5 & 0.9 & 0.9 & 1.2 \\
\hline Age $35-44$ vs. $25-34$ & 0.7 & 0.6 & 0.6 & 2.5 \\
\hline Age $45-54$ vs. $25-34$ & 0.4 & 0.3 & 0.3 & 2.7 \\
\hline Age $55-64$ vs. $25-34$ & 0.2 & 0.1 & 0.1 & 3.4 \\
\hline Age $65+$ vs. 25-34 & 0.1 & 0.0 & 0.0 & 6.0 \\
\hline Border vs. Dublin & 0.5 & 0.5 & 0.5 & 1.2 \\
\hline Midlands vs. Dublin & 0.6 & 0.6 & 0.6 & 1.4 \\
\hline West vs. Dublin & 0.5 & 0.5 & 0.5 & 2.3 \\
\hline Mid-East vs. Dublin & 0.6 & 0.5 & 0.5 & 1.5 \\
\hline Mid-West vs. Dublin & 0.6 & 0.5 & 0.5 & 2.1 \\
\hline South-East vs. Dublin & 0.5 & 0.5 & 0.5 & 1.6 \\
\hline South-West vs. Dublin & 0.5 & 0.5 & 0.5 & 1.9 \\
\hline Caravan vs. permanent structure & 5.0 & 4.6 & 4.6 & 1.1 \\
\hline Primary vs. third level education & & 3.1 & 3.3 & 0.9 \\
\hline Lower 2nd vs. 3rd level education & & 1.9 & 1.9 & 1.5 \\
\hline Upper 2nd vs. 3rd level education & & 1.6 & 1.6 & 1.6 \\
\hline At work vs. not at work & & 0.6 & 0.6 & 1.0 \\
\hline Constant & 0.2 & 0.3 & 0.3 & \\
\hline Nagelkerke R-squared & 0.08 & 0.10 & 0.10 & \\
\hline
\end{tabular}

Source: Census micro-data, 2011, analysis by authors. The table shows odds ratios for living in overcrowded accommodation. Odds ratios greater than one indicate a greater likelihood of not working while odds ratios less than one indicate a lesser likelihood. The interactions show how the pattern is different for Travellers and non-Travellers. In model 3, the odds ratio for Travellers is the product of the 'main effect' ratio and the 'interaction' ratio. 
Table A5.1 Odds of Poor Health, 2011

\begin{tabular}{|c|c|c|c|c|c|}
\hline \multirow[b]{3}{*}{ Traveller vs. non-Traveller } & \multirow{3}{*}{$\begin{array}{r}\text { Model } 1 \\
1.5 \\
\end{array}$} & \multirow{3}{*}{$\begin{array}{r}\text { Model } 2 \\
3.7 \\
\end{array}$} & \multirow{3}{*}{$\begin{array}{c}\text { Model } 3 \\
2.0\end{array}$} & \multicolumn{2}{|c|}{ Model 4} \\
\hline & & & & $\begin{array}{l}\text { Main } \\
\text { effect }\end{array}$ & $\begin{array}{c}\text { Inter- } \\
\text { actions } \\
\text { (Traveller) }\end{array}$ \\
\hline & & & & 5.1 & \\
\hline Single men vs. married men & & 1.8 & 1.6 & 1.6 & 0.8 \\
\hline Formerly married men vs. married men & & 2.0 & 1.9 & 1.9 & 0.6 \\
\hline Single women vs. married men & & 1.5 & 1.6 & 1.6 & 0.7 \\
\hline Married women vs. married men & & 1.0 & 1.0 & 1.0 & 0.9 \\
\hline $\begin{array}{l}\text { Formerly married women vs. married } \\
\text { men }\end{array}$ & & 1.9 & 1.8 & 1.8 & 0.7 \\
\hline Age $0-14$ vs. $25-34$ & & 0.2 & 0.1 & 0.1 & 2.1 \\
\hline Age $15-24$ vs. $25-34$ & & 0.5 & 0.4 & 0.4 & 1.1 \\
\hline Age $35-44$ vs. $25-34$ & & 1.8 & 1.7 & 1.7 & 1.3 \\
\hline Age $45-54$ vs. $25-34$ & & 3.2 & 2.6 & 2.6 & 1.6 \\
\hline Age $55-64$ vs. $25-34$ & & 6.2 & 4.3 & 4.3 & 1.6 \\
\hline Age $65+$ vs. $25-34$ & & 10.8 & 6.5 & 6.5 & 1.3 \\
\hline Border vs. Dublin & & 1.2 & 1.1 & 1.1 & 0.6 \\
\hline Midlands vs. Dublin & & 1.1 & 1.1 & 1.1 & 0.7 \\
\hline West vs. Dublin & & 1.1 & 1.0 & 1.0 & 0.7 \\
\hline Mid-East vs. Dublin & & 0.9 & 0.9 & 0.9 & 0.8 \\
\hline Mid-West vs. Dublin & & 1.1 & 1.0 & 1.0 & 0.7 \\
\hline South-East vs. Dublin & & 1.0 & 1.0 & 1.0 & 0.5 \\
\hline South-West vs. Dublin & & 0.9 & 0.9 & 0.9 & 0.9 \\
\hline Primary vs. third level education & & & 3.4 & 3.4 & 0.6 \\
\hline Lower 2 nd vs. 3rd level education & & & 2.0 & 2.0 & 0.7 \\
\hline Upper 2 nd vs. 3 rd level education & & & 1.6 & 1.6 & 1.1 \\
\hline Live in caravan or mobile home & & & 1.2 & 1.3 & 0.9 \\
\hline Overcrowded & & & 1.2 & 1.3 & 0.8 \\
\hline Constant & 0.102 & 0.031 & 0.023 & 0.023 & \\
\hline Nagelkerke R-squared & 0.000 & 0.163 & 0.181 & 0.181 & \\
\hline
\end{tabular}

Source: Census micro-data, 2011, persons of all ages living in private households, analysis by authors. The table shows odds ratios for having health that is very bad, bad or fair. Odds ratios greater than one indicate a greater likelihood of not working while odds ratios less than one indicate a lesser likelihood. The interactions show how the pattern is different for Travellers. In model 4, the odds ratio for Travellers is the product of the 'main effect' ratio and the 'interaction' ratio. 
